UNIVERSIDADE DE SÃO PAULO

ESCOLA DE ENGENHARIA DE SÃO CARLOS

DEPARTAMENTO DE ENGENHARIA DE PRODUÇÃO

A relação entre cultura organizacional e o uso de técnicas da qualidade e seu impacto no desempenho operacional 
LILLIAN DO NASCIMENTO GAMBI

\section{A relação entre cultura organizacional e o uso de técnicas da qualidade e seu impacto no desempenho operacional}

Tese apresentada à Escola de Engenharia de São Carlos da Universidade de São Paulo para obtenção do título de Doutor em Engenharia de Produção

Área de concentração: Processo e Gestão de Operações.

Orientador: Prof. Titular Luiz C. R. Carpinetti

São Carlos

2014 
AUTORIZO A REPRODUÇÃO TOTAL OU PARCIAL DESTE TRABALHO, POR QUALQUER MEIO CONVENCIONAL OU ELETRÔNICO, PARA FINS DE ESTUDO E PESQUISA, DESDE QUE CITADA A FONTE.

G191a

Gambi, Lillian do Nascimento

A relação entre cultura organizacional e o uso de técnicas da qualidade e seu impacto no desempenho operacional / Lillian do Nascimento Gambi; orientador Luiz Cesar Ribeiro Carpinetti. São Carlos, 2014.

Tese (Doutorado) - Programa de Pós-Graduação em Engenharia de Produção e Area de Concentração em Processos e Gestão de Operaçōes -- Escola de Engenharia de São Carlos da Universidade de São Paulo, 2014.

1. Gestão da qualidade. 2. Técnicas da qualidade. 3. Cultura organizacional. 4. Desempenho operacional. 5. Modelagem de equaçōes estruturais. 6. Survey. I. Título. 


\section{FOLHA DE JULGAMENTO}

\section{Candidata: Farmacêutica LILIAN DO NASCIMENTO GAMBI.}

Título da tese: "A influência da cultura organizacional no uso de técnicas da qualidade e seu impacto no desempenho".

Data da defesa: 28/02/2014

Comissão Julgadora:

Resultado:

Prof. Titular Luiz Cesar Ribeiro Carpinetti

APROVADO

(Escola de Engenharia de São Carlos/EESC)

Prof. Dr. Mateus Cecilio Gerolamo

ARROVAOn

(Escola de Engenharia de São Carlos/EESC)

Profa. Dra. Teresa Cristina Martins Dias

(Universidade Federal de São Carlos/UFSCar)

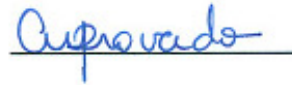

Prof. Dr. Pedro Carlos Oprime

APROVADO

(Universidade Federal de São Carlos/UFSCar)

APRorADo

Dr. Carlos Frederico Bremer

(Axia Value Chain)

Coordenador do Programa de Pós-Graduação em Engenharia de Produção

Prof. Titular Luiz Cesar Ribeiro Carpinetti

Presidente da Comissão de Pós-Graduação:

Prof. Titular Denis Vinicius Coury 
Aos meus pais 


\section{AGRADECIMENTO}

A todos aqueles que, de alguma forma, contribuíram para a realização deste trabalho. Em especial:

- Ao professor Carpinetti pelo apoio, confiança e orientação durante esse tempo que trabalhamos juntos.

- Ao professor Mateus pela presença e apoio no desenvolvimento deste trabalho.

- Ao professor Harry Boer pela atenção, apoio e orientação durante o período em que estive no exterior. E também pelo exemplo de humildade.

- A professora Frances Jørgensen por ter sido tão solícita desde o primeiro contato e pelo trabalho em conjunto.

- Aos membros das comissões julgadoras do exame de qualificação e defesa: Carlos Bremer, Mateus Gerolamo, Pedro Oprime e Teresa Cristina Dias pelas contribuições.

- Aos professores de estatística Cibele Russo, Joachim Scholderer e Teresa Cristina, pelos ensinamentos e discussões.

- Aos meus avós pelo carinho e apoio de sempre.

- Aos meus pais, simplesmente por tudo.

- Ao Henrique e Marcelo que alegram minha vida.

- A tantas pessoas especiais que conheci durante o tempo de pós-graduação e por todos os momentos compartilhados. Às amigas Débora Correa e Luciana Montanari pela presença constante. E para aqueles que fazem parte da minha vida desde muito antes.

- Aos amigos do Laboratório de Gestão de Operações, em especial, Camila Poltronieri, Catarina Careta, Danilo Hisano, Francisco Júnior, Jeferson Straatman, Juliana Kurumoto, Lauro Osito, Larissa Araújo, Lie Yamanaka, Rafael Lima e Yovana Barrera que estiveram comigo por quase todo esse tempo de pós-graduação.

- Aos professores e funcionários do Departamento de Engenharia de Produção.

- Aos profissionais cuja disponibilidade em participar da pesquisa foi imprescindível para realização deste trabalho.

- A Deus pelas conversas imaginárias.

- Ao CNPq pelo apoio financeiro no Brasil e no exterior. 


\section{RESUMO}

GAMBI, L. N. A relação entre cultura organizacional e o uso de técnicas da qualidade e seu impacto no desempenho operacional. 2014. 136p. Tese (Doutorado) - Escola de Engenharia de São Carlos, Universidade de São Paulo, São Carlos, 2014.

Muitas empresas têm adotado alguma iniciativa de gestão da qualidade para melhoria de seu desempenho. Entretanto, muitas dessas iniciativas nem sempre produzem os resultados pretendidos. Dentro desse contexto, a cultura organizacional tem se destacado como uma variável contextual que poderia explicar o sucesso, ou mesmo o fracasso, das iniciativas de gestão da qualidade. Dessa forma, esse estudo investiga a influência da cultura organizacional no uso das técnicas da qualidade e seu impacto no desempenho. Para isso, duas hipóteses foram consideradas 1) a cultura de uma organização influencia o conjunto de técnicas da qualidade que ela adota e, 2) a combinação entre o conjunto de técnicas da qualidade adotada por uma organização e sua cultura organizacional afeta o desempenho. Enquanto a maioria dos estudos anteriores considera a relação entre cultura, gestão da qualidade e desempenho no nível de práticas da qualidade, esse estudo estende essa discussão para o nível das técnicas. A partir de dados obtidos de 250 empresas no Brasil e Dinamarca, utilizou-se da Modelagem de Equações Estruturais para testar as hipóteses formuladas. Quatro grupos de técnicas da qualidade, quatro perfis de cultura organizacional definidos no Competing Values Framework, e diversos indicadores de desempenho foram considerados nesse estudo. Resultados mostram que certos perfis culturais estão mais relacionados ao uso de determinadas técnicas da qualidade que outras. Por exemplo, empresas com cultura de grupo orientada para colaboração e desenvolvimento de recursos humanos, tendem a usar técnicas de estabelecimento de metas e melhoria contínua, mas não técnicas associadas à medição. Em contrapartida, empresas que possuem características das culturas racional e hierárquica, que são orientadas para o controle e competição, tendem a usar mais as técnicas de medição do que aquelas culturas orientadas para colaboração e inovação. Além disso, os resultados também mostraram que as técnicas da qualidade contribuem para melhoria do desempenho desde que sustentadas por características culturais apropriadas. Esta pesquisa fornece contribuições práticas importantes para os gestores no sentido de que eles precisam estar cientes da necessidade de adotar técnicas da qualidade que sejam adequadas às características culturais de suas organizações para, com isso, obter melhores resultados a partir do uso dessas técnicas.

Palavras-chave: Cultura organizacional; Desempenho; Gestão da qualidade; Modelagem de equações estruturais; Survey. 


\begin{abstract}
GAMBI, L. N. The interplay between organizational culture and the use of quality techniques and its impact on operational performance. 2014. 136p. Thesis (PhD) School of Engineering of São Carlos, University of São Paulo, São Carlos, 2014.
\end{abstract}

Most firms have adopted quality management initiatives to improve quality and other indicators of performance. However, quality management initiatives do not always produce the intended results. Organizational culture has been highlighted as one of the contextual variables that may explain the success or, for that matter, failure of quality management initiatives. Accordingly, this study investigates the influence of organizational culture on the use of quality techniques and its impact on performance. Therefore it hypothesizes that 1) a firm's culture affects the quality techniques it adopts, and 2) the quality techniques have a direct effect, and culture a direct and an indirect (i.e. through the quality techniques) effect, on firm operational performance. While most previous studies address the relationships between culture, quality management and performance at the level of quality practices, this study extends this discussion to the level of quality techniques to what should be its core, namely the influence of culture on the performance impact of quality techniques. Based on data collected from 250 firms in Brazil and Denmark, Structural Equation Modeling is used to test these hypotheses. Four quality technique groups, four cultural profiles adopted from the Competing Values Framework, and a wide range of performance indicators are used to operationalize the study. Findings show that culture does not appear to be an unequivocal predictor of the adoption of quality techniques. Furthermore, while the developmental and group cultures strengthen the performance effects of all four quality technique groups considered, the hierarchical culture does so for only one of these groups. In a rational culture the performance effects of all four groups are insignificant. As practical implication findings suggest that managers need to be actively aware of the cultural characteristics of their organization before adopting quality techniques, in order to benefit most from the use of these techniques.

Keywords: Operational performance; Organizational culture; Quality techniques; Structural equation modeling; Survey. 


\section{LISTA DE FIGURAS}

Figura 1. Etapas de desenvolvimento da pesquisa ................................................... 22

Figura 2. Relação dos elementos da qualidade.............................................................. 30

Figura 3. Modelo de Hofstede "Onion Diagram" ...................................................... 38

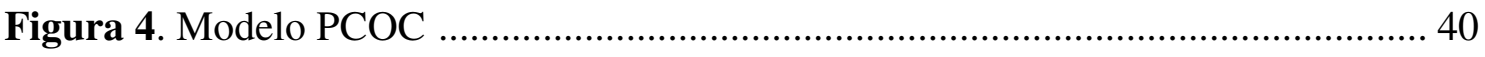

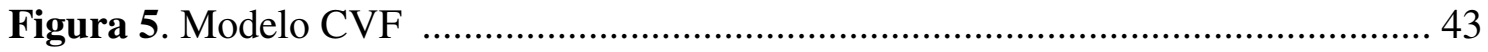

Figura 6. Modelo de mediação e moderação ................................................................ 48

Figura 7. Modelo geral do relacionamento entre perfis culturais e grupos de técnicas da qualidade 62

Figura 8. Modelo geral do relacionamento entre perfis de cultura organizacional, grupos de técnicas da qualidade e desempenho.

Figura 9. Modelo estrutural das relações entre perfis de cultura organizacional e grupos de técnicas da qualidade 84 


\section{LISTA DE QUADROS}

Quadro 1. Elementos da gestão da qualidade............................................................ 29

Quadro 2. Resultados dos estudos de Handfield, Jayaram e Gosh (1999).................... 46

Quadro 3. Perfis de cultura organizacional e principais características .......................55

Quadro 4. Grupos de técnicas da qualidade, características e exemplos ..................... 59

Quadro 5. Efeitos da combinação entre cultura e técnicas da qualidade no desempenho 


\section{LISTA DE TABELAS}

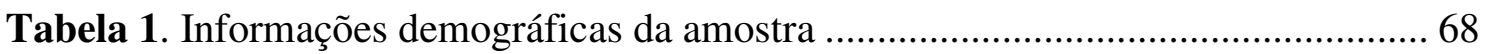

Tabela 2. Coeficiente de correlação de Pearson e medida da confiabilidade .71

Tabela 3. Dados das variáveis observáveis utilizadas para medição da cultura organizacional

Tabela 4. Dados das variáveis observáveis utilizadas para medição de técnicas da qualidade

Tabela 5. Dados das variáveis observáveis utilizadas para medição do desempenho... 78

Tabela 6. Índices de ajuste geral para o modelo de mensuração 82

Tabela 7. Efeitos do relacionamento entre cultura organizacional e grupos de técnicas da qualidade no desempenho 


\section{SUMÁRIO}

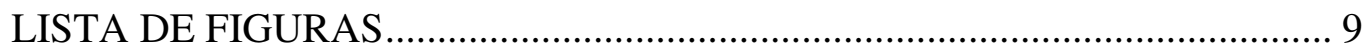

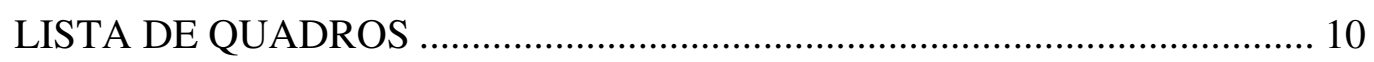

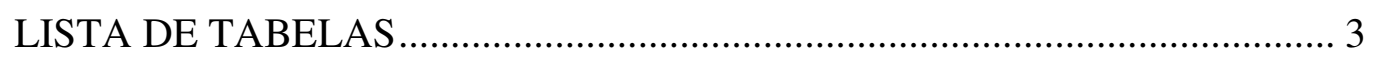

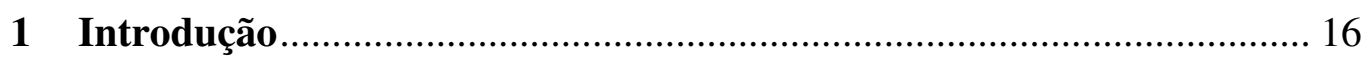

1.1 Contextualização e justificativa .................................................... 16

1.2 Objetivos e contribuições............................................................... 20

1.3 Etapas de desenvolvimento da pesquisa ........................................ 20

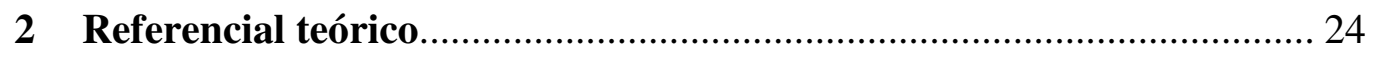

2.1 Conceitos e definições da gestão da qualidade .................................. 24

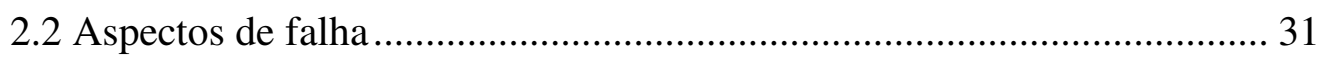

2.3 Cultura organizacional e gestão da qualidade.................................. 33

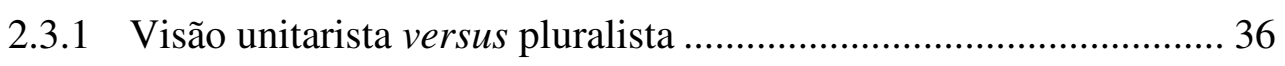

2.3.2 Relação causal entre gestão da qualidade e cultura ...................... 37

2.4 Modelos de cultura organizacional .............................................. 38

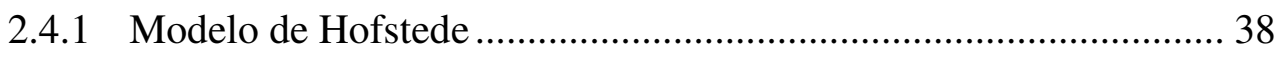

2.4.2 Modelo PCOC (Personal, Customer orientation, Organisational and Culture issues) 40

2.4.3 Modelo OCP (Organizational Culture Profile) ............................ 41

2.4.4 Modelo CVF (Competing Values Framework) ........................... 42 
2.5 Gestão da qualidade, cultura organizacional e desempenho.

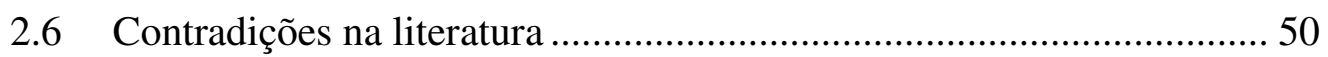

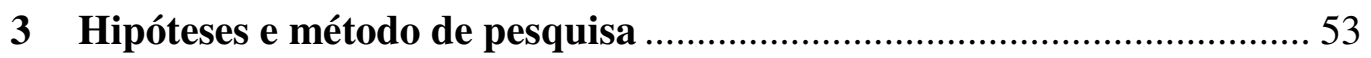

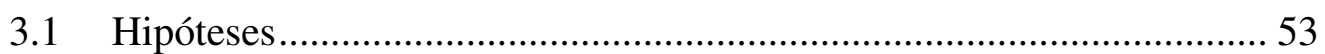

3.2 Abordagem de pesquisa ................................................................. 54

3.3 Operacionalização dos construtos e elaboração do questionário .......... 54

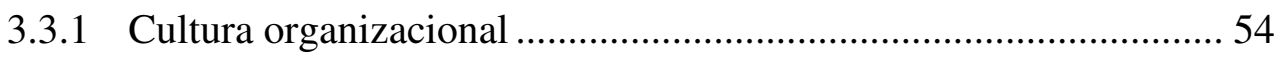

3.3.2 Técnicas de gestão da qualidade ................................................ 55

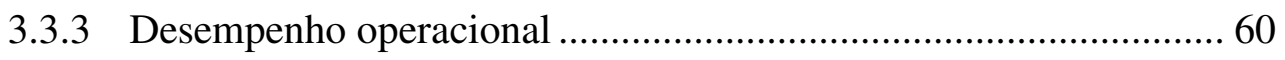

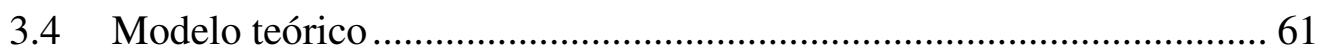

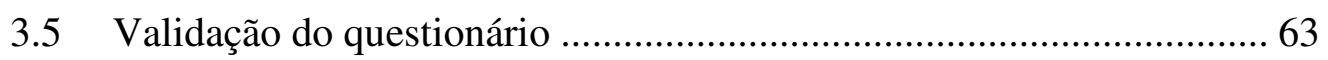

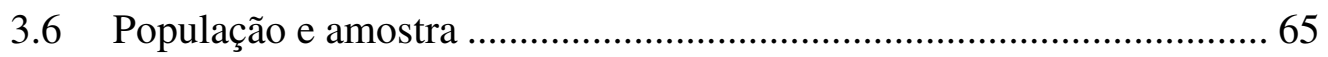

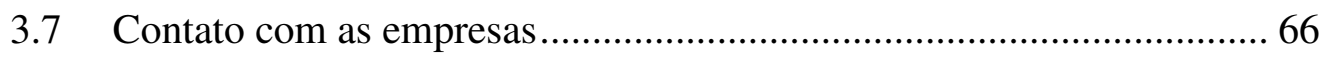

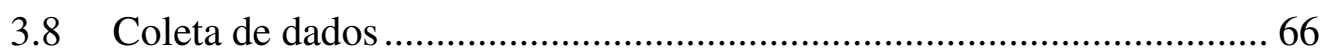

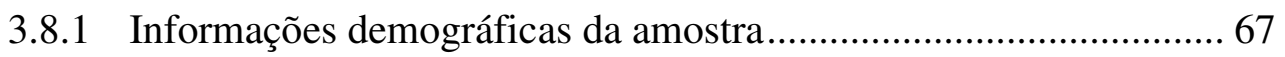

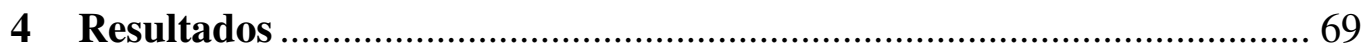

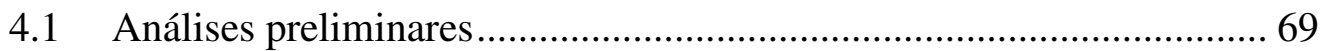

4.1.1 Testes de normalidade, linearidade e homoscedasticidade ............. 69

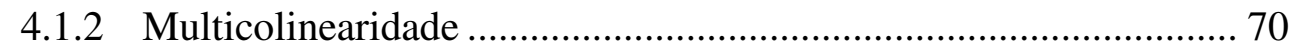

4.1.3 Medidas de confiabilidade e correlações bivariadas ....................... 70

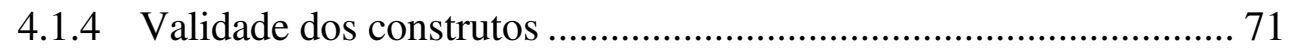

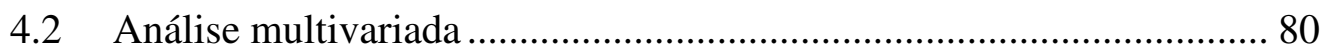


4.2.2 Avaliação do modelo de mensuração

4.2.3 Análise do modelo estrutural 83

5 Discussão 89

5.1 Hipótese 1. Associação entre cultura organizacional e o uso de técnicas da qualidade 89

5.2 Hipótese 2. Associação entre cultura organizacional, técnicas da qualidade e desempenho. 92

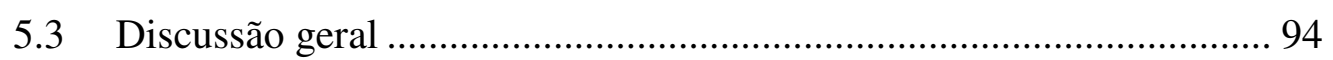

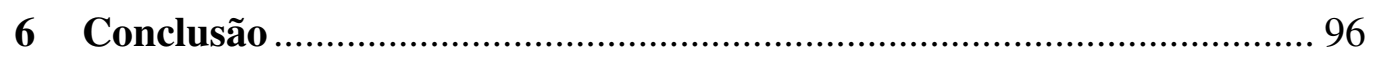

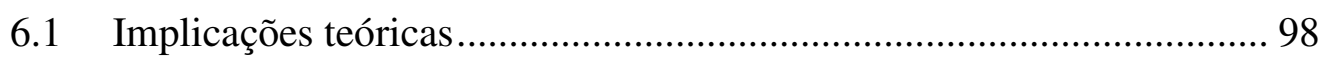

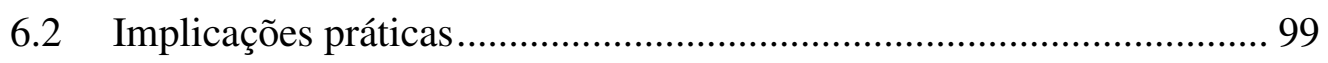

6.3 Limitações do trabalho e pesquisas futuras .................................... 100

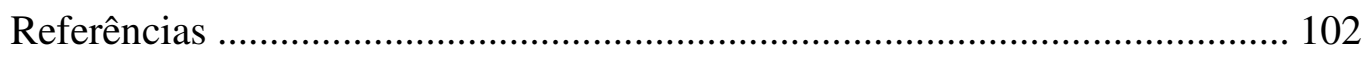

APÊNDICE A - Elementos de gestão da qualidade identificados na revisão da literatura. 109

APÊNDICE B - Variáveis utilizadas em pesquisas survey para medição de cultura organizacional. 111

APÊNDICE C - Variáveis utilizadas em pesquisas survey para medição de elementos da qualidade.

APÊNDICE D - Variáveis utilizadas em pesquisas survey para medição de desempenho 114 
APÊNDICE E - Variáveis utilizadas em pesquisas survey para medição de elementos da qualidade......

APÊEDICE F - Questionário Final .......................................................... 121

APÊENDICE G - Resultados dos testes dos modelos estruturais.................... 131 


\section{Introdução}

\subsection{Contextualização e justificativa}

A melhoria da qualidade dos produtos e serviços é fundamental para a competitividade das empresas que cada vez mais procuram estratégias, como a gestão da qualidade, para aumentar seu desempenho. Porém, embora a gestão da qualidade venha sendo cada vez mais implementada e estudada, são frequentes os casos de falhas associados a essa implementação.

São muitos os trabalhos que apontam resultados aquém dos esperados a partir das iniciativas da qualidade (ASIF et al., 2009; HARARI, 1993; HUBIAK; O'DONNEL, 1996; RAD, 2006; WU; ZHANG; SCHROEDER, 2011). Beer (2003), por exemplo, cita um estudo no qual descreve que cerca de 60 a $70 \%$ dos gerentes estão insatisfeitos com os resultados das iniciativas de qualidade implantadas em suas empresas. O autor ainda afirma que os programas de qualidade geralmente falham em criar uma mudança profunda e sustentável nas organizações.

Sousa e Voss (2002) sugerem que as diferenças entre iniciativas bem sucedidas e fracassadas de gestão da qualidade são decorrentes desta ser dependente do contexto. Embora existam na literatura alguns estudos como o de Sila (2007) cujos resultados não fornecem suporte para o argumento de que a gestão da qualidade seja contexto dependente, muitos outros seguem defendendo a natureza contexto-dependente sugerida por Sousa e Voss (2001).

Wu, Zhang e Schroeder (2011), por exemplo, reforçam essa ideia contextodependente ao afirmarem que estudar os impactos de outras variáveis organizacionais contribuiria para melhorar a compreensão sobre as diferenças de resultados advindos das iniciativas da qualidade. Essa importância em se considerar outras variáveis na organização deixa claro que não existe uma melhor forma de implementar a gestão da qualidade que sirva para todas as empresas.

Por muito tempo a gestão da qualidade foi tratada de forma universal, ou seja, aplicável em qualquer organização independente de suas características individuais. Porém, essa validade universal tem sido questionada por diversos autores (BEER, 2003; MAULL; BROWN; CLIFFE, 2001, SOUSA; VOSS, 2002, WU; ZHANG; SCHROEDER, 2011) que sugerem ser mais útil apoiar os estudos baseando-se numa 
teoria contingencial que implica que a gestão da qualidade deveria ser combinada com determinados aspectos contextuais.

O fato é que a gestão da qualidade se relaciona tanto a aspectos focados em componentes sociais da empresa, mais difíceis de serem medidos e mudados, como trabalho em equipe, autonomia, engajamento, liderança que são descritos na literatura como elementos soft da qualidade (MAULL; BROWN; CLIFFE, 2001; MOLINA; MONTES; MORENO, 2007; RAHMAN; BULLOCK, 2005) ou de "infraestrutura" (infrastructure) (BEER, 2003; FLYNN; SCHROEDER; SAKAKIBARA, 1995, SOUSA; VOSS, 2002), quanto a aspectos técnicos mais observáveis como o controle estatístico de processo, aplicação de ferramentas da qualidade, descritos como elementos hard da qualidade (MAULL; BROWN; CLIFFE, 2001; MOLINA; MONTES; MORENO, 2007; RAHMAN \& BULLOCK, 2005) ou “centrais" (core) (BEER, 2003; SOUSA; VOSS, 2002).

As dificuldades em alinhar o contexto organizacional às iniciativas da qualidade contribuem para o fracasso de iniciativas de sua implementação. Muitos autores afirmam que a cultura organizacional é uma importante variável contextual e que esta deve ser considerada ao abordar a gestão da qualidade (DETERT; SCHROEDER; MAURIEL, 2000, IRANI; BESKESE; LOVE, 2004; NAOR et al., 2008; RAD, 2006).

Nos últimos anos tem crescido a percepção de que a cultura organizacional deve ser considerada nas iniciativas da qualidade, o que pode ser evidenciado pela troca de ênfase sobre os elementos técnicos (hard) da qualidade para elementos sociais (soft). Dessa forma, nos últimos anos, tem-se desenvolvido diversos estudos sobre o relacionamento da gestão da qualidade e cultura organizacional (por ex. Gimenez-Espin, Jimenez-Jimenez e Matínez-Costa (2012); Maull, Brown e Cliffe (2001); Naor et al., (2008); Prajogo e McDermott (2005); Wu; Zhang; Schroeder, (2011)).

Na literatura há duas escolas antagônicas de pensamento (BRIGHT; COOPER, 1993): uma que vê a gestão da qualidade de forma unitarista sugerindo que a gestão da qualidade prospera somente em uma cultura única e simples, orientada para as pessoas, e a outra que vê a gestão da qualidade sob uma visão pluralista que sugere que a gestão da qualidade poderia prosperar numa heterogeneidade de dimensões culturais.

Sob a perspectiva unitarista, aspectos relacionados à cultura organizacional, como boa comunicação, envolvimento e empowerment dos funcionários, ambiente de confiança, bom relacionamento, trabalho em equipe, descentralização e participação na gestão, dentre outros, são colocados por vários autores como pré-requisitos para o 
sucesso na implementação da gestão da qualidade (RAD, 2006; TATA; PRASAD, 1998; ZEITZ; JOHANNENSE; RITCHIE, 1997).

Na visão pluralista, a gestão da qualidade é vista como multidimensional, na qual características culturais diferentes estão associadas a diferentes elementos da gestão da qualidade (CAMERON; QUINN, 2006; WATSON; KORUKONDA, 1995). Essa visão implica, então, que a gestão da qualidade poderia ser adequada a diferentes características culturais. Dessa forma, conhecer as características culturais da organização seria importante no sentido de melhor combinar elementos de gestão da qualidade a essas características.

Essas diferenças entre visões provocam discussões referentes à natureza da gestão da qualidade, pois, se esta for de fato multidimensional em relação à cultura, seria necessário considerar abordagens múltiplas para estimular sua implementação. Alternativamente, se esta for unidimensional, uma cultura única e um conjunto determinado de valores seriam mais apropriados (PRAJOGO; McDERMOTT, 2005).

Prajogo e McDermott (2005), por exemplo, em seus estudos sobre a relação entre cultura organizacional e práticas de gestão da qualidade, identificaram que diferentes práticas de gestão da qualidade se relacionam a diferentes características culturais, concluindo em favor da visão pluralista. Em estudos posteriores, eles investigaram o relacionamento entre cultura e desempenho organizacional concluindo que determinadas culturas se relacionam mais fortemente à inovação e melhoria da qualidade do que outras (PRAJOGO; McDERMOTT, 2011).

Também nessa linha, Zu, Robbins e Fredendall (2010) investigaram o relacionamento entre diferentes tipos de cultura e práticas individuais de gestão da qualidade e ressaltaram a importância de um ambiente cultural adequado que suporte a implementação bem sucedida de práticas da qualidade. Os resultados também demonstraram que a cultura organizacional exerce influência na adoção de determinadas práticas da qualidade.

Naor et al. (2008) em seus estudos afirmam que as práticas relacionadas aos elementos soft da qualidade têm um efeito mais significativo no desempenho da manufatura do que as práticas relacionadas aos elementos hard. Porém, os autores destacam que é fundamental considerar os dois elementos para que as iniciativas de gestão da qualidade contribuam para melhoria do desempenho organizacional.

O trabalho de Wu, Zhang e Schroeder (2011) também avança na compreensão da gestão da qualidade sob uma perspectiva contexto-dependente. Eles, assim como 
Naor et al. (2008), estudaram fatores culturais como variáveis contextuais e confirmaram a sua importância para a gestão da qualidade, destacando a influência da cultura na customização de práticas da qualidade para alcançar maior desempenho afirmando que organizações que focam nas práticas corretas da qualidade possuem maior probabilidade de serem bem sucedidas em suas iniciativas.

Os estudos citados anteriormente deixam clara a importância da cultura organizacional como variável contextual a ser considerada nas iniciativas de gestão da qualidade. Porém, esses estudos consideram, em geral, práticas de gestão da qualidade e, o que se percebe, é uma falta de uniformidade na definição e conceituação dessas práticas. Essas dificuldades na padronização das práticas e de seus conceitos são de alguma forma esperadas, já que estudos sobre a gestão da qualidade ao nível de práticas implicam considerar, principalmente, elementos sociais da qualidade que são mais difíceis de serem definidos e medidos como, por exemplo, liderança e gestão de processos.

Apesar da concordância de que a gestão da qualidade está relacionada à cultura organizacional e à melhoria no desempenho da organização, alguns autores afirmam que mais evidências empíricas são necessárias (WU; ZHANG; SCHROEDER, 2011; NAOR et al., 2008; MAULL; BROWN; CLIFFE, 2001). Além disso, não foi encontrado na revisão da literatura, nenhum estudo que considere explicitamente a influência da cultura organizacional na adoção e uso das técnicas da qualidade, ou seja, com foco nos aspectos mais técnicos da gestão da qualidade e as relacione à cultura organizacional e ao desempenho da empresa.

Dessa forma, esse estudo tem como objetivo cobrir essa lacuna e complementar os estudos do relacionamento entre cultura organizacional e gestão da qualidade na melhoria do desempenho das empresas, ao expandi-los para o nível das técnicas.

Estudar as técnicas da qualidade é importante, pois, as técnicas da qualidade possuem um importante papel na institucionalização dos princípios (por ex. melhoria contínua, comprometimento dos funcionários) e práticas da qualidade (por ex. trabalho em equipe, treinamento) (McQUATER et al., 1995; TARÍ; MOLINA; CASTEJÓN, 2007), na melhoria do desempenho da gestão da qualidade e resultados (HANDFIELD; JAYARAM;GOSH, 1999; TARÍ; SABATER, 2004). 


\subsection{Objetivos e contribuições}

Os objetivos principais dessa pesquisa são 1) estudar o relacionamento entre diferentes perfis de culturas organizacionais e o uso de técnicas de gestão da qualidade, analisando se determinadas características culturais da organização favorecem a implementação de técnicas específicas da qualidade, e 2) investigar se a cultura organizacional, combinada ao uso de técnicas da qualidade, influenciam nos resultados de desempenho da empresa.

Dessa forma, esse estudo procura responder os seguintes questionamentos:

- A cultura organizacional influencia na adoção de técnicas da gestão da qualidade?

- Determinadas técnicas de gestão da qualidade se adéquam melhor a certas empresas dependendo de suas características culturais?

- O desempenho da qualidade é influenciado pela combinação entre cultura organizacional e as técnicas da qualidade?

Como contribuição teórica da pesquisa espera-se fornecer maior evidência empírica sobre a influência que a cultura exerce na gestão da qualidade e o impacto desse relacionamento no desempenho organizacional. Como descrito anteriormente, enquanto os estudos anteriores focam no estudo do relacionamento entre cultura organizacional e gestão da qualidade no nível de práticas da qualidade, esse estudo contribui para expandir essa abordagem levando a análise para o nível das técnicas, considerando também a influência desse relacionamento no desempenho da empresa.

De forma prática, espera-se fornecer diretrizes às empresas sobre quais técnicas seriam mais aplicáveis numa organização considerando suas características culturais e, assim, contribuir para melhoria dos casos de sucesso a partir das iniciativas de gestão da qualidade.

\subsection{Etapas de desenvolvimento da pesquisa}

De forma a atingir seus objetivos, essa pesquisa foi realizada em duas grandes etapas: revisão da literatura e pesquisa survey. A revisão da literatura teve como objetivos mapear a literatura sobre os assuntos abordados na pesquisa: cultura organizacional, gestão da qualidade e desempenho; identificar a lacuna que estimulou o 
desenvolvimento do trabalho, bem como a elaboração das hipóteses e dos modelos teóricos (modelo de mensuração e estrutural) sobre o relacionamento entre gestão da qualidade, cultura organizacional e desempenho.

A revisão da literatura também contribuiu para um levantamento de instrumentos de medidas utilizados por outros autores para investigar elementos da gestão da qualidade, cultura organizacional e desempenho que serviu de base para a elaboração do questionário a ser utilizado para coleta de dados.

A pesquisa survey foi realizada com o objetivo de fornecer dados quantitativos para o teste do modelo teórico e das hipóteses consideradas nesse estudo. Forza (2008) afirma que a pesquisa survey é um dos métodos de pesquisa preferido quando se deseja testar a relação das hipóteses ou comportamento de variáveis em diferentes contextos. A capacidade de generalização das conclusões que o método permite, é uma de suas principais vantagens. Dessa forma, a pesquisa survey é um método adequado para se atingir os objetivos propostos.

O estudo do relacionamento entre cultura organizacional e as técnicas da gestão da qualidade e seu impacto no desempenho organizacional implica em diversas relações entre esses três construtos, o que torna necessário o uso de técnicas estatísticas mais sofisticadas para análise dos dados. Dessa forma, a análise dos dados foi realizada utilizando-se da Modelagem de Equações Estruturais, conhecida pela sigla SEM (Structural Equation Modeling), como técnica estatística multivariada.

O SEM é uma técnica de análise multivariada de dados que busca explicar relações entre múltiplas variáveis, examinando a estrutura de inter-relações expressas em uma série de equações que descrevem a relação entre as variáveis envolvidas na análise (HAIR et al. 2009). Segundo Kline (2011) o SEM permite a avaliação de modelos inteiros, o que traz uma perspectiva mais abrangente para a análise. As análises estatísticas permitiram investigar os questionamentos dessa pesquisa e discutir suas implicações teóricas e práticas.

A Figura 1 apresenta, de forma esquemática, as etapas de desenvolvimento da pesquisa. 


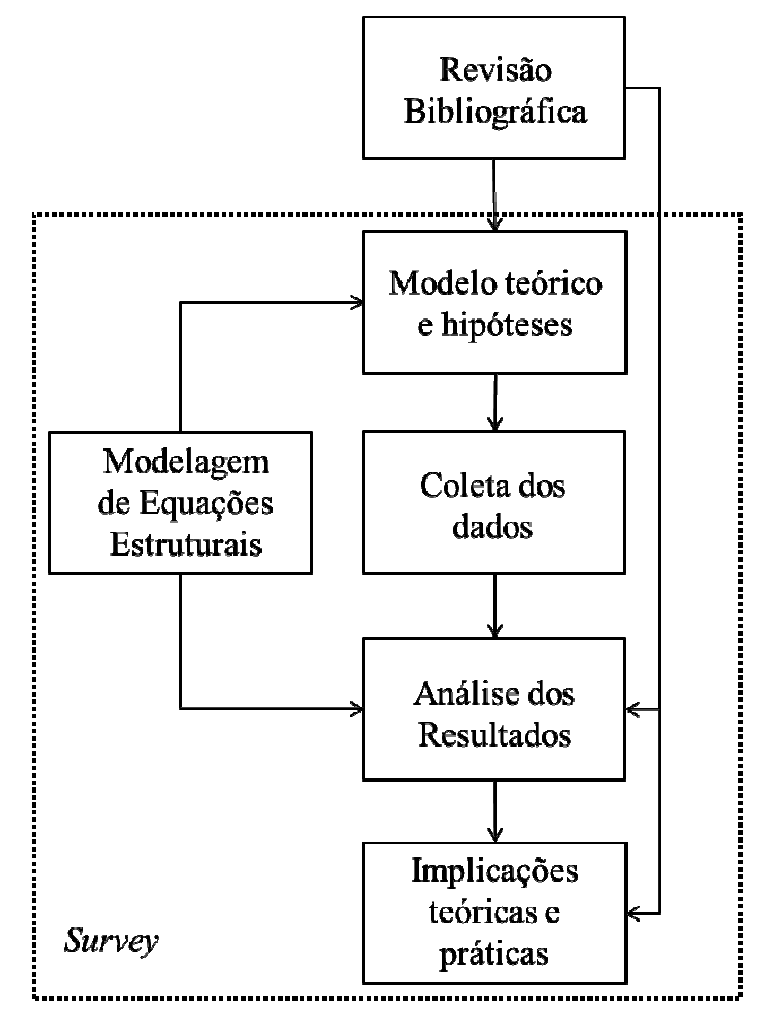

Figura 1. Etapas de desenvolvimento da pesquisa

Baseando nas etapas de desenvolvimento da pesquisa, a estrutura do texto foi organizada em:

Capítulo 1: Introdução. Apresenta a contextualização, justificativa da pesquisa, seus objetivos e contribuições e, por fim, suas etapas de desenvolvimento.

Capítulo 2: Referencial teórico. Esse capítulo apresenta uma revisão bibliográfica sobre gestão da qualidade, cultura organizacional e desempenho.

Capítulo 3: Hipóteses e Método de pesquisa. Apresenta as hipóteses investigadas nesse estudo e o método de pesquisa utilizado, enfatizando aspectos referentes à Modelagem de Equações Estruturais (SEM), como a definição dos modelos de mensuração e estrutural. Esse capítulo descreve também a operacionalização dos construtos, a elaboração e validação do questionário, procedimentos de coleta de dados bem como informações referentes à amostra analisada.

Capítulo 4: Resultados. Esse capítulo apresenta os resultados das análises estatísticas preliminares e das análises multivariadas dos modelos teóricos do relacionamento entre cultura organizacional, técnicas de gestão da qualidade e desempenho. 
Capítulo 5: Discussão. Nesse capítulo estão descritas as discussões dos resultados apresentados no capítulo 4. Nele são discutidas as hipóteses investigadas nesse estudo.

Capítulo 6: Conclusão. Por fim, tem-se o capítulo de conclusões onde são apresentadas as considerações finais desse trabalho, suas contribuições teóricas e práticas, limitações e sugestões de trabalhos futuros. 


\section{Referencial teórico}

\subsection{Conceitos e definições da gestão da qualidade}

A gestão da qualidade pode ser definida como uma abordagem integrada para alcançar e sustentar resultados de alta qualidade, focando na melhoria contínua e prevenção de defeitos em todos os níveis e funções da organização, de forma a atingir ou exceder as expectativas dos consumidores (FLYNN; SCHROEDER; SAKAKIBARA, 1994).

Durante os anos oitenta e noventa, ela se tornou parte da estratégia das empresas sendo utilizada em todo o mundo (RAD, 2006). Muitos benefícios são alcançados a partir das iniciativas da qualidade como, por exemplo: redução do número de defeitos, redução do retrabalho, baixos níveis de inventário, maior competitividade, maiores lucros, aumento da flexibilidade e da satisfação dos funcionários e clientes (GUNASEKARAN, 1999; SILA; EBRAHIMPOUR, 2005).

Além do uso bastante disseminado nas empresas, Sousa e Voss (2002) afirmam que a gestão da qualidade é um tema bastante consolidado também na literatura. De fato, existem na literatura muitas definições de gestão da qualidade assim como elementos que compõem seu conceito. Dentre importantes estudos sobre o assunto, pode-se destacar os de Flynn, Schroeder e Sakakibara (1994) e Ahire, Golhar e Waller (1996), frequentemente citados na literatura.

Flynn, Schroeder e Sakakibara (1994) identificam o que eles chamaram de “dimensões chaves da qualidade" e propõem um modelo e um instrumento de medida para gestão da qualidade. Os autores definem como dimensões da qualidade: "Suporte da alta direção, Informações da qualidade, Gestão dos processos, Desenvolvimento do produto, Gestão da força de trabalho, Envolvimento do fornecedor e Envolvimento do consumidor". Segundo os autores, as dimensões foram definidas baseando-se nos critérios do prêmio Malcom Baldridge da qualidade.

Utilizando-se de revisão da literatura, pesquisa survey com uma amostra de 716 respondentes de 42 empresas norte-americanas e análise estatística, os autores desenvolveram e validaram um instrumento de medida para gestão da qualidade. Segundo Flynn, Schroeder e Sakakibara (1994), um instrumento confiável e validado é 
importante por ser uma ferramenta para autoavaliação, benchmarking e avaliação longitudinal da melhoria contínua.

Ahire, Golhar e Waller (1996), também desenvolveram e validaram um instrumento de medida contendo o que os autores definiram como "construtos de estratégias integradas de gestão da qualidade". O instrumento contém um total de doze construtos: "Comprometimento da alta direção, Foco no consumidor, Gestão da qualidade dos fornecedores, Gestão da qualidade do projeto, Benchmarking, Controle estatístico do processo, Uso de informações da qualidade, Empowerment, Envolvimento dos funcionários, Treinamento, Qualidade do produto, Desempenho do fornecedor".

Por meio de uma pesquisa survey com 371 empresas de manufatura, Ahire, Golhar e Waller (1996) testaram e validaram empiricamente seus construtos. Segundo esses autores enquanto o instrumento deles e de Flynn, Schroeder e Sakakibara (1994) possuem diversos aspectos equivalentes, existem ainda muitas diferenças, como:

- As escalas do instrumento de Flynn, Schroeder e Sakakibara (1994) representam estratégias da qualidade (inputs) enquanto duas das doze escalas do instrumento de Ahire representam resultados: "Qualidade do Produto e Desempenho do Fornecedor" (outputs);

- Ahire, Golhar e Waller (1996) incluíram “Empowerment e Benchmarking”, ausentes no instrumento de Flynn, Schroeder e Sakakibara (1994). Em contrapartida, esses últimos incluíram indicadores relacionados à orientação para times;

- Ahire, Golhar e Waller (1996) definiram uma dimensão específica para "Foco no consumidor ao invés de Interação com o consumidor" (presente no instrumento de Flynn, Schroeder e Sakakibara (1994)). Segundo Ahire, Golhar e Waller (1996), alta interação com os consumidores poderia refletir gestão da qualidade ruim e não foco no consumidor;

- Flynn, Schroeder e Sakakibara (1994) adicionaram indicadores relacionados à "Limpeza e Organização";

- Enquanto Ahire, Golhar e Waller (1996) definem Controle estatístico do processo como uma dimensão distinta, no instrumento de Flynn, Schroeder e Sakakibara, (1994) este é um componente da "Gestão do processo".

Sousa e Voss (2002) fizeram um trabalho de revisão bibliográfica em gestão da qualidade o que, segundo eles, trata-se de "um balanço do conhecimento acumulado no 
que é agora um campo maduro do conhecimento". Os autores compararam importantes estudos sobre o tema, por exemplo, Flynn, Schroeder e Sakakibara (1995); Ahire, Golhar e Waller (1996); Anderson et al. (1995); Powell (1995) e Saraph, Benson e Schroeder (1989) e forneceram uma correspondência entre os elementos de gestão da qualidade neles identificados numa tentativa de sintetizar, organizar e estruturar o conhecimento em gestão da qualidade.

Sousa e Voss (2002) afirmam que existe um acordo substancial sobre o conjunto de elementos classificados sob o conceito de gestão da qualidade o que comprova a maturidade do tema. Porém, esses mesmos autores destacam que não há uma padronização desses termos, chamando atenção para uma necessidade de padronização e definição dos termos classificados sob o conceito de gestão da qualidade. O mesmo foi constatado por Ebrahimi e Sadeghi (2013) que levantaram mais de duzentas práticas em seus estudos de revisão da literatura em gestão da qualidade e concluíram que muitas delas são similares podendo, portanto, ser unidas.

Essa falta de padronização pode ser facilmente identificada na literatura, por exemplo, diferentes termos são usados para "práticas" da qualidade, como "dimensões" (FLYNN; SCHROEDER; SAKAKIBARA, 1994), “fatores" (SILA; EBRAHIMPOUR, 2005), ou ainda uma gama de termos para identificar elementos semelhantes, por exemplo: "foco no consumidor" (AHIRE, GOLHAR; WALLER, 1996; SILA; EBRAHIMPOUR, 2005), “identificação dos requerimentos do consumidor” (BEER, 2003) ou ainda "envolvimento do consumidor" (NAOR et al., 2008).

Sousa e Voss (2002) ainda afirmam que são necessários estudos que deixem explícito em que nível (princípio, prática ou técnica) a gestão da qualidade tem sido abordada na literatura e ressaltam a importância da padronização dos termos adotados. Dean e Bowen (1994) também definem a gestão da qualidade considerando-a sob esses três níveis sugerindo que os princípios são, de forma implícita ou explícita, a base para tudo que se relaciona à gestão da qualidade. Cada princípio é implementado por um conjunto de práticas e estas, por sua vez, sustentadas por uma variedade de técnicas.

Somente a definição de "técnicas" foi identificada na revisão da literatura, para McQuater et al. (1995), técnicas e ferramentas são métodos práticos, habilidades, meios ou mecanismos utilizados em tarefas particulares. Esses autores apresentam definições distintas para esses dois termos, nos quais descrevem ferramenta como um dispositivo de papel claro e aplicação restrita (por ex. diagrama de causa e efeito, pareto) e técnica como tendo uma aplicação mais ampla (controle estatístico do processo, benchmarking) 
e, para isso, requer maiores habilidades e treinamentos. Segundo os autores, de uma forma bem simplista, técnicas podem ser definidas como um conjunto de ferramentas.

A definição para os outros dois níveis (práticas e princípios) não foi identificada na revisão bibliográfica, mas Sousa e Voss (2002) fornecem um exemplo para essa diferenciação. Segundo eles, o princípio "melhoria contínua" pode ser suportado pela prática de "gestão do processo" que, por sua vez, se utiliza de diversas técnicas como "controle estatístico de processo" e "pareto".

De forma a facilitar a compreensão dos diversos elementos classificados sob o conceito gestão da qualidade, este estudo adota a seguinte definição: "princípios da qualidade" como regras fundamentais admitidas como base para gestão da qualidade; "práticas da qualidade" como execução padrão convencionada de técnica(s) de gestão da qualidade, e "técnicas" como ferramentas e/ou métodos (que podem ser intelectuais) que auxiliam no processo de gestão. Neste estudo, o termo "elemento" é utilizado de forma genérica, ou seja, referindo-se tanto aos princípios quanto às práticas e técnicas.

As definições descritas acima estão de acordo com a forma como Sousa e Voss (2002) exemplificam esses diferentes níveis, como Dean e Bowen (1994) definem a gestão da qualidade e como McQuater et al. (1995) definem as ferramentas e técnicas.

Por meio da revisão da literatura ficou evidente que, também em trabalhos atuais, ainda existem diferentes termos sendo usados para identificar e definir um mesmo elemento. O Apêndice A apresenta os diversos elementos descritos sob o conceito de gestão da qualidade identificados na revisão, os diferentes termos utilizados e um agrupamento dos termos semelhantes sob uma denominação comum. Em seguida esses elementos foram classificados nos níveis de princípios, práticas e técnicas, conforme descritos no Quadro 1.

\begin{tabular}{|l|l|c|}
\hline \multicolumn{1}{|c|}{$\begin{array}{c}\text { Elementos da } \\
\text { qualidade }\end{array}$} & \multicolumn{1}{|c|}{ Autores } & Classificação \\
\hline Liderança & $\begin{array}{l}\text { Ahire et al. (1996), Beer (2003), Douglas \& Judge (2001), } \\
\text { Flynn et al. (1994), Jayaram et al. (2010), Naor et al. } \\
\text { (2008), Prajogo \& McDermott (2005), Sila \& } \\
\text { Ebrahimpour (2005), Zu et al. (2008) }\end{array}$ & Princípio \\
\hline Empowerment & Ahire et al. (1996), Jayaram et al. (2010), Wu et al. (2011) & Princípio \\
\hline $\begin{array}{l}\text { Comprometimento } \\
\text { dos funcionários }\end{array}$ & Ahire et al. (1996), Rahaman \& Bullock (2005) & Princípio \\
\hline
\end{tabular}




\begin{tabular}{|c|c|c|}
\hline $\begin{array}{l}\text { Elementos da } \\
\text { qualidade }\end{array}$ & Autores & Classificação \\
\hline $\begin{array}{l}\text { Foco no } \\
\text { consumidor }\end{array}$ & $\begin{array}{l}\text { Ahire et al. (1996), Douglas \& Judge (2001), Flynn et al. } \\
\text { (1994), Hackman \& Wageman (1995), Jayaram et al. } \\
\text { (2010), Mehra et al. (2001), Naor et al. (2008), Prajogo \& } \\
\text { McDermott (2005), Rahman \& Bullock (2005); Sila \& } \\
\text { Ebrahimpour (2005), Wu et al. (2011), Zu et al. (2009) }\end{array}$ & Princípio \\
\hline $\begin{array}{l}\text { Relação ganha- } \\
\text { ganha }\end{array}$ & Beer (2003), Rahman \& Bullock (2005) & Princípio \\
\hline $\begin{array}{l}\text { Melhoria } \\
\text { contínua (kaizen) }\end{array}$ & $\begin{array}{l}\text { Douglas \& Judge (2001), Hackman \& Wageman } \\
\text { (1995), Rahman \& Bullock (2005) }\end{array}$ & Princípio \\
\hline $\begin{array}{l}\text { Decisão baseada } \\
\text { em dados }\end{array}$ & $\begin{array}{l}\text { Beer (2003), Douglas \& Judge (2001), Hackman \& } \\
\text { Wageman (1995) }\end{array}$ & Princípio \\
\hline $\begin{array}{l}\text { Gestão da } \\
\text { qualidade do } \\
\text { fornecedor }\end{array}$ & $\begin{array}{l}\text { Ahire et al. (1996), Baird et al. (2011), Beer (2003), } \\
\text { Flynn et al. (1994), Jayaram et al., (2010), Mehra et } \\
\text { al., (2001), Naor et al. (2008), Rahman \& Bullock } \\
\text { (2005), Sila \& Ebrahimpour (2005), Zu et al. (2010) }\end{array}$ & Prática \\
\hline $\begin{array}{l}\text { Trabalho em } \\
\text { times }\end{array}$ & $\begin{array}{l}\text { Beer (2003), Flynn et al. (1994), Hackman \& } \\
\text { Wageman (1995), Rahaman \& Bullock (2005), Wu et } \\
\text { al. (2011) }\end{array}$ & Prática \\
\hline $\begin{array}{l}\text { Uso de dados da } \\
\text { qualidade }\end{array}$ & $\begin{array}{l}\text { Ahire et al. (1996), Baird et al. (2011), Flynn et al. } \\
\text { (1994), Jayaram et al. (2010), Naor et al., (2008), Sila } \\
\text { \& Ebrahimpour (2005), Zu et al. (2010) }\end{array}$ & Prática \\
\hline $\begin{array}{l}\text { Gestão dos } \\
\text { processos }\end{array}$ & $\begin{array}{l}\text { Baird et al. (2011), Beer (2003), Flynn et al (1994), } \\
\text { Hackman \& Wageman (1995), Jayaram et al (2010), } \\
\text { Naor et al (2008), Prajogo \& McDermott (2005), Wu } \\
\text { et al (2011), Zu et al. (2010) }\end{array}$ & Prática \\
\hline $\begin{array}{l}\text { Desenvolvimento } \\
\text { do produto }\end{array}$ & $\begin{array}{l}\text { Ahire et al. (1996), Baird et al. (2011), Flynn et al. } \\
\text { (1994), Naor et al. (2008), Prajogo \& McDermott } \\
\text { (2005), Zu et al. (2010) }\end{array}$ & Prática \\
\hline $\begin{array}{l}\text { Gestão do } \\
\text { desempenho }\end{array}$ & Carpinetti (2012) & Prática \\
\hline $\begin{array}{l}\text { Gestão das } \\
\text { pessoas }\end{array}$ & $\begin{array}{l}\text { Flynn et al. (1994), Mehra et al. (2001), Naor et al. } \\
\text { (2008), Prajogo \& McDermott (2005), Sila \& } \\
\text { Ebrahimpour (2005), Zu et al. (2010) }\end{array}$ & Prática \\
\hline Treinamento & $\begin{array}{l}\text { Ahire et al. (1996), Douglas \& Judge (2001), Flynn et } \\
\text { al. (1994), Hackman \& Wageman (1995), Jayaram et } \\
\text { al. (2010), Rahman \& Bullock (2005); Wu et al. } \\
(2011)\end{array}$ & Prática \\
\hline $\begin{array}{l}\text { Manutenção } \\
\text { Produtiva Total }\end{array}$ & Pinto et al. (2006) & Prática \\
\hline 6 Sigma & $\begin{array}{l}\text { Carpinetti (2012), Pinto et al., (2006), Zu et al., } \\
(20010)\end{array}$ & Prática \\
\hline
\end{tabular}


Conclusão

\begin{tabular}{|c|c|c|}
\hline $\begin{array}{l}\text { Elementos da } \\
\text { qualidade }\end{array}$ & Autores & Classificação \\
\hline $\begin{array}{l}\text { Ferramentas da } \\
\text { qualidade }\end{array}$ & $\begin{array}{l}\text { Carpinetti (2012), Douglas \& Judge (2001), } \\
\text { McQuarter et al. (1995), Mehra et al. (2001), } \\
\text { Handfield et al. (1999) }\end{array}$ & Técnica \\
\hline Brainstorming & McQuarter et al. (1995), Naor et al. (2008) & Técnica \\
\hline $\begin{array}{l}\text { Métodos } \\
\text { estruturados para } \\
\text { melhoria } \\
\text { contínua }\end{array}$ & Carpinetti (2012), Pinto et al., (2006), Zu et al. (2010) & Técnica \\
\hline $\begin{array}{l}\text { Procedimento } \\
\text { Operacional } \\
\text { Padrão (POP) }\end{array}$ & Flynn et al., (1994) & Técnica \\
\hline $\begin{array}{l}\text { Análise do Modo } \\
\text { e Efeito da Falha } \\
\text { (FMEA) }\end{array}$ & $\begin{array}{l}\text { Carpinetti (2012), Handfield et al., (1999), McQuarter } \\
\text { et al. (1995), Pinto et al. (2006) }\end{array}$ & Técnica \\
\hline $\begin{array}{l}\text { Uso de técnicas } \\
\text { estatísticas }\end{array}$ & $\begin{array}{l}\text { Ahire et al., (1996), Carpinetti (2012), Handfield et } \\
\text { al., (1999), McQuarter et al. (1995), Pinto et al. } \\
\text { (2006) }\end{array}$ & Técnica \\
\hline Poka yoke & Ahire et al. (1996), McQuarter et al. (1995) & Técnica \\
\hline $\begin{array}{l}\text { Desdobramento } \\
\text { da Função } \\
\text { Qualidade } \\
\text { (QFD) }\end{array}$ & $\begin{array}{l}\text { Ahire et al. (1996), Beer (2003), Carpinetti (2012), } \\
\text { Handfield et al. (1999), Jayaram et al. (2010), } \\
\text { McQuarter et al. (1995) }\end{array}$ & Técnica \\
\hline Benchmarking & $\begin{array}{l}\text { Ahire et al. (1996), Carpinetti (2012), Hackman \& } \\
\text { Wageman (1995), McQuarter et al. (1995) }\end{array}$ & Técnica \\
\hline $\begin{array}{l}\text { Uso de } \\
\text { indicadores de } \\
\text { desempenho }\end{array}$ & Mehra et al. (2001), Zu et al. (2010) & Técnica \\
\hline $5 \mathrm{~S}$ & $\begin{array}{l}\text { Carpinetti (2012), Flynn et al. (1994), Pinto et al. } \\
(2006)\end{array}$ & Técnica \\
\hline Evento kaizen & Handfield et al. (1999), Pinto et al. (2006) & Técnica \\
\hline Brainstorming & McQuarter et al. (1995), Naor et al. (2008) & Técnica \\
\hline $\begin{array}{l}\text { Manutenção } \\
\text { preventiva }\end{array}$ & Handfield et al., (1999) & Técnica \\
\hline $\begin{array}{l}\text { Inspeção da } \\
\text { qualidade }\end{array}$ & Handfield et al. (1999), Naor et al. (2008) & Técnica \\
\hline $\begin{array}{l}\text { Certificação de } \\
\text { fornecedores }\end{array}$ & Naor et al. (2008) & Técnica \\
\hline
\end{tabular}

Quadro 1. Elementos da gestão da qualidade 
Esses três níveis da gestão da qualidade e seus elementos estão diretamente relacionados entre si. A Figura 2 apresenta, de forma esquemática, exemplos do relacionamento dos elementos da gestão da qualidade em seus três níveis.

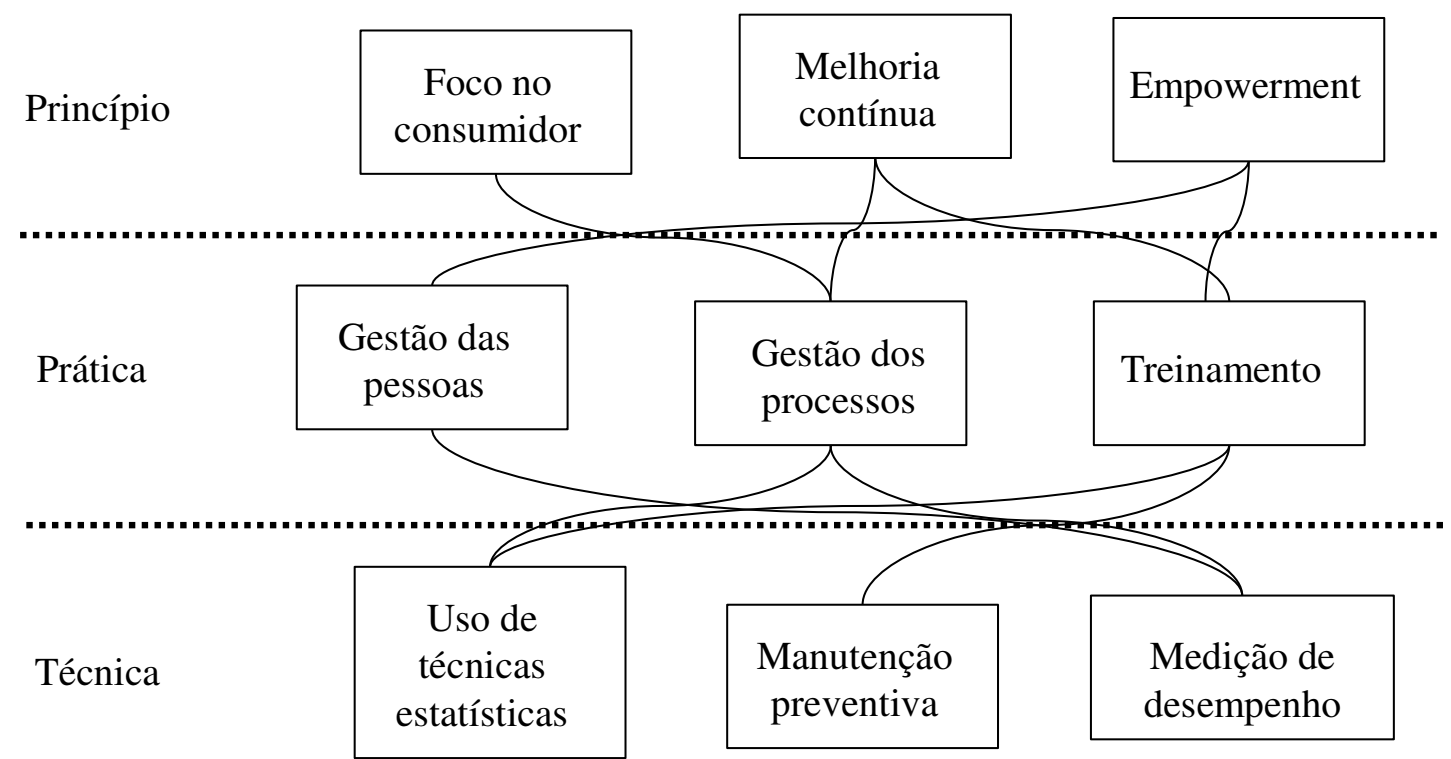

Figura 2. Relação dos elementos da qualidade

Dean e Bowen (1994) afirmam que a gestão da qualidade, por ter sido direcionada principalmente por práticos, foi considerada, por muito tempo, de forma implicitamente universal e independente do contexto. Segundo esses autores, havia uma pequena atenção sobre condições para sua aplicabilidade e como variações de características organizacionais poderiam ser refletidas em sua implementação.

Essa ótica universal implica que as organizações deveriam adotar os elementos da gestão da qualidade da mesma forma e no mesmo grau, e que elas seriam igualmente aplicáveis em qualquer empresa independente de seu contexto, obtendo-se resultados semelhantes. Segundo Asif et al. (2009), a abordagem universal se tornou popular pela proeminência dos sistemas de produção japonês, benchmarking das melhores práticas e dos prêmios da qualidade.

Porém, essa validade universal é questionada por pesquisadores que defendem que a gestão da qualidade precisa ser combinada com outros aspectos organizacionais de forma a potencializar seus resultados positivos. Isso quer dizer que, cada vez mais, os pesquisadores defendem que as iniciativas da qualidade devem ser baseadas numa abordagem contingencial, dependente do contexto. 
Os casos de insucesso resultante das iniciativas de implementação da gestão da qualidade, descritos na literatura e pelos práticos, têm estimulado o desenvolvimento de pesquisas que consideram variáveis contextuais como, por exemplo, cultura organizacional (BAIRD; HU; REEVE, 2011; KULL; WACKER, 2010, WU; ZHANG; SCHROEDER, 2011, ZU; ROBBINS; FREDENDALL, 2010) tamanho da organização, tipo da indústria, duração e nível de maturidade dos programas da qualidade (AHIRE; DREYFUS, 2000; JAYARAM; AHIRE; DREYFUS, 2010).

Asif et al. (2009) afirmam que é justamente essa falha em considerar aspectos contextuais que aumentam a possibilidade de fracasso das iniciativas da qualidade nas empresas. Como citado anteriormente, dentre essas variáveis contextuais, a cultura organizacional é um dos aspectos frequentemente citados como influenciadores desses resultados. A seção 2.2 apresenta alguns aspectos descritos na literatura que contribuem para o fracasso de iniciativas de gestão da qualidade.

\subsection{Aspectos de falha}

A literatura em gestão da qualidade possui inúmeros estudos desenvolvidos por pesquisadores e empresas de consultoria que apontam que nem sempre os resultados esperados a partir das iniciativas de gestão da qualidade são atingidos na prática. Conforme afirmam Cândido e Santos (2011), as estimativas de casos de falha descritos da literatura variam de $7 \%$ a $80 \%$, apontando melhora ao longo dos anos. Porém, eles chamam a atenção para o fato de que esses estudos não são facilmente comparáveis, já que os pesquisadores usam diferentes critérios para se definir sucesso e falha resultantes da implementação da gestão da qualidade, além de terem sido realizados em diferentes momentos no tempo.

Entretanto, independente da real taxa de casos de falhas descrita na literatura, o fato é que muitas empresas atingem resultados muito aquém dos esperados a partir das iniciativas de gestão da qualidade. Nesse contexto Asif et al., (2009) defendem que é importante considerar a gestão da qualidade não de forma isolada mas interligada a áreas como gestão de operações e estratégia das empresas. Segundo os autores, a gestão da qualidade, quando efetivamente institucionalizada e alinhada à estratégia organizacional, poderia ser uma fonte de vantagem competitiva. Eles também argumentam que os elementos técnicos da qualidade são fundamentais para implementação da gestão da qualidade, mas que seu uso somente sob uma perspectiva 
técnica, independente do contexto e não alinhada de forma coerente com a estratégia organizacional, pode direcionar a fazer as coisas certas de forma errada.

Outro autor que chama atenção para a importância de tornar a gestão da qualidade como algo institucionalizado na organização é Beer (2003). Segundo ele, as iniciativas top-down de gestão da qualidade geralmente falham em criar uma mudança profunda e institucionalizada nas organizações, o autor ainda critica a inconsistência entre a retórica da alta direção e a realidade do que ocorre nos processos de implementação da gestão da qualidade, afirmando que as falhas nas iniciativas de gestão da qualidade são causadas por falhas gerenciais.

Rad (2006) lista algumas dificuldades enfrentadas pelas organizações em suas iniciativas de gestão da qualidade, como por exemplo: falta de comprometimento da alta direção, falta de planos estratégicos para mudança, falta de uma cultura voltada para qualidade, resistência à mudança, ausência de clareza nas estratégias e conflitos de prioridades, dentre outras e conclui que a cultura organizacional tem um efeito significativo em implementações bem sucedidas da gestão da qualidade. Muitos desses aspectos de falha são também sugeridos nos estudos de Cândido e Santos (2011).

Rahman e Bullock (2005) em seus estudos de gestão da qualidade investigaram problemas para a implementação de iniciativas da qualidade e identificaram que existem dificuldades em estabelecer uma filosofia de apropriação dos processos de qualidade pelos funcionários e a própria cultura organizacional. Os entrevistados apontaram que mudanças na cultura da organização e o treinamento e educação dos funcionários são os fatores mais significantes para impedir a institucionalização dos processos da melhoria da qualidade na organização.

Por meio dos aspectos de falhas descritos na literatura percebe-se que eles recaem sobre aspectos sociais da organização. Moosa et al., (2010) afirmam que quando os elementos da qualidade são colocados em prática, eles geralmente entram em conflito com o contexto organizacional existente.

Em outras palavras, é possível afirmar que existe na literatura um acordo substancial de que as dificuldades em integrar aspectos sociais da organização às iniciativas da qualidade contribuem para os resultados de sua implementação e manutenção. Assim, é comum identificar autores como Cameron e Quinn (2006), Detert, Schroeder e Mauriel, (2000), Irani, Beskese e Love (2004), Naor et al. (2008), Prajogo e McDermott (2005), Rad (2006) que sugerem que a cultura organizacional 
exerce um papel central nos casos de sucesso e falha das iniciativas de gestão da qualidade.

Uma vez que a cultura organizacional é considerada uma importante variável contextual relacionada à gestão da qualidade, a seção 2.3 apresenta a definição de cultura organizacional e algumas considerações sobre o assunto. Por fim, são apresentados alguns modelos descritos na literatura, utilizados para identificar diferentes perfis de cultura organizacional.

\subsection{Cultura organizacional e gestão da qualidade}

A cultura organizacional afeta a forma como uma organização opera em diferentes situações. Nela é reconhecido que o sistema de valores constantemente influencia as decisões e comportamentos das pessoas (WU; ZHANG; SCHROEDER, 2011). Como descrito anteriormente, o interesse pelo estudo da cultura organizacional se dá pela percepção da importância de fatores culturais nas práticas de gestão.

As organizações tendem a desenvolver uma cultura organizacional dominante ao longo do tempo. Segundo Schein (1984), a cultura organizacional cria tanto a estabilidade, ao reforçar a continuidade e consistência na organização, quanto a adaptabilidade, por fornecer um conjunto de diretrizes a serem seguidas quando a estratégia lida com novas circunstâncias para a organização.

A literatura apresenta controvérsias importantes que se relacionam a como definir cultura organizacional, como medi-la e que dimensões chaves deveriam caracterizá-la. Na maioria das vezes, os pesquisadores definem cultura sob uma perspectiva coletiva e fundamentada na sociologia, ou seja, na visão de que as organizações possuem culturas. Estudos recentes como o de Detert, Schroeder e Mauriel (2000), Prajogo e McDermott (2005, 2011) e Gimenez-Espin, Jiménez-Jiménez e Matínez-Costa (2012), também consideram a cultura organizacional sob essa ótica que está bem alinhada com uma definição clássica de cultura apresentada por Schein (1984):

[...] cultura organizacional é o padrão de pressupostos básicos que um dado grupo tem inventado, descoberto, ou desenvolvido durante seu processo de aprendizado para lidar com seus problemas de adaptação externa e integração interna, e que tem funcionado bem o bastante para ser considerado válido e, portanto, 
para ser ensinado para novos membros como a forma correta para perceber, pensar, e sentir em relação a esses problemas.

As organizações tendem a desenvolver uma cultura organizacional dominante ao longo do tempo baseando-se em como elas se adaptam e respondem a mudanças no ambiente. De acordo com Shein (1984), a cultura organizacional, paradoxalmente, cria tanto a estabilidade quanto a adaptabilidade para a organização. Ela cria a estabilidade que mantém a organização junta e reforça a continuidade e consistência na organização através da aderência a um conjunto de valores consensuais, e também promove adaptabilidade por fornecer um claro conjunto de princípios para serem seguidos quando a estratégia lida com novas circunstâncias.

A gestão da qualidade vai além da implementação de práticas e técnicas de gestão e requerem o suporte da cultura e atitudes dos membros da organização (HACKMAN; WAGEMAN, 1995). Como afirmam Wu, Zhang e Schroeder (2011), se uma empresa quer adotar práticas de qualidade, ainda que falte uma cultura que dê sustentação (por ex., falta de empowerment), seus funcionários poderiam se sentir intimidados a pararem a linha de produção quando eles se deparassem com algum problema, contribuindo para o fracasso das iniciativas da qualidade. Dessa forma, cresce o interesse em se considerar a influência que a cultura organizacional exerce nas iniciativas de gestão da qualidade.

Adequar práticas e técnicas da qualidade, que sejam mais coerentes à cultura organizacional da empresa, parece ser a forma menos desgastante de obter sucesso nas iniciativas da qualidade. Porém, não se pode desconsiderar que a cultura organizacional poderia se adequar a determinados elementos da gestão da qualidade. Alguns autores como Baird, Hu e Reeve (2011); Irani, Beskese e Love (2004); Sohal e Terziovski (2000) defendem a necessidade de mudar a cultura organizacional e atitudes dos trabalhadores para que iniciativas de implementação dos elementos de gestão da qualidade sejam efetivas.

Entretanto, mudar a cultura de uma organização é um processo mais lento, gradual e que exige maiores esforços. Pois, conforme sugerido por Maull, Brown e Cliffe (2001), enquanto os elementos da gestão da qualidade possam refletir a cultura de uma organização, esta por si só é embutida em padrões de crenças e valores compartilhados, nela instituídos com o passar do tempo. 
Dessa forma, pela natureza da cultura, a dificuldade em mudá-la e o fato dela refletir a combinação de características organizacionais e práticas adotadas, é pouco provável que a implementação de uma determinada prática ou técnica de gestão da qualidade, não coerente com a cultura atual, tenha um impacto imediato na cultura organizacional.

Assim, conforme afirmam Irani, Beskese e Love (2004), independente da abordagem sobre a gestão da qualidade e a natureza de seu relacionamento com a cultura organizacional, é importante destacar que muitos autores concordam que a gestão da qualidade e cultura organizacional estão relacionados e precisam ser considerados.

O trabalho desses autores destaca a importância de uma cultura de qualidade forte como um elemento chave para melhorar a cultura organizacional. Para eles, muitas organizações precisarão mudar sua cultura interna para sobreviver no mercado global e sugerem que o foco no consumidor e melhoria contínua, conceitos centrais da qualidade, podem construir uma cultura forte. Além disso, afirmam que tanto as características individuais dos funcionários quanto as características gerais da organização são importantes para o sucesso da qualidade.

Já Baird, Hu e Reeve (2011) afirmam que organizações que promovem colaboração entre unidades e entre os funcionários e que valorizam os direitos dos indivíduos são mais prováveis de usar a gestão da qualidade em um contexto maior. Segundo esses autores, os funcionários são os ativos mais importantes da gestão da qualidade. Essa afirmação reforça a importância dos elementos soft da qualidade destacadas, por exemplo, por Sousa e Voss (2002) e Naor et al. (2008).

Os resultados dos estudos de $\mathrm{Wu}$, Zhang e Schroeder (2011) confirmam a importância da cultura na implementação de elementos da qualidade, particularmente no sentido de que ela influencia em como customizá-las para serem mais efetivas na melhoria do desempenho da empresa. Eles afirmam que a gestão da qualidade é um sistema complexo e que, geralmente, precisa de alguns anos para ser implementada. Nesse processo de implementação, as organizações que focam nos elementos corretos da qualidade estão mais propensas a obterem sucesso.

Esses autores ainda citam como exemplo o caso de uma empresa que tem uma cultura de foco na eficiência e tende a produzir em grandes lotes. Quando a alta gerência decide adotar iniciativas de gestão da qualidade, a filosofia começa a ser disseminada na empresa, mas ainda não está institucionalizada. O comportamento dos funcionários 
ainda é guiado pela cultura organizacional dominante, e eles têm receio de fazer as coisas contra essa cultura. Os autores defendem que nesse estágio, seria mais fácil e benéfico, implementar controle estatístico do processo para, dessa forma, encorajar os funcionários a solucionar problemas na linha de produção espontaneamente e voluntariamente.

As iniciativas de implementação da qualidade devem ser realizadas considerando as intervenções em aspectos técnicos e também, na compreensão de questões culturais que deem suporte ao sucesso dessas intervenções (KUJALA; LILLRANK, 2004; RAD, 2006).

Naor et al., (2008) afirmam que diversos atributos culturais estão ligados a elementos soft da qualidade. Uma cultura desenvolvimentista, por exemplo, é facilitada pelo encorajamento dos funcionários a assumir riscos, serem flexíveis e com capacidade de adaptação às mudanças de mercado, já práticas de trabalho em equipe como brainstorming e compartilhamento de responsabilidades são consistentes com uma cultura de grupo. Por sua vez, empresas que possuem uma característica de evitar as incertezas utilizam elementos como certificação de fornecedores, controle do processo de produção, testes e inspeções. Já aquelas cujo objetivo principal é ganhar mercado, utilizam elementos como envolvimento com o consumidor de forma a antecipar suas necessidades são destacadas.

\subsubsection{Visão unitarista versus pluralista}

A literatura em gestão da qualidade apresenta uma discussão sobre duas visões divergentes da natureza do relacionamento entre gestão da qualidade e cultura. Enquanto a visão unitarista sugere que o sucesso da gestão da qualidade está associado a um único perfil cultural, a visão pluralista defende a ideia de que a gestão da qualidade pode ser bem sucedida em diferentes perfis culturais, sugerindo que não há apenas um perfil cultural exclusivo que forneça condições apropriadas para o sucesso da gestão da qualidade.

Nos estudos de Prajogo e McDermott (2005) essas duas visões são testadas e os autores concluem em favor da visão pluralista da qualidade, ou seja, a gestão da qualidade deve ser considerada como multidimensional se adequando a variadas características culturais. 
Nessa mesma linha, Maull, Brown e Cliffe (2001), por meio de seus estudos, forneceram um diagnóstico com informações sobre diferenças culturais em diferentes áreas de uma organização financeira. Esses autores consideraram a implementação de elementos da gestão da qualidade como iniciativas de melhoria e afirmaram que conhecer a cultura da organização poderia ajudá-la em suas iniciativas de qualidade. Dessa forma, não é possível considerar a premissa de que um conjunto pré-estabelecido de iniciativas da qualidade seria aplicável a qualquer empresa. Partindo desse pressuposto, apoia-se a teoria de que a gestão da qualidade é dependente do contexto, reforçando a visão pluralista da qualidade onde ela seria adequada a características culturais diferentes.

\subsubsection{Relação causal entre gestão da qualidade e cultura}

A literatura apresenta, também, uma discussão sobre a direção causal do relacionamento entre gestão da qualidade e cultura. Alguns autores consideram cultura como um antecedente à gestão da qualidade e estudam o efeito que ela exerce na gestão da qualidade. Maull, Brown e Cliffe (2001) estudando diferentes unidades de uma mesma organização concluem que as iniciativas da qualidade precisam ser adaptadas de acordo com os diferentes perfis culturais característicos das diferentes unidades estudadas. Prajogo e McDermott (2005) e Naor et al., (2008) sugerem que diferentes tipos de cultura estão associados com a implementação de diferentes práticas da qualidade. Em suma, esses autores sugerem que cultura organizacional antecede as iniciativas de gestão da qualidade.

Por outro lado, outros autores argumentam numa direção causal oposta. Por exemplo, Sohal e Terziovski (2000), Irani, Beskese e Love (2004) e Baird, Hu e Reeve (2011) concluem que é necessária uma mudança na cultura organizacional e nas atitudes dos funcionários para que as iniciativas da qualidade sejam mais efetivas.

Outros autores sugerem ainda um possível relacionamento recíproco entre gestão da qualidade e cultura. Wu, Zhang e Schroeder (2011) sugerem que a cultura organizacional precisa dar suporte à implementação e uso das iniciativas de gestão da qualidade adotadas. Isto é, de forma a obterem benefícios completos advindos das múltiplas práticas da gestão da qualidade, as empresas precisam desenvolver características associadas a múltiplas culturas. 
Na literatura, existem modelos que buscam identificar diferentes tipos de cultura organizacional, dentre eles, o modelo de Hofstede (2001); o modelo PCOC (Personal, Customer Orientation, Organisational e Cultural issues) de Maull, Brown e Cliffe (2001), derivada da abordagem da análise cultural de Hosftede, no qual eles afirmam que as pessoas, consumidores e organização estão inter-relacionados com elementos culturais; o modelo de O'Reilly III, Chatman e Caldwell (1991): OCP (Organizational Cultural Profile) e o de Quinn e Rohrbaugh (1983): CVF (Competing Values Framework). Esses modelos são apresentados na Seção 2.4.

\subsection{Modelos de cultura organizacional}

\subsubsection{Modelo de Hofstede}

Hofstede (2001) define cultura como um programa coletivo de pensamento que distingue os membros de um grupo de outros, ou diferenças entre as pessoas. Por meio de seu "Onion Diagram" (Diagrama de Cebola), representado na Figura 3, ele descreve manifestações da cultura em diferentes níveis de profundidade.

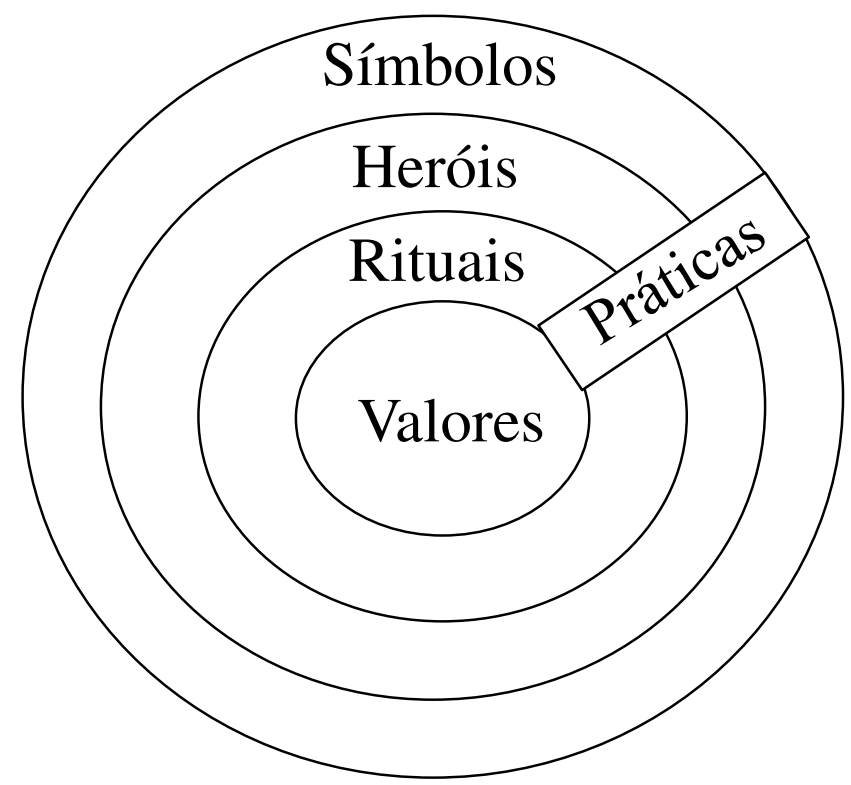

Figura 3. Modelo de Hofstede “Onion Diagram” (Hofstede, 2001)

Segundo Hofstede (2001), os valores são invisíveis até que eles se tornem evidentes no comportamento e, outros elementos como rituais, heróis e símbolos são manifestações visíveis da cultura, conforme descritos abaixo: 
- Símbolos: são palavras, gestos, figuras e objetos que carregam significados complexos reconhecidos somente por aqueles que compartilham a mesma cultura. Novos símbolos são facilmente substituídos ou símbolos de um grupo cultural são facilmente copiados por outros. Esse é o motivo dos símbolos aparecerem na camada mais externa do diagrama.

- Heróis: são pessoas que possuem características que são fortemente premiadas na cultura e servem de modelo para o comportamento;

- Rituais: atividades coletivas que são tecnicamente desnecessárias para alcançar fins desejados, mas são considerados socialmente essenciais na cultura.

- Práticas: símbolos, heróis e rituais são nomeados de práticas; assim eles são visíveis para um observador de fora. Porém, seus significados culturais são invisíveis e somente interpretáveis pelas pessoas de dentro da organização.

Hofstede (2001) definiu algumas dimensões culturais a partir de um estudo survey que realizou para a empresa IBM ${ }^{\circledR}$ e suas subsidiárias em diferentes países. A pesquisa foi realizada entre 1967 e 1973, abrangendo 71 países. Os objetivos dos estudos eram desenvolver uma terminologia comumente aceitável e empiricamente fundamentada para descrever diferentes culturas e analisar dados coletados de forma sistemática e não apenas baseado em impressões. A análise evidenciou que as respostas entre os países poderiam ser explicadas pelas seguintes dimensões (HOFSTEDE, 2001):

- Distância do poder: até que ponto os membros menos poderosos da organização aceitam e esperam que o poder seja distribuído de forma desigual;

- Resistência à incerteza: indica até que ponto os membros de uma cultura se sentem confortáveis ou desconfortáveis nas situações de incerteza;

- Individualismo versus coletivismo: refere-se ao grau em que os indivíduos olham para além de si mesmos e ao quanto eles olham para o grupo;

- Masculinidade versus feminilidade: refere-se à distribuição dos papéis emocionais entre os gêneros; a masculinidade se relaciona à competição, a um comportamento hostil, enquanto a feminilidade aproxima-se de um comportamento mais carinhoso e atencioso. 
A partir dessas dimensões, um expressivo número de trabalhos considerando cultura organizacional foi realizado. Porém, os estudos de Hofstede (2001) enfatizam características culturais entre diferentes nacionalidades, sendo, dessa forma, mais adequado para estudar cultura nacional que cultura organizacional. Outro modelo organizacional para análise da cultura que será abordado neste capítulo foi derivado da abordagem de Hofstede e está apresentado na Seção 2.4.2.

\subsubsection{Modelo PCOC (Personal, Customer orientation, Organisational and Culture issues)}

Esse modelo foi desenvolvido por Maull, Brown e Cliffe (2001) e é derivado da abordagem de Hofstede. Segundo os autores, o PCOC surgiu da necessidade dos gerentes identificarem primeiramente a cultura organizacional antes das iniciativas de melhoria. O modelo PCOC está representado na Figura 4.

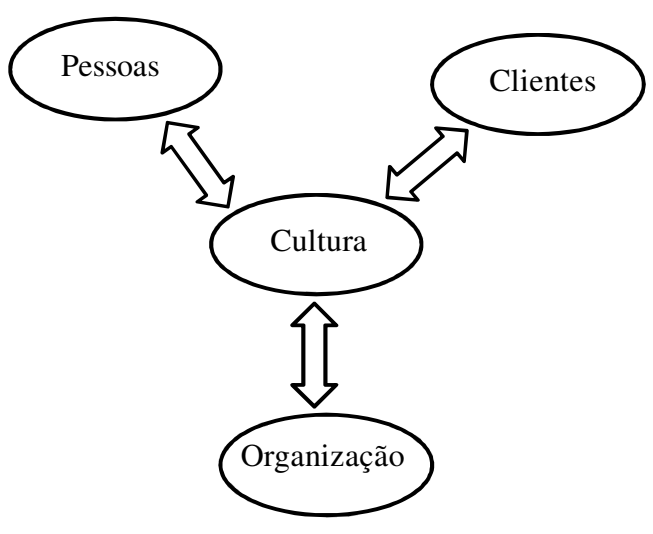

Figura 4. Modelo PCOC (Maull, Brown e Cliffe, 2001)

Os autores destacam que o modelo é holístico, não sendo possível determinar causalidade entre os elementos que o compõem. O objetivo deles foi operacionalizar o modelo na forma de um questionário constituído por 100 (cem) questões de forma a fornecer a base para avaliação da cultura organizacional.

Os autores argumentam que, dessa forma, os gerentes poderiam conhecer a cultura da organização e identificar áreas que poderiam auxiliar as melhorias organizacionais através do desenvolvimento de intervenções focadas. Ou seja, conhecer inicialmente a cultura organizacional para que as iniciativas de melhoria tenham maior possibilidade de serem bem sucedidas. 
Maull, Brown e Cliffe (2001) descrevem a aplicação desse modelo em sete passos, conforme apresentado a seguir:

- Identificar o que precisa ser medido e como os resultados serão analisados e comunicados na organização;

- Identificar as pessoas que representarão o grupo foco para se conseguir um modelo cultural apropriado para esse grupo;

- Assegurar que a informação é coletada na forma mais acurada possível;

- Aplicar o questionário;

- Analisar os dados obtidos a partir da aplicação do questionário;

- Comunicar os resultados, assegurando que as pessoas recebam informações sobre os resultados;

- Identificar áreas que precisam ser gerenciadas quando a mudança organizacional for implementada.

Esse modelo é interessante no sentido de destacar a importância de se conhecer a cultura organizacional antes da adoção de iniciativas de melhoria. Ou seja, as empresas precisam gerenciar as mudanças pela medição e compreensão de características culturais, antes das intervenções serem planejadas ou implementadas. Porém, como os autores destacaram, este é um modelo holístico e seu principal benefício é fornecer informações sobre diferenças na cultura, em diferentes partes da organização. Dessa forma, este modelo não fornece informações, por exemplo, sobre quais iniciativas de melhoria seriam mais adequadas às culturas identificadas.

\subsubsection{Modelo OCP (Organizational Culture Profile)}

O Modelo OCP foi desenvolvido para investigar o ajuste da pessoa à cultura organizacional, ele é constituído por 54 (cinquenta e quatro) afirmações de valores que podem genericamente capturar valores individuais e organizacionais (O'REILLY III; CHATMAN; CALDWELL, 1991).

Para definir o perfil da cultura organizacional, os funcionários devem responder às afirmações de valores de acordo com o grau em que cada item é característico da organização. Para as preferências individuais, os funcionários deveriam responder quais valores consideram ideais para a organização. A partir dos resultados, e para demonstrar o quanto pessoas que se adequam à cultura organizacional produzem resultados 
melhores, os autores mediram outras variáveis como, por exemplo: comprometimento organizacional, satisfação no trabalho e turnover.

Esse modelo fornece uma definição de valores que refletem a cultura organizacional e também as preferências individuais. Porém, ele não categoriza os valores em diferentes tipos de culturas organizacionais e nem classifica diferentes tipos de cultura organizacional. Por meio da aplicação desse modelo é possível, por exemplo, identificar os indivíduos que possuem alta necessidade de atingir metas mostrando, assim, uma preferência significante deles por uma cultura agressiva, orientada para resultados.

Mas, embora este modelo forneça uma descrição dos valores organizacionais, o objetivo principal desse modelo parece ser o de combinar as preferências individuais à cultura organizacional de forma a melhorar a satisfação dos funcionários, seu comprometimento e consequente melhoria do desempenho organizacional.

Alguns autores utilizaram desse modelo em seus estudos, como é o caso de Baird, Hu e Reeve (2011) que estudaram o relacionamento entre a cultura organizacional, práticas de gestão da qualidade e desempenho organizacional. Porém, esses autores utilizaram apenas seis dimensões culturais do modelo (orientação para os resultados, atenção aos detalhes, trabalho em equipe/respeito pelas pessoas, inovação, estabilidade e agressividade) e, considerando essas dimensões culturais, investigaram a extensão do uso da gestão da qualidade em empresas australianas.

\subsubsection{Modelo CVF (Competing Values Framework)}

O modelo CVF de Quinn e Rohrbaugh (1983) foi inicialmente desenvolvido para explicar perfis culturais existentes em diferentes modelos organizacionais. $\mathrm{O}$ modelo foca na competição de tensões e conflitos inerentes em qualquer sistema humano: estabilidade e mudança, e no conflito entre o ambiente interno e externo (DENISON; SPREITZER, 1991).

Uma dimensão deste modelo se refere ao enfoque organizacional, se este está voltado ao desenvolvimento do indivíduo na organização ou ao desenvolvimento da própria organização, ênfase no ambiente interno e externo, respectivamente; a outra dimensão está relacionada à estrutura organizacional podendo estar mais voltada à estabilidade e controle ou, de forma oposta, à flexibilidade e à mudança. A combinação dessas duas dimensões resulta em quatro perfis culturais que caracterizam diferentes 
culturas organizacionais: cultura de grupo, desenvolvimentista, hierárquica e racional. A Figura 5 apresenta esse modelo e descreve as principais características relacionadas a cada um deles.

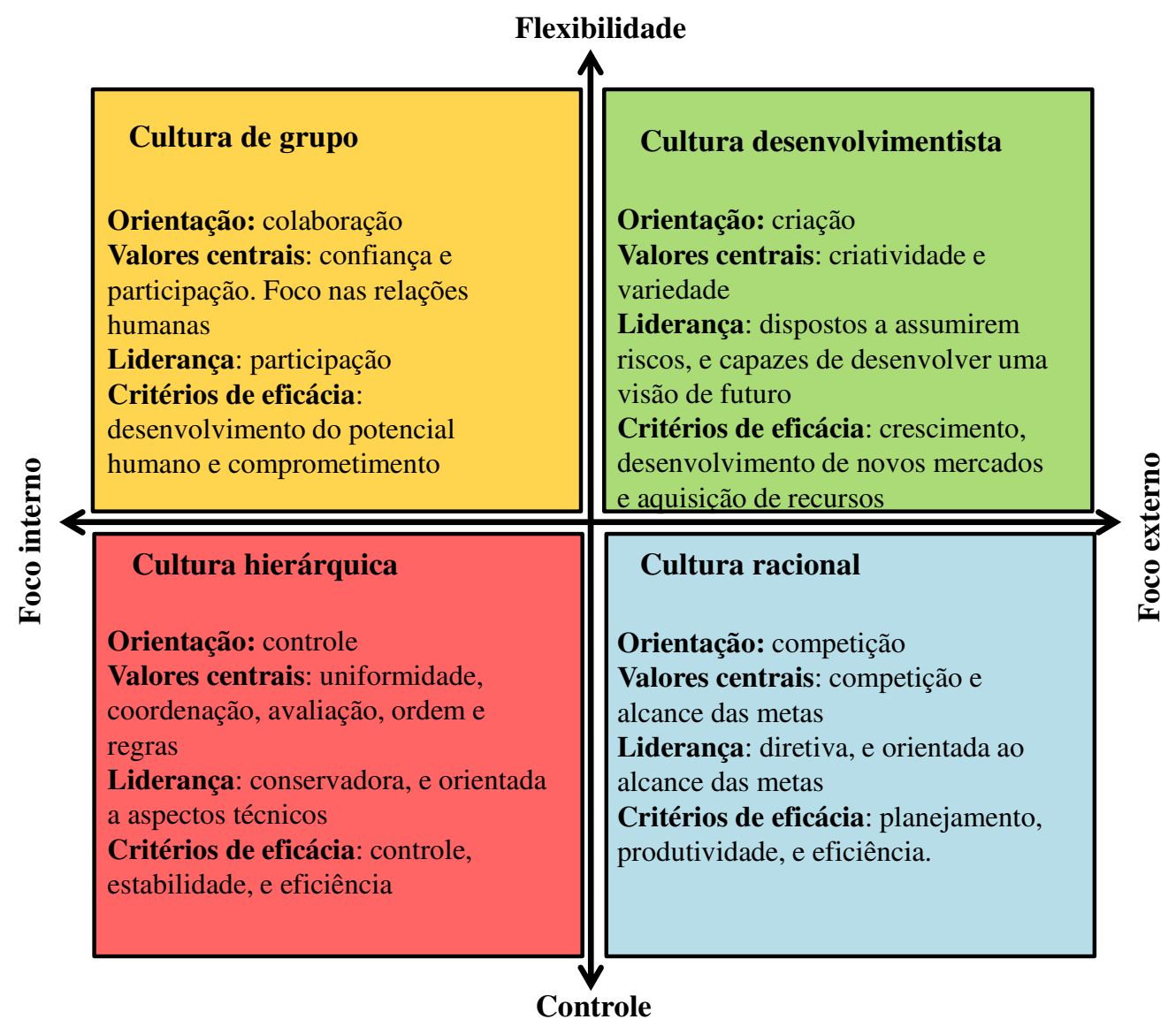

Figura 5. Modelo CVF (Adaptado de Cameron e Quinn, 2006)

A cultura de grupo dá ênfase à flexibilidade e ao ambiente interno da organização. Empresas com ênfase nessa cultura promovem desenvolvimento de recursos humanos. É uma cultura orientada para a colaboração e tem como valores a comunicação aberta, o comprometimento e o desenvolvimento dos recursos humanos. Cameron e Quinn (2006) citam o empowerment, a organização do trabalho em times, comunicação aberta e foco no desenvolvimento dos recursos humanos, como estratégias da qualidade relacionadas a essa cultura.

A cultura desenvolvimentista também enfatiza flexibilidade, porém o foco está voltado ao ambiente externo, sendo orientada em direção ao crescimento, criatividade, aquisição de recursos, inovação e constante adaptação ao ambiente externo. Tem como valores a inovação, transformação, agilidade e constante adaptação ao ambiente externo. Dentre as estratégias da qualidade relacionadas a essa cultura estão inovação, 
antecipação das necessidades dos clientes, melhoria contínua e criação de novos padrões (CAMERON; QUINN, 2006).

Já a cultura racional é também focada no ambiente externo, mas é orientada para o controle, onde a ênfase se dá na produtividade, desempenho, alcance dos objetivos e uma das motivações primárias é a competição; a cultura hierárquica é orientada ao controle e ao ambiente interno, ela enfatiza regras e padronização para alcançar controle e estabilidade (PRAJOGO \& McDERMOTT, 2005). Cameron e Quinn (2006) sugerem como estratégias da qualidade relacionadas a essa cultura: melhoria da produtividade, criação de parcerias, aumento da competitividade e envolvimento dos fornecedores e consumidores, onde a ênfase se dá na melhoria da produtividade e do desempenho.

Por fim, a cultura hierárquica enfatiza a estabilidade e o controle assim como a cultura racional, porém possui foco no ambiente interno da organização. Ela é orientada ao controle e tem como valores a eficiência, consistência e uniformidade, enfatizando regras e padronização para alcance do controle e estabilidade. Dentre as estratégias da qualidade relacionadas a ela, citadas por Cameron e Quinn (2006) estão: detecção de erros, medições, controle de processo e o uso de ferramentas da qualidade.

Embora cada quadrante represente um tipo ideal, é muito provável que uma organização exiba uma combinação de diferentes características culturais com uma mais dominante que outras (WU; ZHANG; SCHROEDER, 2011). Dessa forma, o modelo identifica combinações dos diferentes tipos culturais, com alguns mais predominantes que outros. Cameron e Quinn (2006) destacam ainda a importância do equilíbrio entre as diferentes culturas, já que a ênfase em apenas um quadrante pode tornar a organização disfuncional: muita flexibilidade, por exemplo, levaria a organização ao caos, em contrapartida, muito controle, tornaria a organização muito rígida.

O CVF foi utilizado em diversos estudos (por ex. Prajogo e McDermott (2005, 2011); Wu, Zhang e Schroeder (2011), Zu, Robbins e Fredendall (2010), dentre outros). Além disso, Denison e Spreitzer (1991) afirmam que esse modelo é um método de analisar a cultura organizacional de uma forma, em parte, mais quantitativa, o que contrasta com a forma qualitativa geralmente utilizada para se estudar cultura organizacional.

De fato, Detert, Schroeder e Mauriel (2000) fizeram um levantamento da literatura para determinar que dimensões normativas têm sido usadas para definir a cultura ideal para implementação da gestão da qualidade. Os autores identificaram dois tipos de trabalho: aqueles que os pesquisadores exploram a gestão da qualidade e 
aqueles que focam na medição de valores e crenças e sua relação com a implementação da gestão da qualidade.

No primeiro grupo de estudos encontram-se modelos que, implicitamente ou explicitamente, referem somente a práticas que deveriam ser observadas nas organizações que implementam elementos de gestão da qualidade; e o segundo grupo, no qual os pesquisadores usam instrumentos ou abordagens para medir a cultura, que discutem como perfis culturais se relacionam à qualidade. É o caso de estudos que usam modelos como Competing Values Framework (CVF) e Organizational Culture Profile (OCP). Detert, Schroeder e Mauriel (2000) criticam esses estudos, pois dizem que, embora eles forneçam informações úteis sobre certos aspectos da cultura e sua relação com a implementação de práticas de gestão da qualidade, eles são limitados pelos aspectos de cultura cobertos pelo instrumento.

Apesar dessa crítica, o CVF, por exemplo, é um modelo bem demonstrado na pesquisa empírica (NAOR et al., 2008). Além disso, Cameron e Quinn (2006) afirmam que o CVF também é útil em identificar uma abordagem mais ampla para qualidade, pois ele destaca elementos-chave de cada uma dessas quatro culturas e as estratégias de qualidade utilizadas em cada uma delas.

\subsection{Gestão da qualidade, cultura organizacional e desempenho}

Diversos trabalhos estudam o relacionamento entre gestão da qualidade e desempenho (por ex.: Handfield, Jayaram e Gosh (1999), Samson e Terziovski (1999); Kaynak (2003). Outros estudos consideram a cultura organizacional nesse contexto, como é o caso dos estudos de Baird, Hu e Reeve (2011); Giménez-Espin, JiménezJiménez e Martínez-Costa (2013); Naor et al. (2008); Prajogo e McDermott (2005, 2011) e Wu, Zhang e Schroeder (2011).

Handfield, Jayaram e Gosh (1999) estudaram o relacionamento entre elementos técnicos da qualidade (o que eles chamaram de ferramentas) da gestão da qualidade e desempenho. Dessa forma, os autores primeiro identificaram uma lista de ferramentas da qualidade e por meio de análise fatorial exploratória (EFA - Exploratory Factor Analysis), eles identificaram quatro grupos de ferramentas da qualidade, aos quais eles deram o nome de "Ferramentas de disciplina, Ferramentas de recursos humanos, Ferramentas de medição e Ferramentas de projeto". 
Posteriormente à identificação desses grupos de ferramentas, esses autores investigaram o relacionamento entre esses grupos e um conjunto de indicadores de desempenho (de qualidade e organizacional) e, também, com estratégias de qualidade (Inspeção, Controle do processo, Melhoria do processo, Qualidade do Projeto). Os autores concluíram que os grupos de ferramentas da qualidade afetam diversas dimensões do desempenho que estão relacionadas tanto ao desempenho da qualidade (número de defeitos, refugos e retrabalho) quanto ao desempenho organizacional (como market share, posição competitiva e crescimento), concluindo, também, que esses impactos variam de acordo com as estratégias da qualidade adotadas por essas empresas.

O Quadro 2 resume algumas das conclusões de Handfiel, Jayaram e Gosh (1999) relacionados a cada um dos grupos de ferramentas da qualidade identificados por eles, bem como as ferramentas classificadas dentro de cada um desses grupos.

\begin{tabular}{|c|c|}
\hline Padrões de ferramentas da qualidade & Conclusões \\
\hline $\begin{array}{l}\text { Ferramentas de Dis ciplina } \\
\text {-Programas de melhoria contínua; } \\
\text {-Programas de gestão da qualidade total; } \\
\text {-Manutenção preventiva }\end{array}$ & $\begin{array}{l}\text { São empregadas para modificar uma cultura da qualidade } \\
\text { existente ou para instalar uma nova cultura; } \\
\text { Efetivas em contextos nos quais existe uma alta incidência de } \\
\text { taxas de defeitos e rejeitos; } \\
\text { Relacionadas a medidas de qualidade orientadas aos } \\
\text { consumidores e ao desempenho dos negócios. }\end{array}$ \\
\hline $\begin{array}{l}\text { Ferramentas de Recursos Humanos } \\
\text {-Inspeção final; } \\
\text {-Inspeção em processo; } \\
\text {-Funcionários responsáveis pelo defeito } \\
\text { fazem o retrabalho; } \\
\text {-Programas de sugestões de melhoria; } \\
\text {-Círculos da qualidade. }\end{array}$ & $\begin{array}{l}\text { Contribuem para capacitar e envolver os funcionários em } \\
\text { iniciativas de melhoria da qualidade } \\
\text { Em um nível moderado, podem contribuir para a redução das } \\
\text { taxas de defeitos; } \\
\text { Parecem afetar mais fortemente as medidas de desempenho } \\
\text { dos negócios; } \\
\text { Tem objetivo de servirem de suporte ou de facilitadoras para as } \\
\text { demais ferramentas }\end{array}$ \\
\hline $\begin{array}{l}\text { Ferramentas de Medidas } \\
\text {-Histogramas; } \\
\text {-Pareto; } \\
\text {-Estudos de capabilidade do processo; } \\
\text {-Regressão; } \\
\text {-Controle estatístico do processo. }\end{array}$ & $\begin{array}{l}\text { Tem o papel de avaliar os resultados das iniciativas de melhoria } \\
\text { da qualidade; } \\
\text { Parecem ser igualmente efetivas para o controle do processo e } \\
\text { estratégias de melhoria do processo; } \\
\text { Afetam medidas de desempenho de qualidade que estão } \\
\text { diretamente ligadas aos processos internos; }\end{array}$ \\
\hline $\begin{array}{l}\text { Ferramentas de projeto } \\
\text {-QFD; } \\
\text {-DOE; } \\
\text {-FMEA; } \\
\text {-Projeto para manufatura; } \\
\text {-Programa de zero defeito. }\end{array}$ & $\begin{array}{l}\text { Implantadas para re-engenharia de processos e normalmente } \\
\text { envolvem múltiplas funções; } \\
\text { Conducentes em contextos nos quais a definição de qualidade } \\
\text { se relaciona mais ao projeto do que a conformidade }\end{array}$ \\
\hline
\end{tabular}

Quadro 2. Resultados dos estudos de Handfield, Jayaram e Gosh (1999) 
Samson e Terziovski (1999) também consideraram o relacionamento entre gestão da qualidade e cultura organizacional, porém, focando na gestão da qualidade no nível de práticas. Assim, eles investigaram o relacionamento entre práticas de gestão da qualidade (liderança, gestão de pessoas, foco no consumidor, planejamento estratégico, informação e análise, gestão de processos) e desempenho operacional (satisfação do consumidor, moral dos funcionários, produtividade, saída da qualidade e desempenho da entrega). Os resultados de seus estudos mostram que os elementos soft da qualidade (por ex. gestão de pessoas) estão mais fortemente relacionados ao desempenho que elementos hard da qualidade (por ex. informação e análise).

Nessa mesma linha, Kaynak (2003) estudou o relacionamento entre sete práticas de gestão da qualidade (liderança, treinamento, relação dos funcionários, dados da qualidade, gestão da qualidade do fornecedor, desenvolvimento de produtos/serviços, e gestão dos processos) e os efeitos dessas práticas do desempenho operacional e financeiro/mercado. Seus resultados mostram que algumas práticas da qualidade possuem um efeito direto no desempenho, enquanto outras afetam o desempenho indiretamente, além de sugerir que o efeito positivo das práticas de gestão da qualidade é mediado pelo desempenho operacional.

Esses e outros estudos têm mostrado que a gestão da qualidade tem um impacto positivo significante no desempenho. Entretanto, conforme discutido anteriormente, na prática, muitas das iniciativas da gestão da qualidade têm falhado em alcançar os resultados pretendidos fazendo com que fatores contextuais sejam considerados, incluindo em particular a cultura organizacional.

Nesse contexto Naor et al., (2008), estudaram empresas de manufatura em seis países a fim de investigar o relacionamento entre cultura organizacional e elementos da gestão da qualidade e seu impacto no desempenho (custo, qualidade, entrega e flexibilidade). Os autores dividiram os elementos da qualidade no que eles denominaram práticas soft (suporte da alta direção, gestão da força de trabalho, envolvimento dos fornecedores, envolvimento dos consumidores) e práticas hard (uso de informações da qualidade, gestão dos processos, desenvolvimento do produto) de gestão da qualidade.

Os autores realizaram seus estudos utilizando-se dois modelos alternativos: o de mediação, o qual especifica a existência de um mecanismo de intervenção entre a variável antecedente e a consequente; neste modelo, os elementos de gestão da qualidade foram definidos como mediadoras do relacionamento entre cultura e 
desempenho. O modelo de moderação testa o impacto de uma interação na variável consequente; neste modelo, os elementos da qualidade foram definidos como moderadoras da relação entre cultura e desempenho.

Nos testes dos dois modelos os resultados foram consistentes entre si mostrando que as práticas soft da gestão da qualidade tem um efeito direto positivo no desempenho, o que não foi verificado quando as práticas hard foram consideradas. Além disso, os resultados mostraram um efeito moderador não significante das práticas (soft e hard) de gestão da qualidade na relação entre cultura e desempenho, enquanto o efeito mediador se mostrou insignificante. Ou seja, as práticas de gestão da qualidade apresentam um efeito mediador nessa relação, e não moderador.

A Figura 6 apresenta de forma esquemática os modelos testados por Naor et al. (2008).

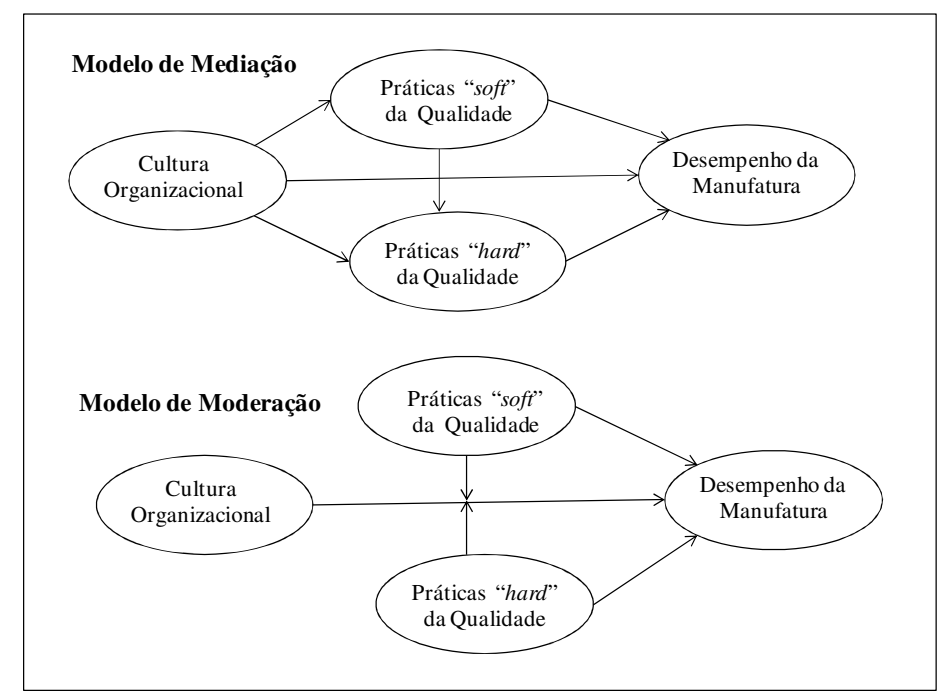

Figura 6. Modelo de mediação e moderação (Naor et al., 2008)

Além disso, testando o modelo de mediação, os autores ainda identificaram que a cultura organizacional tem uma influência mais forte nas práticas soft do que hard da gestão da qualidade. Esses resultados contribuem para enfatizar a importância de considerar a cultura quando se decide adotar iniciativas de gestão da qualidade para melhoria do desempenho na empresa.

Já os estudos de Rahman e Bullock (2005), demonstraram relação positiva entre os elementos técnicos (hard) e sociais (soft) da qualidade. Os autores concluíram que, adicionalmente a esse efeito direto, os elementos sociais também afetam indiretamente o desempenho através do seu efeito nos elementos técnicos, destacando que os elementos 
sociais da gestão da qualidade estão significativamente relacionados a medidas de desempenho organizacional. Isso fornece evidência para sugerir que as organizações precisam ter elementos sociais apropriados para criar condições que permitam difusão e utilização efetiva de elementos técnicos.

Prajogo e McDermott (2011) usando o Competing Values Framework (CVF) examinaram o relacionamento entre os perfis de cultura organizacional (grupo, desenvolvimentista, hierárquica e racional) e desempenho (qualidade e inovação do produto, qualidade e inovação do processo). Dentre os tipos culturais estudados, a desenvolvimentista mostrou maior relação com o desempenho quando comparado aos demais tipos culturais, predizendo mais fortemente os indicadores relacionados à qualidade e inovação dos produtos, e inovação dos processos que os demais perfis culturais. Segundo os autores, isso por que esse tipo de cultura reconhece as necessidades dos clientes e possuem a habilidade de serem flexíveis.

A cultura hierárquica, por sua vez, prediz somente a qualidade do processo, enquanto a cultura de grupo prediz qualidade e inovação do processo, e a cultura racional está relacionada à qualidade do produto e processo.

Para Prajogo e McDermott (2011), o efeito positivo da cultura racional e desenvolvimentista na qualidade do produto reflete a importância de uma compreensão balanceada da qualidade tanto como desempenho como conformidade. Em relação à cultura de grupo, destacam que ela está associada com qualidade e inovação do processo, sugerindo a importância de uma cultura orientada à flexibilidade, enquanto a cultura hierárquica tem uma associação positiva com qualidade do processo.

Dessa forma, os autores concluem que é importante para as empresas compreenderem essas relações no desempenho já que elas poderiam permitir ou limitar a habilidade das organizações em alcançar seus objetivos estratégicos. Por exemplo, se uma organização luta em alcançar liderança através da inovação e qualidade de produtos, os gerentes se beneficiariam se tivessem a compreensão sobre quais elementos culturais estão mais relacionados ao sucesso desses objetivos.

Baird, Hu e Reeve (2011) investigaram o relacionamento entre o que eles chamaram de dimensões da cultura organizacional (orientação aos resultados, atenção aos detalhes, trabalho em equipe/respeito pelas pessoas, e inovação) e quatro práticas de gestão da qualidade (dados da qualidade e relatório, gestão da qualidade do fornecedor, gestão dos processos, e desenvolvimento de produtos/serviços) e o efeito dessas práticas no desempenho operacional (qualidade e desempenho da gestão de estoques). Os 
resultados sugerem que trabalho em equipe/respeito pelas pessoas, orientação para os resultados e inovação contribuem para aumentar o uso de práticas da qualidade. Considerando que essas dimensões são características, respectivamente, das culturas de grupo, racional e desenvolvimentista, essas conclusões confirmam resultados de estudos anteriores.

Já Gimenez-Espin, Jiménez-Jiménez e Martinez-Costa (2013) em seus estudos, concluíram que a cultura de grupo não tem efeito significante nas práticas de gestão da qualidade (liderança, informação da qualidade, controle do processo, melhoria contínua, treinamento em técnicas da qualidade, trabalho em equipe, relacionamento com o fornecedor, e orientação ao consumidor), e que os efeitos da cultura racional e hierárquica na gestão da qualidade são negativos. Resultados que contrastam com resultados de estudos anteriores. Esses resultados contraditórios serão discutidos em maiores detalhes na Seção 2.6.

Além dos quatro perfis culturais definidos pelo CVF, esses autores propuseram um quinto perfil, ao qual deram o nome de "cultura para a qualidade", que se trata de um perfil cultural entre a cultura desenvolvimentista e de grupo, com uma orientação interna e, ao mesmo tempo, externa. Seus resultados sugerem que essa cultura é mais apropriada para as iniciativas de gestão da qualidade. Adicionalmente, os autores mostram um efeito positivo da gestão da qualidade no desempenho dos negócios, sem, entretanto, indicar como o desempenho foi operacionalizado em seus estudos.

\subsection{Contradições na literatura}

Conforme sugerido por Mehra, Hoffman e Sirias (2001), a gestão da qualidade tem mudado de significado ao longo do tempo. Ainda que Sousa e Voss (2002) afirmem que exista um acordo substancial sobre o conjunto de construtos classificados sob a definição de gestão da qualidade e que esta tenha sólidas fundamentações teóricas, ambos afirmam que os pesquisadores devem se esforçar ao máximo para uma padronização da definição dos termos e argumentam que os estudos precisam explicitar em qual nível (princípios, práticas ou técnicas) a gestão da qualidade é abordada, de forma a evitar resultados conflitantes advindos de um nível de análise não bem delimitado e definido. 
Existem na literatura publicações associando: cultura e desempenho, gestão da qualidade e desempenho, cultura e gestão da qualidade, cultura e gestão da qualidade e desempenho. Em cada um dessas categorias existem estudos que confirmam os resultados entre si, mas, também, estudos que apresentam resultados diferentes ou contraditórios.

Uma das causas dessas diferenças e até mesmo contradições pode estar associada a diferenças na definição dos conceitos e nível de abordagem da gestão da qualidade (conforme sugerem Sousa e Voss (2001)), na operacionalização, medição dos construtos, além de diferenças nas abordagens analíticas dos resultados.

Os trabalhos de Prajogo e McDermott (2005) e Giménez-Espin, JiménezJiménez e Martínez-Costa (2013) servem para ilustrar esse problema. Enquanto Prajogo e McDermott (2005) concluem que a cultura de grupo é a mais dominante entre os perfis culturais considerados em seus estudos, Giménez-Espin, Jiménez-Jiménez e Martínez-Costa (2013) sugerem que essa cultura não tem efeito significante nas práticas de gestão da qualidade. Enquanto os dois estudos operacionalizam cultura utilizando o Competing Values Framework (CVF), Prajogo e McDermott (2005) se apoia no modelo de Denison e Spreitzer (1991) e mede as variáveis de cultura organizacional utilizando uma escala de Likert de cinco pontos. Já Giménez-Espin, Jiménez-Jiménez e MartínezCosta (2013) baseiam suas medições no instrumento de Cameron e Quinn (2006), onde o perfil cultural é definido pela distribuição de 100 (cem) pontos entre os quatro perfis culturais definidos no CVF.

Além disso, Prajogo e McDermott (2005) operacionalizam gestão da qualidade em seis construtos, enquanto Giménez-Espin, Jiménez-Jiménez e Martínez-Costa (2013) utilizam oito construtos. Alguns desses construtos sendo similares e outros claramente diferentes. Os dois estudos utilizam escala de Likert de cinco pontos para medir gestão da qualidade. Por fim, Prajogo e McDermott (2005) usam a modelagem de equações estruturais para análise de seus dados, enquanto Giménez-Espin, JiménezJiménez e Martínez-Costa (2013), regressão hierárquica linear.

Ainda, a maioria das publicações foca nas práticas de gestão da qualidade (BAIRD; HU; REEVE, 2011, KAYNAK, 2003, ZU; ROBBINS; FREDENDALL, 2010). Apenas poucos artigos consideram somente as técnicas da qualidade (HANDFIELD; JAYARAM; GOSH, 1999). Entre esses dois tipos de estudos, estão aqueles que operacionalizam gestão da qualidade usando práticas e técnicas, que têm sido referidos como soft e hard (RAHMAN; BULLOCK, 2005) ou "infrastructure" e "core" (NAOR 
et al., 2008) práticas. Nessa categoria, alguns autores analisam práticas e técnicas da qualidade separadamente. Naor et al. (2008), por exemplo, concluem que as práticas de infraestrutura (sociais) afetam o desempenho, enquanto práticas "core" (técnicos) não apresentam um efeito significativo no desempenho.

Outros autores estudam a interação entre práticas e técnicas. Alguns desses estudos, como os de Powell (1995), Dow, Samson e Ford (1999), Samson e Terziovski, (1999) sugerem que elementos soft da qualidade podem melhorar o desempenho sem a presença dos elementos hard. Outros estudos como os de Dean e Bowen, (1994), Flynn, Schroeder e Sakakibara (1994) sugerem que a interação entre os elementos soft e hard da qualidade são essenciais para melhoria do desempenho. Ainda, outros autores não fazem uma clara distinção entre práticas e técnicas. Singh, Bhardwaj e Sachdeva (2009), por exemplo, incluem práticas e técnicas entre seus construtos de gestão da qualidade não fazendo uma distinção entre eles em suas análises.

De forma a reduzir esses problemas referentes às contradições na literatura, esse estudo deixa claro que a abordagem para a gestão da qualidade é considerada no nível de técnicas da qualidade. Além disso, a maioria das variáveis utilizadas para medição dos construtos, neste estudo, foi previamente utilizada em instrumentos validados em estudos anteriores. Em seguida, o Capítulo 3 apresenta as hipóteses e o método de pesquisa utilizado para investiga-las. 


\section{Hipóteses e método de pesquisa}

\subsection{Hipóteses}

As discussões anteriores mostram que, embora existam algumas contradições, a literatura apresenta evidências empíricas de que a cultura organizacional influencia na gestão da qualidade e no desempenho da organização. Porém, conforme descrito anteriormente, esses estudos foram realizados considerando a gestão da qualidade no nível de práticas (ou seja, relacionados principalmente a elementos sociais da qualidade) surgindo um questionamento referente a essa influência também no nível das técnicas da qualidade (mais relacionado aos aspectos técnicos).

Hackman e Wageman (1995) afirmam que as técnicas da qualidade são facilitadoras do processo de aprendizado e que os elementos sociais da qualidade somente poderiam ter um efeito positivo no desempenho se os elementos técnicos estivessem presentes. Em contrapartida, alguns estudos contestam essa necessidade da presença dos elementos técnicos para que os elementos sociais tivessem um efeito positivo no desempenho (BAIRD; HU; REEVE, 2011; SAMSON; TERZIOVSKI, 1999).

Por sua vez, Sousa e Voss (2002) afirmam que não existem conclusões definitivas de que somente os elementos sociais da qualidade contribuem para um efeito positivo no desempenho. Além disso, os estudos de Handfiel, Jayaram e Gosh (1999) fornecem suporte empírico de que as técnicas da qualidade contribuem significativamente para melhoria do desempenho.

Dessa forma, considerando que as técnicas da qualidade, assim como as práticas, também são influenciadas pela cultura organizacional e que esse relacionamento exerce influência no desempenho da empresa, duas hipóteses são testadas nesse estudo:

H1: A cultura de uma organização influencia o conjunto de técnicas da qualidade que ela adota.

H2: A combinação entre o conjunto de técnicas da qualidade adotada por uma organização e sua cultura organizacional afeta o desempenho. 


\subsection{Abordagem de pesquisa}

De forma a atingir os objetivos propostos nesta pesquisa, foi realizada uma pesquisa survey, utilizando-se de uma abordagem quantitativa confirmatória. Para isso, modelos teóricos foram desenvolvidos para testar as hipóteses formuladas.

\subsection{Operacionalização dos construtos e elaboração do questionário}

\subsubsection{Cultura organizacional}

Esse estudo adota o Competing Values Framework (CVF) (Quinn e Rohrbaugh, 1981, 1983) para identificar diferentes perfis de cultura organizacional. Como descrito previamente, o CVF é baseado em duas dimensões principais: uma que reflete a competição entre mudança e estabilidade e outra onde a competição é criada pela diferença de foco no ambiente interno ou externo da organização. Essas duas dimensões formam quatro perfis culturais: cultura de grupo, desenvolvimentista, hierárquica, e racional. O Quadro 3 apresenta características desses perfis culturais.

\begin{tabular}{|c|c|c|c|c|}
\hline \multirow[b]{2}{*}{ Características } & \multicolumn{4}{|c|}{ Perfis de Cultura Organizacional } \\
\hline & Grupo & $\begin{array}{l}\text { Desenvolvi- } \\
\text { mentista }\end{array}$ & Hierárquica & Racional \\
\hline Orientação & $\begin{array}{l}\text { Flexibilidade e } \\
\text { foco no ambiente } \\
\text { interno da } \\
\text { organização. } \\
\text { Preocupação com } \\
\text { as relações } \\
\text { humanas }\end{array}$ & $\begin{array}{l}\text { Crescimento, } \\
\text { criatividade e } \\
\text { adaptação ao } \\
\text { ambiente } \\
\text { externo }\end{array}$ & $\begin{array}{l}\text { Eficiência } \\
\text { interna, } \\
\text { uniformidade, } \\
\text { coordenação e } \\
\text { avaliação }\end{array}$ & $\begin{array}{l}\text { Produtividade, } \\
\text { desempenho e } \\
\text { cumprimento das } \\
\text { metas }\end{array}$ \\
\hline Valores centrais & $\begin{array}{l}\text { Envolvimento, } \\
\text { confiança e } \\
\text { participação }\end{array}$ & $\begin{array}{l}\text { Criatividade e } \\
\text { variedade }\end{array}$ & $\begin{array}{l}\text { Segurança, } \\
\text { ordem, regras e } \\
\text { regulação }\end{array}$ & $\begin{array}{l}\text { Competição e } \\
\text { sucesso no } \\
\text { cumprimento das } \\
\text { metas }\end{array}$ \\
\hline Liderança & Participativa & $\begin{array}{l}\text { Pronta para } \\
\text { assumir riscos e } \\
\text { apta para } \\
\text { desenvolver uma } \\
\text { visão de futuro }\end{array}$ & $\begin{array}{l}\text { Conservadora e } \\
\text { precavida, } \\
\text { atenta a aspectos } \\
\text { técnicos }\end{array}$ & $\begin{array}{l}\text { Direta e } \\
\text { orientada às } \\
\text { metas }\end{array}$ \\
\hline
\end{tabular}




\begin{tabular}{|l|l|l|l|l|}
\hline \multirow{2}{*}{ Características } & \multicolumn{3}{|c|}{ Perfis de Cultura Organizacional } \\
\cline { 2 - 5 } & Grupo & $\begin{array}{l}\text { Desenvolvi- } \\
\text { mentista }\end{array}$ & Hierárquica & Racional \\
\hline $\begin{array}{l}\text { Critério de } \\
\text { efetividade }\end{array}$ & $\begin{array}{l}\text { Desenvolvimento } \\
\text { do potencial } \\
\text { humano e } \\
\text { comprometimento }\end{array}$ & $\begin{array}{l}\text { Crescimento, } \\
\text { desenvolvimento } \\
\text { de novos } \\
\text { mercados e } \\
\text { aquisição de } \\
\text { recursos }\end{array}$ & $\begin{array}{l}\text { Controle, } \\
\text { eficiência e } \\
\text { estabilidade }\end{array}$ & $\begin{array}{l}\text { Planejamento, } \\
\text { produtividade e } \\
\text { eficiência }\end{array}$ \\
\hline
\end{tabular}

Quadro 3. Perfis de cultura organizacional e principais características (Adaptado de Cameron e Quinn, 2006, Denison e Spreitzer, 1991)

Esse modelo é bastante consolidado na literatura, tendo sido usado em diversos estudos de gestão da qualidade. Por exemplo, nos estudos de Naor et al., (2008), Prajogo e McDermott (2011); Wu, Zhang e Schroeder (2011); Zu, Robbins e Fredendall (2010). O Apêndice B apresenta um levantamento de variáveis já utilizadas em questionários para medição da cultura organizacional.

Baseando-se nesse levantamento, um total de vinte itens foi utilizado para operacionalização desse construto, sendo cinco itens referentes a cada um dos quatro perfis culturais. Todos os itens foram medidos utilizando-se de uma escala Likert de cinco pontos (conforme estudos de Prajogo e McDermott, 2011), variando de $1=$ "Discordo totalmente" até 5 = "Concordo totalmente".

A cultura organizacional foi considerada, nesse estudo, como uma variável independente, apoiando-se na premissa temporal de que uma organização tem suas características culturais antes que qualquer iniciativa da qualidade fosse implementada.

\subsubsection{Técnicas de gestão da qualidade}

Os elementos técnicos (hard) da qualidade proporcionam um ambiente de institucionalização das práticas e princípios da gestão da qualidade. Por exemplo, a realização de eventos kaizen para solução de um problema específico envolvem os funcionários e os motivam a pensarem em melhorias, fornecendo um ambiente propício para aplicação de outras técnicas resultando em um ciclo contínuo de melhorias.

Além disso, o uso de técnicas da qualidade como Controle Estatístico do Processo (CEP), Quality Function Deployment (QFD), uso de ferramentas da qualidade contribuem para reduzir a variabilidade no processo produtivo, permite respostas rápidas se algum problema surge, possibilita a redução de erros de projetos de novos 
produtos contribuindo para melhoria do desempenho organizacional. Ahire e Dreyfus (2000), por exemplo, concluíram em seus estudos que o QFD tem um impacto direto no desempenho do projeto do produto e nos esforços da gestão da qualidade nos processos, como redução no número de defeitos, refugos e retrabalho.

Handfield, Jayaram e Gosh (1999) concluíram que o emprego de técnicas da qualidade é uma iniciativa estratégica que pode contribuir para melhoria do desempenho da manufatura e dos negócios. Embora na literatura sejam enumeradas centenas de técnicas da qualidade, um grande número delas não é utilizado na prática (HANDFIELD; JAYARAM; GOSH, 1999). De forma a delimitar as técnicas da qualidade a serem investigadas nesse estudo, foram consideradas algumas técnicas da qualidade comumente utilizadas na prática e citadas na literatura, a saber:

Ferramentas da Qualidade: são técnicas que dão suporte ao processo de melhoria na organização, incluem ferramentas de identificação e priorização de problemas, análise de causa-raiz, priorização de problemas (por ex. Ishikawa, matriz GUT, 5 por quês), e ferramentas de melhoria contínua (por ex. ciclo PDCA e DMAIC) (ISHIKAWA, 1985; McQUATER et al., 1995).

Uso de técnicas estatísticas: segundo Modarres e Ansari (1989), as técnicas estatísticas podem variar das mais simples como aquelas técnicas estatísticas das ferramentas da qualidade (por ex.: pareto, diagrama de dispersão) e controle estatístico do processo (CEP), que envolvem técnicas que analisam as alterações no processo produtivo, de modo a determinar sua natureza e a frequência com que ocorre, até técnicas mais complexas como o delineamento de experimentos (DOE), análise de variância (ANOVA), entre outras.

Benchmarking: é uma técnica da qualidade usada para identificar e estimular a adoção de melhores práticas, sendo uma importante ferramenta para a gestão (UNGAN, 2004). Underdown e Talluri, (2002), afirmam ainda que o benchmarking é uma técnica adequada para as empresas lidarem com desafios e pressões de seus ambientes internos e externos.

FMEA (Failure Mode and Effect Analysis): é uma técnica da qualidade usada para identificação de possíveis falhas antes que elas ocorram, inclui identificar as causas e 
efeitos dessas falhas com o objetivo de mitigá-las ou eliminá-las (CASSANELLI et al., 2006).

QFD (Quality Function Deployment): é uma técnica que se relaciona ao processo de desenvolvimento do produto e processo e dedica-se a traduzir os requisitos dos clientes em atividades de desenvolvimento de produtos e serviços que auxilia a organização a responder rapidamente às suas necessidades e desejos (AKAO, 1990). Os benefícios do uso dessa técnica se relacionam a melhorias no projeto e em seu gerenciamento, além da redução no número de reclamações e aumento da satisfação dos clientes (CARNEVALLI; MIGUEL, 2008).

Manutenção preventiva: é uma técnica fundamental da prática da Manutenção Produtiva Total (TPM) e consiste em atividades realizadas após um período de tempo específico ou período de uso de um equipamento, baseado na probabilidade estimada de parada por quebra ou mau funcionamento, mas realizadas anteriormente a sua ocorrência (WU; ZUO, 2010). É uma técnica relacionada à eficiência operacional, produtividade e segurança, contribuindo para melhoria do desempenho da organização (AHUJA; KHAMBA, 2008; SUN; YAM; WAI-KEUNG, 2003).

Brainstorming: é uma técnica utilizada por um grupo de pessoas com o objetivo de gerar ideias sobre assuntos diversos como a causa potencial de um problema, possíveis soluções, melhorias nos processos, dentre outros. Hackman e Wageman (1995) afirmam que seu objetivo é "explorar a criatividade dos membros do grupo excluindo avaliações dos outros membros e, dessa forma, encorajando de forma ativa o desenvolvimento de outras ideias".

5S: é uma técnica que foca na implementação de uma ordem visual, organização, limpeza e padronização que criam um processo contínuo para a melhoria do ambiente de trabalho (WOMACK et al., 1990). Segundo Liker (2005), o 5S cria um processo contínuo de melhoria do ambiente de trabalho ao contribuir para sua organização e racionalização. Além disso, permite um maior controle visual das atividades executadas possibilitando a identificação mais rápida de problemas que possam interferir no fluxo contínuo de produção da empresa. 
Evento kaizen: envolve uma iniciativa sistemática de melhoria contínua por um grupo multidisciplinar que trabalha para alcançar metas específicas num intervalo de tempo reduzido. Segundo Develin (1995) e Bodek (2002), o kaizen serve para estimular os funcionários na solução de problemas e aumentar a motivação deles na participação de ações de melhorias futuras contribuindo para um aumento significativo na eficiência do sistema.

Informações visuais da qualidade: se relaciona ao uso de informações visuais de indicadores da qualidade. É uma técnica de controle visual que fornece informações relevantes e atualizadas da qualidade, possibilitando que se entenda rapidamente a situação atual, fornecendo informações que auxiliam na tomada de decisão. Liker (2005) afirma que o controle visual está ligado à criação de informações instantâneas de forma a contribuir para a execução rápida e adequada de operações e processos.

Dispositivos à prova de erros: se referem ao uso de dispositivos que reduzem ou evitam a possibilidade da ocorrência de erros, seu objetivo é eliminar defeitos pela prevenção, correção ou identificação de erros humanos à medida que eles ocorrem (STEWART; GROUT, 2001; TSOU; CHEN, 2005).

Indicadores de desempenho da qualidade: se relaciona ao uso de indicadores que tem a finalidade de quantificar a eficiência e efetividade de ações que direcionam a melhoria do desempenho (NEELY; GREGORY; PLATTS, 2005). O uso dos indicadores de desempenho da qualidade contribui para maior clareza das metas de qualidade e transparências das decisões, possibilitando maior velocidade de reação, sendo importante ferramenta no processo de gestão.

Baseando-se nas características dessas técnicas, elas foram categorizadas em quatro grupos de técnicas que são utilizadas nesse estudo. Esses grupos foram definidos de forma a possibilitarem a inclusão de outras técnicas da qualidade, não citadas anteriormente. O Quadro 4 apresenta a definição desses grupos, suas características e exemplos de técnicas da qualidade. 


\begin{tabular}{|c|c|c|}
\hline $\begin{array}{l}\text { Grupos de técnicas } \\
\text { da qualidade }\end{array}$ & Características & Exemplos \\
\hline $\begin{array}{l}\text { Estabelecimento de } \\
\text { Metas (EM) }\end{array}$ & $\begin{array}{l}\text { Técnicas que enfatizam o desenvolvimento de } \\
\text { produtos e processos baseados nas melhores } \\
\text { práticas e nas necessidades e desejos dos } \\
\text { consumidores. Essas técnicas são úteis para } \\
\text { auxiliar a organização no estabelecimento de } \\
\text { metas que direcionam a melhores resultados. }\end{array}$ & QFD, benchmarking \\
\hline $\begin{array}{l}\text { Melhoria Contínua } \\
\text { (MC) }\end{array}$ & $\begin{array}{l}\text { Técnicas que são orientadas para as pessoas e } \\
\text { auxiliam os funcionários a usarem seus } \\
\text { conhecimentos de forma efetiva dando suporte à } \\
\text { melhoria contínua. Essas técnicas enfatizam } \\
\text { abertura e paricipação, contribuindo para o } \\
\text { envolvimento das pessoas. }\end{array}$ & $\begin{array}{l}\text { Brainstorming, } \\
\text { evento kaizen, } \\
\text { ferramentas da } \\
\text { qualidade, } 5 \mathrm{~S}\end{array}$ \\
\hline Medição (MD) & $\begin{array}{l}\text { Técnicas que estão relacionadas à medição de } \\
\text { indices da qualidade e fornecem informações } \\
\text { sobre a qualidade das atividades de manufatura. } \\
\text { Essas técnicas auxiliam a organização na tomada } \\
\text { de ações rápidas baseando-se em dados, além de } \\
\text { promover o alinhamento para o alcance de metas } \\
\text { da qualidade. }\end{array}$ & $\begin{array}{l}\text { Uso de indicadores } \\
\text { de desempenho da } \\
\text { qualidade, } \\
\text { informações visuais } \\
\text { da qualidade. }\end{array}$ \\
\hline $\begin{array}{l}\text { Prevenção de Falhas } \\
\text { e Controle (PFC) }\end{array}$ & $\begin{array}{l}\text { Técnicas que tem como objetivo 1) identificar e } \\
\text { gerar informações úteis sobre possíveis causas } \\
\text { de variações na qualidade da produção, e } 2 \text { ) } \\
\text { prevenir a ocorrência de defeitos no processo de } \\
\text { manufatura. Essas técnicas contribuem para um } \\
\text { fluxo produtivo estável e controlado. }\end{array}$ & $\begin{array}{l}\text { Técnicas estatíticas, } \\
\text { FMEA, dispositivos } \\
\text { a prova de erros, } \\
\text { manutenção } \\
\text { preventiva }\end{array}$ \\
\hline
\end{tabular}

Quadro 4. Grupos de técnicas da qualidade, características e exemplos

Os grupos de técnicas da qualidade descritos anteriormente representam os construtos de gestão da qualidade considerados nesse estudo. O Apêndice C apresenta um levantamento de variáveis utilizadas em questionários disponíveis na literatura para medição de elementos da gestão da qualidade. A partir desse levantamento, definiu-se os itens utilizados para operacionalizar os grupos de qualidade. O conjunto de itens usados para medição dos grupos de técnicas da qualidade analisados nessa pesquisa foram baseados, principalmente, nos instrumentos de Ahire, Golhar e Waller (1996), Flynn, Schroeder e Sakakibara (1994), Naor et al., (2008) e Zu, Robbins e Fredendall (2010). Itens foram acrescentados baseando-se na revisão da literatura tendo como base as características das técnicas que constituem cada grupo. Por fim, um conjunto de trinta 
e seis itens foi definido e medido numa escala Likert de cinco pontos, variando de $1=$ "Discordo totalmente" até 5 = "Concordo totalmente".

\subsubsection{Desempenho operacional}

A operacionalização do desempenho pode ocorrer em diferentes níveis. Kaynak (2003), por exemplo, identificou e validou medidas de desempenho para a gestão da qualidade, referentes ao desempenho financeiro (por ex. retorno sobre investimento, crescimento das vendas e dos lucros), desempenho da qualidade (por ex. custo de refugo e de retrabalho, leadtime) e desempenho da gestão do estoque (por ex. giro do material comprado e do material total).

Observando as dimensões de desempenho investigadas por Kaynak (2003) é possível perceber que tanto o desempenho da qualidade, quanto a gestão de estoque referem-se a um nível de desempenho de manufatura ou operacional, enquanto a dimensão de desempenho financeiro e de mercado refere-se a um nível global, de desempenho dos negócios, envolvendo indicadores de crescimento das vendas, market share, etc. Outros autores que consideraram, em seus estudos sobre qualidade, esses dois níveis de desempenho (operacional e global) foram Handfiel, Jayaram e Gosh (1999), concluindo que as técnicas da qualidade afetam ambos os níveis. Os estudos de Forker, Vickery e Drooge (1996) demonstraram que dimensões da qualidade referentes à conformidade com as especificações, qualidade de projeto e melhoria do produto estão significativamente relacionadas ao crescimento do retorno sobre investimento e ao crescimento das vendas. Esses resultados mostram que o desempenho operacional está relacionado ao desempenho dos negócios.

Baird, Hu e Reeve (2011) e Naor et al., (2008) avaliaram o desempenho no nível operacional, considerando em seus estudos indicadores de desempenho em custo, qualidade, entrega, e flexibilidade. Já Samson e Terziovski (1999) em seus estudos sobre gestão da qualidade e desempenho, utilizaram indicadores de satisfação dos consumidores, moral dos funcionários, produtividade, qualidade das saídas (outputs) e desempenho de entrega, para medir desempenho em nível operacional.

Neste estudo são considerados indicadores de desempenho no nível operacional, por considerarmos que eles seriam afetados diretamente pelas técnicas de gestão da qualidade, além da importância que o desempenho nesse nível exerce no desempenho 
global da empresa. O Apêndice D apresenta as variáveis identificadas na revisão da literatura para medição do desempenho.

Os questionários utilizados por Baird, Hu e Reeve (2011), Kaynak (2003), Naor et al., (2008), Prajogo e McDermott (2011) e Samson e Terziovski (1999) foram úteis na operacionalização das medidas de desempenho utilizadas nesse estudo. Em adição, outros itens foram acrescentados, baseando-se na revisão da literatura. Segundo Kaynak (2003), a maior dificuldade em se investigar desempenho está na dificuldade de se obter dados objetivos. Dessa forma, de acordo com os estudos descritos anteriormente, o desempenho foi medido nesse estudo de forma qualitativa.

Assim o desempenho foi operacionalizado em onze itens utilizados para medir desempenho da manufatura (custo, tempo e qualidade), desempenho em relação aos consumidores (satisfação) e recursos humanos (turnover, absenteísmo) e em relação aos concorrentes (produto, desenvolvimento de produto e mudanças tecnológicas/processo). Os itens foram medidos utilizando-se de escala Likert de cinco pontos, os pontos extremos da escala variaram de acordo com o indicador medido. Essa escala também incluiu um sexto ponto na escala, nomeado "não tenho certeza". A inclusão desse item na escala teve como objetivo reduzir o viés no caso do respondente, de fato, não ter certeza da resposta e escolher qualquer uma das demais respostas disponíveis.

\subsection{Modelo teórico}

Para investigar as hipóteses propostas, dois modelos foram elaborados. O modelo apresentado na Figura 7 mostra as relações estudadas entre os quatro perfis culturais e os grupos de técnicas da qualidade, sendo utilizado para testar a H1.

H1: A cultura de uma organização influencia o conjunto de técnicas da qualidade que ela adota. 


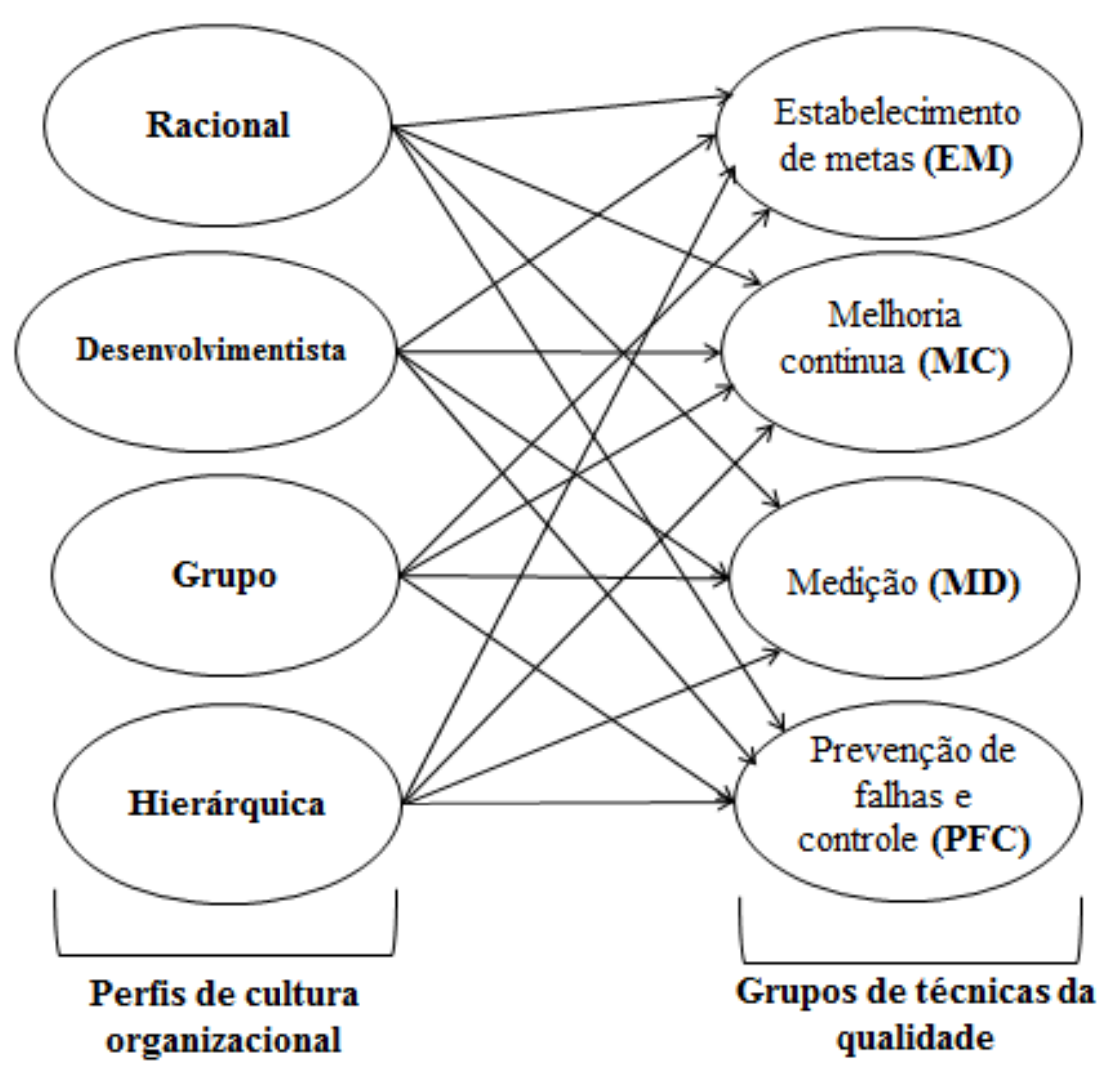

Figura 7. Modelo geral do relacionamento entre perfis culturais e grupos de técnicas da qualidade

O modelo da Figura 8 ilustra as relações entre os perfis de cultura organizacional, grupos de técnicas da qualidade, e desempenho que foram testadas nesse estudo. Esse modelo examina o efeito direto da cultura organizacional (seta (a)) e das técnicas da qualidade (seta (c)) no desempenho, e o efeito indireto da cultura organizacional no desempenho por meio do uso de técnicas da qualidade (seta (b) e seta (c)) e foi elaborado para teste da $\mathrm{H} 2$.

H2: A combinação entre o conjunto de técnicas da qualidade adotada por uma organização e sua cultura organizacional afeta o desempenho. 


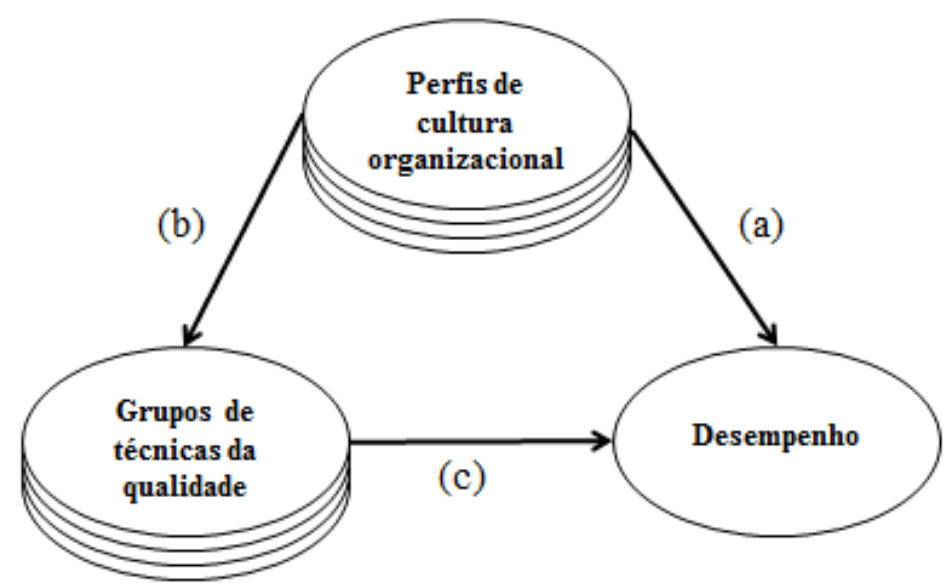

Figura 8. Modelo geral do relacionamento entre perfis de cultura organizacional, grupos de técnicas da qualidade e desempenho

\subsection{Validação do questionário}

Para validação do questionário, foi realizado um teste piloto. O questionário disponível no Apêndice E foi enviado, via eletrônica (Google docs), para 23 respondentes de 11 diferentes empresas de manufatura (incluindo empresas do setor farmacêutico, de bens de consumo, da linha branca e de produção de couros). O prérequisito para a escolha dos respondentes foi que eles ocupassem cargos de liderança e/ou que estivessem envolvidos com as áreas de qualidade e/ou manufatura. Esse prérequisito foi definido por considerarmos que, dessa forma, os respondentes teriam familiaridade com os tópicos abordados e maior facilidade para responder $\mathrm{o}$ questionário. No questionário foram incluídas também questões visando melhoria do instrumento (item "Informações sobre o questionário", Apêndice E).

Dos 23 questionários enviados, 12 retornaram respondidos. Uma vez que a amostra utilizada no teste piloto foi pequena, a análise estatística foi limitada à análise de confiabilidade do instrumento de medida, além de uma análise prévia de correlação bivariada entre os construtos.

A análise do instrumento de medida fornece segurança de que os resultados refletem uma medida acurada do que está sendo observado. Conforme sugerido por Forza (2008), essa análise é particularmente importante quando se trata da medição de variáveis latentes. Para o teste de confiabilidade das variáveis medidas foi usado o teste do alfa $(\alpha)$ de Cronbach (CRONBACH, 1951), utilizando-se o software IBM ${ }^{\circledR}$ PASW Statistics versão 17. 
O coeficiente de confiabilidade $\alpha$ de Cronbach avalia a consistência da escala inteira usada num instrumento de medida. Ele mede a correlação entre as respostas dadas pelos respondentes, apresentando a média das correlações entre os itens que compõem o instrumento de medida. É calculado a partir da variância dos itens individuais e da variância da soma dos itens do instrumento, apresentando valores que variam de 0,00 a 1,00. (HAIR et al., 2009; STREINER, 2003). A medição deste coeficiente é importante, pois este avalia o grau em que um conjunto de variáveis é consistente com o que se pretende medir. Se múltiplas medidas forem realizadas, as medidas confiáveis serão consistentes em seus valores (HAIR et al., 2009).

Segundo Forza (2008), esse teste é o mais usado como indicador de confiabilidade em pesquisas survey na área de gestão de operações e cita que para o desenvolvimento de medidas pode ser aceito um valor maior ou igual a 0,6. Em outras situações o valor de 0,7 é considerado o limiar, e com um valor de alfa maior ou igual a 0,8 , a medida é bastante confiável.

Todas as dimensões analisadas apresentaram confiabilidade satisfatória de seus itens. Mesmo que no caso da cultura hierárquica e cultura racional, o valor de alpha tenha sido inferior a 0,70 (0,66 e 0,63 , respectivamente), a eliminação de questões específicas aumentaria esses valores acima do valor limiar 0,70 . Porém, por se tratar de uma amostra muito pequena, optou-se por manter todas as questões utilizadas para medição dessas dimensões.

Considerando as questões utilizadas para a medição da cultura organizacional e técnicas de gestão da qualidade, apenas pequenas alterações de escrita dos itens foram realizadas. Embora as questões utilizadas para medição de desempenho terem apresentado uma confiabilidade satisfatória (alfa de 0,74), elas sofreram alterações mais consideráveis, dois itens foram retirados do questionário, a saber:

- “Em nossa organização, as unidades fabricadas com defeitos, representam:” $e$

- “Os produtos entregues dentro do prazo aos consumidores, representam”.

A retirada desses itens foi justificada pelo fato destes representarem realidades distintas para setores diferentes da indústria.

Em contrapartida, outros cinco itens foram acrescentados:

- "Em minha organização, o turnover dos funcionários está:" 
- “Em minha organização, a taxa de absenteísmo dos funcionários está:

- “Em minha organização, o desempenho dos nossos produtos comparado aos produtos similares fabricados pelos nossos concorrentes é:"

- "Em minha organização, a velocidade do processo de desenvolvimento de novos produtos comparada à velocidade do desenvolvimento pelos nossos concorrentes é:"

- "Em minha organização, a taxa de inovação nos nossos processos e tecnologia comparada a de nossos concorrentes é:"

O objetivo da adição desses indicadores de desempenho foi o de abranger diferentes perspectivas, incluindo, por exemplo, desempenho em relação aos recursos humanos e em relação aos concorrentes. O questionário final contendo todas as variáveis medidas está disponível no Apêndice F.

\subsection{População e amostra}

A população alvo considerada nessa pesquisa é composta por empresas de manufatura (Seção C, divisões 10 a 33, segundo CNAE - Classificação Nacional de Atividade Econômica) no Brasil e Dinamarca. A amostra foi selecionada a partir dessa população de forma aleatória.

No Brasil, foi utilizada a Base de Dados das Empresas Certificadas pela ISO 9000, emitidos no Brasil. Essa base de dados foi desenvolvida por iniciativa do Inmetro e da Associação Brasileira de Normas Técnicas (ABNT), para disponibilizar informações sobre empresas certificadas na ISO9000 por organismos oficiais de certificação. A partir dessa base de dados, outra base foi elaborada contendo informações de empresas de manufatura: nome da empresa, nome do funcionário responsável pela Gestão do Sistema da Qualidade na empresa, seu email e telefone de contato. Ao final foi consolidado um banco de dados contendo 1.643 contatos.

$\mathrm{Na}$ Dinamarca foi utilizada uma base de dados de empresas dinamarquesas disponível na Universidade de Aalborg. O acesso a essa base de dados é limitada a alunos e funcionários da Universidade. A partir dessa base, outro banco de dados foi criado contendo informações (nome da empresa, número de funcionários, website e número de telefone) sobre as empresas de manufatura disponibilizadas no banco de dados da universidade. Ao final foram consolidados 1.104 contatos. 


\subsection{Contato com as empresas}

O contato com as empresas ocorreu de forma distinta no Brasil e na Dinamarca. No Brasil, como a base de dados já fornecia informações suficientes para o procedimento de coleta de dados (nome do funcionário responsável pelo Sistema de Gestão da Qualidade na empresa e seu endereço de email), o contato com as empresas foi estabelecido inicialmente durante a etapa de coleta. Na Dinamarca, foi feito um contato inicial com a empresa para identificar nome e contato do funcionário que seria um potencial respondente da pesquisa (funcionários que ocupassem cargo de gestão relacionado à qualidade ou à produção). Uma vez identificado esse funcionário na empresa, um novo contato foi realizado com o objetivo de conversar diretamente com esse funcionário, explicando sobre a pesquisa e verificando sua intenção em participar. Uma vez que ele concordasse em participar, seu nome e email de contato foram registrados no banco de dados. Esses contatos iniciais com a empresa foram realizados por meio de chamadas telefônicas, o procedimento teve a duração de dois meses. Ao final, foi elaborada uma lista com 423 contatos.

\subsection{Coleta de dados}

A coleta de dados ocorreu por meio do envio de questionário eletrônico via SurveyMonkey®. O processo de coleta de dados levou em torno de dois meses em cada um dos países. Durante esse período, três emails foram enviados aos participantes (baseando-se no método de Dillman, 1978), contendo o link que direcionava ao questionário da pesquisa. Além dessas três ondas de email, outros procedimentos foram adotados de forma a obter uma taxa de resposta satisfatória (DILLMAN, 1991; SCHAEFER; DILLMAN, 1998; FROHLICH, 2002). Dentre esses procedimentos estão, por exemplo: email com breve explicação sobre objetivos e importância da pesquisa, email personalizado aos participantes, apresentação do pesquisador, universidade de origem, adição no questionário da logomarca da universidade e das agências de fomento à pesquisa, envio de um relatório às empresas participantes contendo os resultados ao final da pesquisa.

A coleta de dados no Brasil foi realizada nos meses de novembro e dezembro de 2012 e, na Dinamarca, nos meses de janeiro e fevereiro de 2013. No total foram 
enviados 2.066 emails, dos quais 305 retornaram indicando mensagem de falha na entrega, o que significa que 1.761 emails estavam válidos. Ao final do período de coleta dos dados, 250 questionários retornaram respondidos. Dos questionários respondidos, 132 foram de empresas brasileiras, e 118, de empresas dinamarquesas, representando uma proporção muito semelhante de respondentes nos dois países $(52,8 \%$ e 47,2\%, respectivamente). A taxa de resposta foi de $14,2 \%$.

De forma a estimar o possível viés dos questionários não respondidos foram realizados testes $t$-independentes nas amostras referentes à primeira e terceira ondas de respostas (cf. Kaynak, 2003). O teste $t$ é um teste de inferência usado para avaliar a significância estatística de diferenças entre grupos. Nele, a hipótese nula testada é a igualdade de médias de uma variável ao longo de grupos (Hair et al. 2009). Os testes não indicaram diferenças significativas entre as duas sub-amostras $(p>0,10)$. Adicionalmente, dezessete empresas foram contatadas por email ou por telefone para verificar porque elas escolheram não participar nesse estudo, dentre as principais razões citadas estão falta de tempo ou interesse. Além disso, com o objetivo de identificar possíveis diferenças entre as amostras coletadas no Brasil e na Dinamarca foram realizados teste $t$ - independentes nessas amostras, os resultados também não indicaram diferenças estatísticas significantes entre elas.

\subsubsection{Informações demográficas da amostra}

Os dados incluem 250 empresas de manufatura localizadas na Dinamarca e Brasil, sendo que a maioria dos respondentes (80\%) ocupa o cargo de gerente da produção ou qualidade. A análise dos dados foi feita ao nível da empresa, ou seja, a empresa representa a unidade de análise nessa pesquisa. A amostra é constituída principalmente $(62,7 \%)$ por empresas do setor alimentício, produtos de borracha e de material plástico, metalurgia, produtos de metal e máquinas e equipamentos (CNAE 10, $22,24,25$ e 28, respectivamente), sendo a maioria $(79,6 \%)$ composta por pequenas e médias empresas, conforme descrito na Tabela 1. 
Tabela 1. Informações demográficas da amostra

\begin{tabular}{lcccr}
\hline CNAE $^{(\mathbf{1})}$ - Setor Industrial & Brasil & Dinamarca & Total & \% \\
\hline 10 - Produtos alimentícios & 5 & 16 & 21 & $\mathbf{1 0 , 1}$ \\
16 - Fabricação de produtos de madeira & 3 & 3 & 6 & 2,9 \\
17 - Fabricação de celulose, papel e produtos de papel & 6 & 1 & 7 & 3,4 \\
20 - Produtos químicos & 9 & 1 & 10 & 4,8 \\
21 - Produtos farmacoquímicos e farmacêuticos & 3 & 5 & 8 & 3,9 \\
22 - Produtos de borracha e de material plástico & 16 & 8 & 24 & $\mathbf{1 1 , 6}$ \\
24 - Metalurgia & 24 & 13 & 37 & $\mathbf{1 7 , 9}$ \\
25 - Produtos de metal, exceto máquinas e equipamentos & 14 & 13 & 27 & $\mathbf{1 3 , 0}$ \\
27 - Máquinas, aparelhos e materiais elétricos & 7 & 8 & 15 & 7,2 \\
28 - Máquinas e equipamentos & 8 & 13 & 21 & $\mathbf{1 0 , 1}$ \\
31 - Fabricação de móveis & 0 & 5 & 5 & 2,4 \\
32 - Fabricação de produtos diversos & 8 & 3 & 11 & 5,3 \\
Outros & 6 & 9 & 15 & 7,2 \\
Total & 109 & 98 & 207 & 100 \\
\hline
\end{tabular}

\begin{tabular}{lccccc}
\hline Número de funcionários & Brasil & Dinamarca & Total & \% \\
\hline Até 19 funcionários & 6 & 0 & 6 & 2,4 \\
De 20 a 99 funcionários & 36 & 50 & 86 & $\mathbf{3 5 , 1}$ \\
De 100 a 499 funcionários & 57 & 52 & 109 & $\mathbf{4 4 , 5}$ \\
Igual ou superior a 500 funcionários & 30 & 14 & 44 & 18,0 \\
Total & 129 & 116 & 245 & 100,0 \\
\hline
\end{tabular}

${ }^{(1)}$ Classificação Nacional de Atividade Econômica

O Capítulo 4 apresenta os resultados das análises estatísticas preliminares e das análises multivariadas dos modelos teóricos do relacionamento entre cultura organizacional, técnicas de gestão da qualidade e desempenho. 


\section{Resultados}

\subsection{Análises preliminares}

Essa seção apresenta análises realizadas anteriormente à análise multivariada dos dados. O objetivo dessa etapa foi verificar se os dados obtidos apresentam pressupostos básicos para se seguir uma análise multivariada. Todos os testes estatísticos listados a seguir foram realizados utilizando o software PASW Statistics 17.

\subsubsection{Testes de normalidade, linearidade e homoscedasticidade}

Nessa seção estão descritas algumas análises realizadas nas variáveis individuais para verificação do atendimento das suposições básicas inerentes às análises multivariadas.

Normalidade: se refere à forma da distribuição de dados para uma variável individual e sua correspondência com a distribuição normal. Segundo Hair et al. (2009) a normalidade multivariada significa que as variáveis individuais são normais em um sentindo univariado. Dessa forma, a análise da normalidade foi realizada nesse estudo examinando a curtose e assimetria das variáveis individuais, assumindo o pressuposto de que uma vez verificada a normalidade para as variáveis individuais, considera-se também normalidade multivariada.

Linearidade: verificar a linearidade é importante uma vez que as análises estatísticas posteriores se baseiam em medidas correlacionais de associação. Como as correlações representam apenas a associação linear entre as variáveis, os efeitos não-lineares não serão representados no valor de correlação o que poderia resultar numa subestimação da força real da relação (HAIR et al., 2009, TABACHNICK; FIDELL, 2007). Assim, testes de linearidade foram realizados entre as variáveis dependentes e independentes. Diversas são as formas para se avaliar a linearidade; nesse estudo ela foi verificada por meio do teste de linearidade no teste de variância (ANOVA), disponível no PASW Statistics 17. 
Homoscedasticidade: se relaciona a relações de dependência entre as variáveis, e significa que as variáveis dependentes exibem níveis semelhantes (homogeneidade) ao longo de valores da variável independente. De forma a verificar a homoscedasticidade dos dados foi realizado teste de Levene (HAIR et al., 2009, TABACHNICK; FIDELL, 2007)

Para verificação desses pressupostos também foram realizadas análises gráficas como curva de distribuição normal, histograma e diagrama de dispersão. Nenhuma das análises de normalidade, linearidade e homoscedasticidade apresentaram violações estatísticas significantes desses pressupostos.

\subsubsection{Multicolinearidade}

Multicolinearidade é a extensão em que uma variável pode ser explicada por outras variáveis na análise. À medida que a multicolinearidade aumenta, ela torna difícil a interpretação das relações entre as variáveis (HAIR et al., 2009) Nesse estudo, a multicolinearidade foi avaliada por meio do fator de inflação de variância (VIF Variance Inflation Factor), que é um indicador do efeito que as outras variáveis independentes têm sobre o erro padrão de um coeficiente de regressão (HAIR et al., 2009); valores maiores que 10,0 indicam um alto grau de correlação entre as variáveis independentes o que indica a presença de multicolinearidade (KUTNER; NACHTSHEIN; NETER, 2004). O maior valor de VIF verificado nos dados foi de 9,5, isto é, nenhum dos valores excedeu o limite de 10,0, indicando que estes apresentam um nível de multicolinearidade aceitável.

\subsubsection{Medidas de confiabilidade e correlações bivariadas}

Para avaliação prévia do conjunto de dados foram realizadas medidas de teste de confiabilidade (discutidas em maiores detalhes na Seção 4.1.4) e medidas de correlação bivariada (coeficiente de correlação de Pearson). Segundo Tabachnick e Fidell (2007), o coeficiente de Pearson é o coeficiente de correlação mais utilizado como base para análises multivariadas já que independe da escala de medição e do tamanho da amostra. Este coeficiente mede o grau de correlação entre duas variáveis, apresentando valores que variam de $-1,00$ a 1,00 . Nos quais, valores de 1,00 e $-1,00$ indicam, respectivamente, correlação positiva total e correlação negativa total entre duas 
variáveis. Enquanto valores iguais a zero $(0,00)$ significam que duas variáveis não dependem linearmente uma da outra (HAIR et al., 2009; TABACHNICK; FIDELL, 2007) A Tabela 2 apresenta correlação bivariada entre as variáveis, bem como medidas de confiabilidade.

Tabela 2. Coeficiente de correlação de Pearson e medida da confiabilidade

\begin{tabular}{lcccccccccc}
\hline Variáveis & 1 & 2 & 3 & 4 & 5 & 6 & 7 & 8 & 9 & $\alpha$ de Cronbach \\
\hline 1. CH & 1 & & & & & & & & 0,75 \\
2. CG & $0,58^{* *}$ & 1 & & & & & & & 0,86 \\
3. CR & $0,64^{* *}$ & $0,60^{* *}$ & 1 & & & & & & 0,76 \\
4. CD & $0,49^{* *}$ & $0,70^{* *}$ & $0,63^{* *}$ & 1 & & & & & 0,82 \\
5. EM & $0,62^{* *}$ & $0,74^{* *}$ & $0,65^{* *}$ & $0,70^{* *}$ & 1 & & & & 0,84 \\
6. MC & $0,59^{* *}$ & $0,68^{* *}$ & $0,68^{* *}$ & $0,63^{* *}$ & $0,80^{* *}$ & 1 & & & 0,91 \\
7. MD & $0,57^{* *}$ & $0,43^{* *}$ & $0,61^{* *}$ & $0,42^{* *}$ & $0,64^{* *}$ & $0,73^{* *}$ & 1 & & \\
8. PFC & $0,62^{* *}$ & $0,61^{* *}$ & $0,65^{* *}$ & $0,55^{* *}$ & $0,75^{* *}$ & $0,82^{* *}$ & $0,74^{* *}$ & 1 & & 0,87 \\
9. Desem- & & & & & & & 0,90 \\
penho & $0,27^{* *}$ & $0,36^{* *}$ & $0,34^{* *}$ & $0,38^{* *}$ & $0,40^{* *}$ & $0,40^{* *}$ & $0,33^{* *}$ & $0,35^{* *}$ & 1 & 0,79 \\
\hline
\end{tabular}

$* * p<0,01(\mathrm{~N}=250)$

Nota - CH: Cultura hierárquica, CG: Cultura de grupo, CR: Cultura racional, CD: Cultura desenvolvimentista, EM: Técnicas de estabelecimento de metas; MC: Técnicas de melhoria contínua; MD: Técnicas de medição de desempenho; PFC: Técnicas de prevenção de falha e controle

Segundo Hair et al. (2009), a verificação da correlação entre as variáveis é importante para realização de análises estatísticas subsequentes. Pois, se todas as correlações são pequenas (inferiores a 0,30), ou iguais (mostrando que não existe qualquer estrutura para agrupar variáveis), ou ainda muito elevadas (superiores a 0,80) tornam inapropriadas análises estatísticas subsequentes como por ex. análise fatorial ou mesmo a modelagem de equações estruturais. Apenas uma das medidas de correlação apresentou valor inferior a 0,30 , e, outra, valor superior a 0,80 , o que não compromete análises subsequentes.

\subsubsection{Validade dos construtos}

A validade de um construto é o grau que um conjunto de itens medidos (variáveis observáveis) reflete o construto teórico (variáveis latentes) que estes devem 
medir (TABACHNICK; FIDELL, 2007). Um construto precisa ter validade convergente, discriminante e validade de expressão, existindo diversas maneiras de se avaliar cada um desses componentes (HAIR et al., 2009).

Validade convergente: as variáveis observáveis que representam variáveis de um construto devem compartilhar uma elevada proporção de variância em comum. Nesse estudo, ela foi estimada por meio da confiabilidade, das cargas fatoriais e comunalidade. Para medida de confiabilidade foi utilizado o coeficiente $\alpha$ de Cronbach (vide Tabela 2). Esse coeficiente é uma estimativa frequentemente utilizada, sendo que valores superiores a 0.70 sugerem uma boa confiabilidade (TABACHNICK; FIDELL, 2007). Conforme apresentado na Tabela 2, todos os construtos medidos nesse estudo apresentam um coeficiente $\alpha$ consideravelmente superior a 0,70 , o que indica elevada confiabilidade dos construtos. Isso significa que todas as medidas consistentemente representam o mesmo construto latente.

Cargas fatorias e comunalidade para cada uma das variáveis observáveis utilizadas para medir os construtos de cultura organizacional, técnicas de gestão da qualidade e desempenho, estão representadas nas Tabelas 3, 4 e 5, respectivamente.

A carga fatorial é a correlação entre as variáveis originais e os construtos (dimensões). A significância das cargas fatoriais varia com base no tamanho da amostra. Para amostras de tamanhos iguais ou superiores a 250, uma carga fatorial de 0,35 é considerada significante (HAIR et al., 2009).

Comunalidade é a quantia total de variância que uma variável original compartilha com todas as outras variáveis na análise. Em geral valores de comunalidade superiores a 0,50 são considerados adequados (HAIR et al., 2009). Embora esse estudo tenha uma abordagem confirmatória para teste das hipóteses, nessa etapa foram realizados testes de natureza exploratória (análise fatorial exploratória) para medidas da comunalidade e carga fatorial das variáveis observáveis. $\mathrm{O}$ objetivo foi o de verificar a adequação dos dados para análises subsequentes. Dessa forma foi realizada uma análise fatorial exploratória (EFA - Exploratory Factor Analysis), utilizando o método do Componente Principal com rotação varimax.

A Tabela 3 apresenta a carga fatorial e a comunalidade de cada uma das variáveis observáveis utilizadas para medição da cultura organizacional. 
Tabela 3. Dados das variáveis observáveis utilizadas para medição da cultura organizacional

\begin{tabular}{|c|c|c|}
\hline Cultura Organizacional & $\begin{array}{l}\text { Carga } \\
\text { Fatorial }\end{array}$ & $\begin{array}{l}\text { Comunali- } \\
\text { dade }\end{array}$ \\
\hline \multicolumn{3}{|l|}{ Cultura Hierárquica } \\
\hline $\begin{array}{l}\text { Em minha organização, procedimentos } \\
\text { formalizados geralmente governam o que as } \\
\text { pessoas fazem. }\end{array}$ & 0,54 & 0,71 \\
\hline $\begin{array}{l}\text { Minha organização enfatiza eficiência e } \\
\text { controle para alcançar resultados previsíveis } \\
\text { de desempenho }\end{array}$ & 0,79 & 0,62 \\
\hline $\begin{array}{l}\text { Em minha organização, cumprir prazos, seguir } \\
\text { a programação e produzir a baixos custos é o } \\
\text { foco principal }\end{array}$ & 0,60 & 0,49 \\
\hline $\begin{array}{l}\text { O estilo gerencial em minha organização } \\
\text { prioriza conformidade, previsibilidade e } \\
\text { estabilidade }\end{array}$ & 0,68 & 0,62 \\
\hline \multicolumn{3}{|l|}{ Cultura de Grupo } \\
\hline $\begin{array}{l}\text { Em minha organização, o desenvolvimento de } \\
\text { recursos humanos e a preocupação com as } \\
\text { pessoas são muito valorizados }\end{array}$ & 0,76 & 0,61 \\
\hline $\begin{array}{l}\text { Em minha organização, os funcionários são } \\
\text { encorajados a trabalhar em equipe, } \\
\text { trocar experiências, opiniões e ideias. }\end{array}$ & 0,79 & 0,64 \\
\hline $\begin{array}{l}\text { Em minha organização, os funcionários } \\
\text { podem discutir abertamente sobre suas } \\
\text { opiniões e ideias com seus superiores. }\end{array}$ & 0,62 & 0,46 \\
\hline $\begin{array}{l}\text { Em minha organização, os funcionários são } \\
\text { encorajados a tomarem decisões. }\end{array}$ & 0,71 & 0,66 \\
\hline $\begin{array}{l}\text { O estilo gerencial da minha organização é } \\
\text { caracterizado por trabalho em equipe, } \\
\text { consenso e participação. }\end{array}$ & 0,80 & 0,68 \\
\hline \multicolumn{3}{|l|}{ Cultura Racional } \\
\hline $\begin{array}{l}\text { Minha organização define sucesso com base } \\
\text { no ganho e liderança de mercado. }\end{array}$ & 0,42 & 0,49 \\
\hline $\begin{array}{l}\text { Em minha organização, nosso sistema de } \\
\text { recompensa nos encoraja a alcançar as metas } \\
\text { da empresa. }\end{array}$ & 0,62 & 0,58 \\
\hline $\begin{array}{l}\text { Minha organização é orientada para } \\
\text { resultados; as pessoas são competitivas e } \\
\text { buscam realização profissional. }\end{array}$ & 0,69 & 0,56 \\
\hline $\begin{array}{l}\text { Em minha organização, os objetivos e metas } \\
\text { estão claramente definidos. }\end{array}$ & 0,66 & 0,58 \\
\hline $\begin{array}{l}\text { O estilo gerencial na minha organização é } \\
\text { caracterizado por competitividade e } \\
\text { exigência de realização. }\end{array}$ & 0,66 & 0,57 \\
\hline
\end{tabular}


Conclusão

$\begin{array}{cc}\text { Carga } & \begin{array}{c}\text { Comunali- } \\ \text { Fatorial }\end{array} \\ \text { dade }\end{array}$

\section{Cultura Desenvolvimentista}

Minha organização enfatiza a busca de oportunidades e a criação de novos desafios.

$0,80 \quad 0,63$

Minha organização se esforça em antecipar novas práticas e tecnologias de

$0,66 \quad 0,52$ manufatura.

Minha organização é um lugar dinâmico que estimula as pessoas a ousarem

$0,65 \quad 0,67$
profissionalmente.

O estilo gerencial em minha organização é caracterizado pela liberdade dada aos funcionários para assumirem riscos e inovarem em suas decisões profissionais.

Minha organização define sucesso baseando-se na inovação e diferenciação de seus produtos.

Os dados da Tabela 3 mostram que as variáveis observáveis utilizadas para medição da cultura organizacional apresentaram cargas fatoriais bem superiores ao limite de 0,35, consideradas significantes para o tamanho da amostra analisada $(\mathrm{N}=250)$. Quanto à comunalidade, embora três variáveis tenham apresentado valores de 0,49, 0,46 e 0,49, para medir cultura hierárquica, de grupo e racional respectivamente, essas variáveis compartilham quase $50 \%$ de variância com as demais variáveis na análise. Além disso, possuem carga fatorial de 0,60, 0,62 e 0,42, respectivamente, valores bem superiores a 0,35 que é considerado significante para essa análise. Dessa forma, os dados individuais das variáveis observáveis utilizadas para medição de todos os perfis culturais investigados nesse estudo, se mostraram significantes. A Tabela 4 apresenta os dados individuais das variáveis observáveis utilizados para medição dos grupos de técnicas da qualidade. 
Tabela 4. Dados das variáveis observáveis utilizadas para medição de técnicas da qualidade

\begin{tabular}{ccc}
\hline Grupos de Técnicas da Qualidade & Carga & $\begin{array}{c}\text { Comunali- } \\
\text { Fatorial }\end{array}$ \\
& dade \\
\hline
\end{tabular}

\section{Estabelecimento de Metas}

Minha empresa usa método sistemático para identificar os desejos dos clientes e se preocupa em considera-los no desenvolvimento dos

$0,62 \quad 0,46$
nossos produtos.

Minha organização traduz as necessidades e expectativas dos clientes em características técnicas do produto.

Em minha organização, trabalhamos em equipes multifuncionais para identificar as expectativas dos clientes e considera-las no desenvolvimento de nossos produtos.

Em minha organização identificamos melhores práticas existentes entre as diferentes áreas e buscamos disseminá-las por toda organização.

Em minha organização, os funcionários são encorajados a conhecerem as atividades realizadas em outras áreas.

Em minha organização, melhores práticas tem ajudado na melhoria dos nossos

$0,78 \quad 0,58$
produtos/processos.

$0,82 \quad 0,65$

\section{Melhoria Contínua}

Em minha organização, os funcionários frequentemente se juntam para discutir problemas e suas causas-raízes.

$0,70 \quad 0,62$

Durante as reuniões para solução de problemas, busca-se as opiniões e ideias da maioria dos membros do grupo antes que a decisão seja tomada.

Em minha organização, levantar uma variedade de perspectivas para solução de problemas direciona a melhores soluções.

$0,67 \quad 0,56$

Em minha organização, os funcionários são incentivados a pensarem em melhorias no seu diaadia de trabalho.

$0,70 \quad 0,54$

Em minha organização, a maioria das sugestões de melhoria dadas pelos funcionários é transformada em projetos de $0,68 \quad 0,52$ melhoria. 


\begin{tabular}{ccc}
\hline Grupos de Técnicas da Qualidade & $\begin{array}{c}\text { Carga } \\
\text { Fatorial }\end{array}$ & $\begin{array}{c}\text { Comunali- } \\
\text { dade }\end{array}$ \\
\hline
\end{tabular}

\section{Melhoria Contínua}

Em minha organização, existem ações focadas e estruturadas para se alcançar melhorias específicas num intervalo de tempo $0,77 \quad 0,61$ definido.

Em minha organização, é comum que uma equipe multifuncional trabalhe para alcançar metas de melhoria num intervalo de tempo definido.

Em minha organização, é comum seguirmos métodos estruturados (por ex., PDCA, DMAIC, MASP) para melhoria contínua.

$0,66 \quad 0,59$

Em minha organização, a maioria dos funcionários é treinada no uso de ferramentas da qualidade (por ex., diagrama de $0,68 \quad 0,58$ causa e efeito, pareto, histograma).

Em minha organização, fazemos uso extensivo de métodos para identificação e priorização dos problemas.

Em minha organização, enfatizamos manter o ambiente de trabalho organizado, tendo um local apropriado para cada coisa.

Em minha organização, na rotina do dia a dia, os funcionários mantêm suas áreas de trabalho limpas e organizadas.

$0,78 \quad 0,65$

\section{Medição}

Em minha organização, os dados de qualidade (por ex. taxa de erros, de defeitos, de refugos, custos da qualidade) estão prontamente disponíveis para os funcionários.

Em minha organização, gráficos mostrando o acompanhamento da produção estão visíveis no chão de fábrica.

Em minha organização, informações de produtividade estão prontamente disponíveis para os funcionários.

Em minha organização, estabelecemos metas para a melhoria da qualidade e monitoramos essas metas por meio de indicadores de desempenho. 


\begin{tabular}{ccc}
\hline Grupos de Técnicas da Qualidade & $\begin{array}{c}\text { Carga } \\
\text { Fatorial }\end{array}$ & $\begin{array}{c}\text { Comunali- } \\
\text { dade }\end{array}$ \\
\hline
\end{tabular}

\section{Medição}

Em minha organização, utilizamos indicadores (por ex., taxa de erros, defeitos, refugos, custo da qualidade) para medir o $0,76 \quad 0,57$ desempenho da qualidade.

Em minha organização, utilizamos informações sobre o desempenho da qualidade para avaliar melhorias na empresa.

$0,82 \quad 0,65$

\section{Prevenção de Falhas e Controle}

Em minha organização, fazemos uso extensivo de técnicas estatísticas para analisar a variação nos processos.

Em minha organização, o controle estatístico do processo tem contribuído para

melhoria da qualidade de nossos produtos.

Em minha organização, os funcionários do chão de fábrica são bem treinados em controle estatístico do processo.

$0,69 \quad 0,68$

Em minha organização, nós incluímos tempo destinado para manutenção dos equipamentos no planejamento de nossas atividades.

Em minha organização, nós enfatizamos a manutenção preventiva como uma estratégia para se ter uma produção conforme $0,70 \quad 0,60$ ao cronograma planejado.

Em minha organização, a área de manutenção dá suporte aos funcionários da linha produção para que eles executem manutenção preventiva nos equipamentos que eles operam.

Em minha organização, os processos são projetados de forma a minimizarem as chances de ocorrência de erros.

Em minha organização, a maioria dos equipamentos possui dispositivos que indicam quando algum erro acontece no processo.

Em minha organização usamos métodos para identificar as falhas, suas possíveis causas e os meios existentes para sua detecção nos $0,70 \quad 0,68$ produtos/processos. 


\begin{tabular}{lcc}
\hline \multicolumn{1}{c}{ Grupos de Técnicas da Qualidade } & $\begin{array}{c}\text { Carga } \\
\text { Fatorial }\end{array}$ & $\begin{array}{c}\text { Comunali- } \\
\text { dade }\end{array}$ \\
\hline $\begin{array}{l}\text { Prevenção de Falhas e Controle } \\
\begin{array}{l}\text { Em minha organização implementamos planos } \\
\text { de ação para melhoria dos }\end{array}\end{array}$ & & \\
$\begin{array}{l}\text { produtos/processos a partir da análise detalhada } \\
\text { de possíveis falhas e suas causas. }\end{array}$ & 0,73 & 0,71 \\
$\begin{array}{l}\text { Em minha organização registramos o histórico } \\
\text { de falhas dos produtos/processos e as ações } \\
\text { para redução dessas falhas. }\end{array}$ & 0,68 & 0,63 \\
\hline
\end{tabular}

Os dados da Tabela 4 mostram que as variáveis observáveis utilizadas para medição dos grupos de técnicas da qualidade apresentaram cargas fatoriais bem superiores ao limite de 0,35 , consideradas significantes para o tamanho da amostra analisada $(\mathrm{N}=250)$. Quanto à comunalidade, embora três variáveis tenham apresentado valores de 0,46, 0,48 e 0,47, para medir o grupo de técnicas de estabelecimento de metas, de melhoria contínua, e prevenção de falhas e controle, respectivamente, essas variáveis compartilham quase $50 \%$ de variância com as demais variáveis na análise.

Além disso, possuem carga fatorial de 0,62,0,46 e 0,47, respectivamente, valores consideravelmente superiores a 0,35 que é considerado significante para essa análise. Dessa forma, os dados das variáveis observáveis utilizadas para medição de todos os grupos de técnicas da qualidade investigados nesse estudo, se mostraram significantes. A Tabela 5 apresenta os dados individuais das variáveis observáveis utilizados para medição do desempenho.

Tabela 5. Dados das variáveis observáveis utilizadas para medição do desempenho

\begin{tabular}{lcc}
\hline \multicolumn{1}{c}{ Desempenho } & $\begin{array}{c}\text { Carga } \\
\text { Fatorial }\end{array}$ & $\begin{array}{c}\text { Comunali- } \\
\text { dade }\end{array}$ \\
\hline $\begin{array}{l}\text { Considerando a satisfação dos consumidores, } \\
\text { minha organização: }\end{array}$ & 0,42 & 0,50 \\
$\begin{array}{l}\text { Em minha organização, a produtividade está: } \\
\begin{array}{l}\text { Em minha organização, o custo unitário da } \\
\text { manufatura está: }\end{array}\end{array}$ & 0,46 & 0,40 \\
$\begin{array}{l}\text { Em minha organização, nosso leadtime está: } \\
\begin{array}{l}\text { Em minha organização, o número de } \\
\text { reclamações dos clientes está: }\end{array}\end{array}$ & 0,48 & 0,66 \\
\hline
\end{tabular}




\begin{tabular}{|c|c|c|}
\hline Desempenho & $\begin{array}{c}\text { Carga } \\
\text { Fatorial }\end{array}$ & 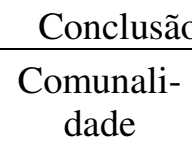 \\
\hline $\begin{array}{l}\text { Em minha organização, o número de unidades } \\
\text { defeituosas, refugadas ou retrabalhadas está: }\end{array}$ & 0,68 & 0,58 \\
\hline $\begin{array}{l}\text { Em minha organização, o turnover dos } \\
\text { funcionários está: }\end{array}$ & 0,40 & 0,41 \\
\hline $\begin{array}{l}\text { Em minha organização, a taxa de absenteísmo } \\
\text { dos funcionários está: }\end{array}$ & 0,54 & 0,38 \\
\hline $\begin{array}{l}\text { Em minha organização, o desempenho dos } \\
\text { nossos produtos comparado aos produtos } \\
\text { similares fabricados pelos nossos concorrentes } \\
\text { é: }\end{array}$ & 0,39 & 0,42 \\
\hline $\begin{array}{l}\text { Em minha organização, a velocidade do } \\
\text { processo de desenvolvimento de novos } \\
\text { produtos comparada à velocidade do } \\
\text { desenvolvimento pelos nossos concorrentes é: }\end{array}$ & 0,35 & 0,64 \\
\hline $\begin{array}{l}\text { Em minha organização, a taxa de inovação nos } \\
\text { nossos processos e tecnologia comparada a de } \\
\text { nossos concorrentes é: }\end{array}$ & 0,33 & 0,67 \\
\hline
\end{tabular}

Os dados da Tabela 5 mostram que, com exceção de uma das variáveis, todas as variáveis observáveis utilizadas para medição do desempenho apresentaram cargas fatoriais superiores ao limite de 0,35, consideradas significantes para o tamanho da amostra analisada $(\mathrm{N}=250)$. A variável observável com carga fatorial inferior a 0,35 possui carga fatorial bem próxima a esse valor (a saber, 0,33). Além disso, tal variável apresentou uma comunalidade de 0,67 , ou seja, compartilhando uma variância de $67 \%$ com as demais variáveis na análise.

Quanto à comunalidade, embora quatro variáveis tenham apresentado valores de 0,40, 0,41 e 0,38 e 0,42, para medição do desempenho, elas apresentaram carga fatorial de 0,46, 0,40, 0,54 e 0,38, respectivamente. Dessa forma, possuem resultados significantes para serem mantidos na análise.

Validade discriminante: é o grau em que um construto é verdadeiramente diferente dos demais. Também existem diversas maneiras de se medir a validade discriminante, nesse trabalho ela foi avaliada por meio da correlação entre as variáveis latentes e a comparação dessa correlação com os coeficientes de confiabilidade de cada um deles, conforme avaliação feita nos estudos realizados por Kaynak (2003). Um instrumento tem validade discriminante se as correlações entre as medidas dos diferentes construtos 
forem menores que o coeficiente de confiabilidade. Os resultados apresentados na Tabela 2 mostram que todas as medidas apresentam validade discriminante.

Validade de expressão: se refere ao quanto o conteúdo dos itens é consistente com a definição do construto, com base no julgamento subjetivo do pesquisador (HAIR et al., 2009). A validade de expressão foi avaliada durante a realização do teste piloto tanto por profissionais das empresas que participaram respondendo o questionário, quanto por acadêmicos especialistas nos assuntos investigados. Por meio dessas avaliações, concluiu-se que as variáveis medidas apresentam também validade de expressão.

\subsection{Análise multivariada}

\subsubsection{Escolha do método estatístico}

Esse estudo utiliza como técnica estatística de análise multivariada a Modelagem de Equações Estruturais (SEM). O SEM é uma extensão de algumas outras técnicas multivariadas, mais precisamente da regressão múltipla e análise fatorial (HAIR et al., 2009). O objetivo de usar essa técnica é simultaneamente analisar as relações presentes nos modelos teóricos desenvolvidos (vide Figuras 7 e 8) e, dessa forma, investigar as hipóteses propostas. Kline (2011) afirma que essa técnica traz uma perspectiva superior para as análises ao permitir a avaliação de modelos inteiros. Da mesma forma, Hair et al. (2009) destaca a habilidade desse método em avaliar as relações de forma abrangente sem comprometer a eficiência estatística.

De fato essa técnica permite a análise de modelos complexos uma vez que é possível considerar diversas variáveis dependentes e independentes simultaneamente numa mesma análise. Além disso, ela permite incorporar variáveis latentes (que não podem ser medidas diretamente) às análises. Segundo Tabachnick e Fidell (2007), essa técnica apresenta vantagens em relação a outras técnicas multivariadas, por exemplo: quando as relações entre os fatores são examinados, as relações são livres de erros já que estes são estimados e removidos, ficando na análise apenas a variância comum. Além disso, esses autores ainda afirmam que quando o fenômeno de interesse é complexo e multidimensional, o SEM é o único método de análise que permite testes completos e simultâneos para todas as relações. 
Porém, esses mesmos autores chamam a atenção para o fato de que sendo uma técnica que apresenta as vantagens descritas anteriormente, ela se torna, também, mais complexa. Shah e Goldstein (2006) listam alguns fatores críticos na aplicação do SEM, como, por exemplo, base teórica para especificação das relações entre os construtos, (identificação dos modelos de mensuração e estrutural) e uma amostra grande (em geral maior que 200 unidades).

Esse trabalho segue os dois passos de análises sugeridos por Hair et al. (2009): 1) avaliação do modelo de mensuração, que representa como e quão bem as variáveis medidas representam o construto estudado; e 2) avaliação do modelo estrutural, que mostra como esses conceitos se relacionam entre si.

\subsubsection{Avaliação do modelo de mensuração}

A teoria de mensuração especifica como variáveis medidas representam de forma lógica e sistemática os conceitos envolvidos num modelo teórico. Esses conceitos podem ser definidos em termos teóricos, mas não podem ser diretamente medidos ou medidos sem erros. Assim, o objetivo do modelo de mensuração é fornecer maneiras de medir conceitos de uma forma confiável e válida, contribuindo para uma boa análise do modelo estrutural.

O modelo de mensuração será avaliado por meio da Análise Fatorial Confirmatória (CFA), usando o software IBM $^{\circledR} \operatorname{SPSS}^{\circledR}$ Amos para a realização dos testes estatísticos. O CFA testa o modelo de mensuração ao fornecer evidência sobre a validade de medidas individuais com base no ajuste geral do modelo e outras evidências sobre a validade do construto.

Segundo Hair et al. (2009), uma das maiores vantagens de CFA é sua habilidade para avaliar a validade dos construtos de uma teoria de mensuração proposta. A validade do construto é o grau em que um conjunto de itens medidos realmente reflete a dimensão que os itens devem medir.

Uma vez que critérios para a validade dos construtos (validade convergente e validade discriminante) foram avaliados nas análises estatísticas preliminares (Seção 4.1), nessa etapa serão realizados testes para verificar o quão bem a teoria se ajusta aos dados. Para isso, foram utilizados alguns índices de ajuste absoluto e incremental para testar o ajuste do modelo geral. 
Os índices de ajuste absoluto medem o quão bem o modelo especificado reproduz os dados observados, ou seja, fornecem uma avaliação de quão bem a teoria se ajusta aos dados da amostra. Já os índices de ajuste incremental diferem dos absolutos no sentido de que eles avaliam o quão bem um modelo especificado se ajusta em relação a algum modelo alternativo.

Sempre que a teoria é usada para especificar um modelo a partir do qual os parâmetros são estimados, o ajuste do modelo compara a teoria com a realidade representada pelos dados. Quanto mais próximo esses valores (teoria e dados), melhor será o ajuste do modelo (KLINE, 2011).

Para teste do ajuste do modelo de mensuração, foram medidos o $x^{2}$ (chi-squared) normalizado e raiz do erro quadrático médio de aproximação (RMSEA) - índices de ajuste absoluto, e os índices de ajuste normalizado (NFI), de ajuste comparativo (CFI) e o de Tucker Lewis (TLI) - índices de ajuste absoluto. Considerando os três construtos investigados nessa pesquisa - cultura organizacional, grupos de técnicas da qualidade e desempenho - foram realizados três análises fatoriais confirmatórias de forma a verificar o ajuste geral do modelo de mensuração, apresentados na Tabela 6 .

Tabela 6. Índices de ajuste geral para o modelo de mensuração

\begin{tabular}{lccc}
\hline \multicolumn{1}{c}{ Medidas de ajuste geral } & $\begin{array}{c}\text { Perfis de cultura } \\
\text { organizacional }\end{array}$ & $\begin{array}{c}\text { Grupos de técnicas } \\
\text { da qualidade }\end{array}$ & Desempenho \\
\hline$x^{2}$ normalizado $\left(\boldsymbol{x}^{2} / \boldsymbol{d} \boldsymbol{f}\right)$ & 2,07 & 1,70 & 2,30 \\
Índice de ajuste comparativo $(\boldsymbol{C F I})$ & 0,93 & 0,93 & 0,88 \\
Índice de ajuste incremental $(\boldsymbol{I F I})$ & 0,93 & 0,93 & 0,88 \\
Índice de Tucker-Lewis $(\boldsymbol{T L I})$ & 0,91 & 0,92 & 0,84 \\
Raiz do erro quadrático médio de & 0,06 & 0,05 & 0,07 \\
aproximação $(\mathbf{R M S E A})$ & & & \\
\hline
\end{tabular}

Como referências para análise desses índices foi utilizado RMSEA $<0,05$ (bom), 0,05 < RMSEA < 0,08 (satisfatório) e RMSEA > 0,08 (ruim). Para $x^{2}$ normalizado $\left(x^{2} / d f\right)$, valores inferiores a 2.0 são considerados muito bons; entre 2.0 e 3.0 são bons, e < 5.0 são aceitáveis (HAIR et al., 2009). Para os índices de ajuste incremental (CFI, IFI e TLI) os valores variam de 0.0 (sem ajuste) a 1.0 (ajuste perfeito) (HAIR et al., 2009; TABACHINICK; FIDELL, 2007). Os resultados apresentados na Tabela 6 mostram medidas satisfatórias de ajuste do modelo de mensuração aos dados. Essas medidas demonstram que os conceitos descritos no modelo são válidos e 
confiáveis. Uma vez validado o modelo de mensuração, pode-se prosseguir com a análise do modelo estrutural.

\subsubsection{Análise do modelo estrutural}

O modelo estrutural representa a teoria focando, principalmente, nas relações entre os construtos (cultura organizacional, grupos de técnicas de gestão da qualidade e desempenho). Segundo Hair et al. (2009), modelos estruturais diferem de modelos de mensuração, pois a ênfase passa da relação entre as dimensões e variáveis medidas para a natureza e magnitude das relações entre os construtos.

Nessa etapa foram testadas as relações entre os construtos apresentadas nos modelos teóricos (vide Figuras 7 e 8), para teste das hipóteses propostas.

Teste da H1. A H1: A cultura de uma organização influencia o conjunto de técnicas da qualidade que ela adota

foi testada baseando-se no modelo estrutural geral apresentado na Figura 7 (página 62). A partir desse modelo foram testadas dezesseis relações entre perfis de cultura organizacional e grupos de técnicas da qualidade. Os resultados iniciais mostraram que nem todas essas dezesseis relações foram estatisticamente significantes. As relações não significantes $(p>0,1)$ do modelo estrutural geral foram, então, omitidas.

Os índices de ajuste geral do modelo mantido foram $x^{2} / \mathrm{df}=2,04, \mathrm{CFI}=0,83$, IFI $=0,83, \mathrm{TLI}=0,82$ e RMSEA $=0,06$, o que sugerem um ajuste satisfatório do modelo. A Figura 10 apresenta o modelo e os coeficientes das relações mantidas.

Os resultados apresentados na Figura 9 confirmam a hipótese de que o relacionamento entre cultura e as técnicas da qualidade variam entre os diferentes perfis de cultura organizacional e grupos de técnicas da qualidade:

- A cultura racional está positivamente relacionada com todos os grupos de técnicas da qualidade: estabelecimento de metas, melhoria contínua, medição e prevenção de falhas e controle. Ou seja, empresas com características da cultura racional, orientadas para competição, tendem a usar técnicas da qualidade de todos os grupos de técnicas considerados nesse estudo. 


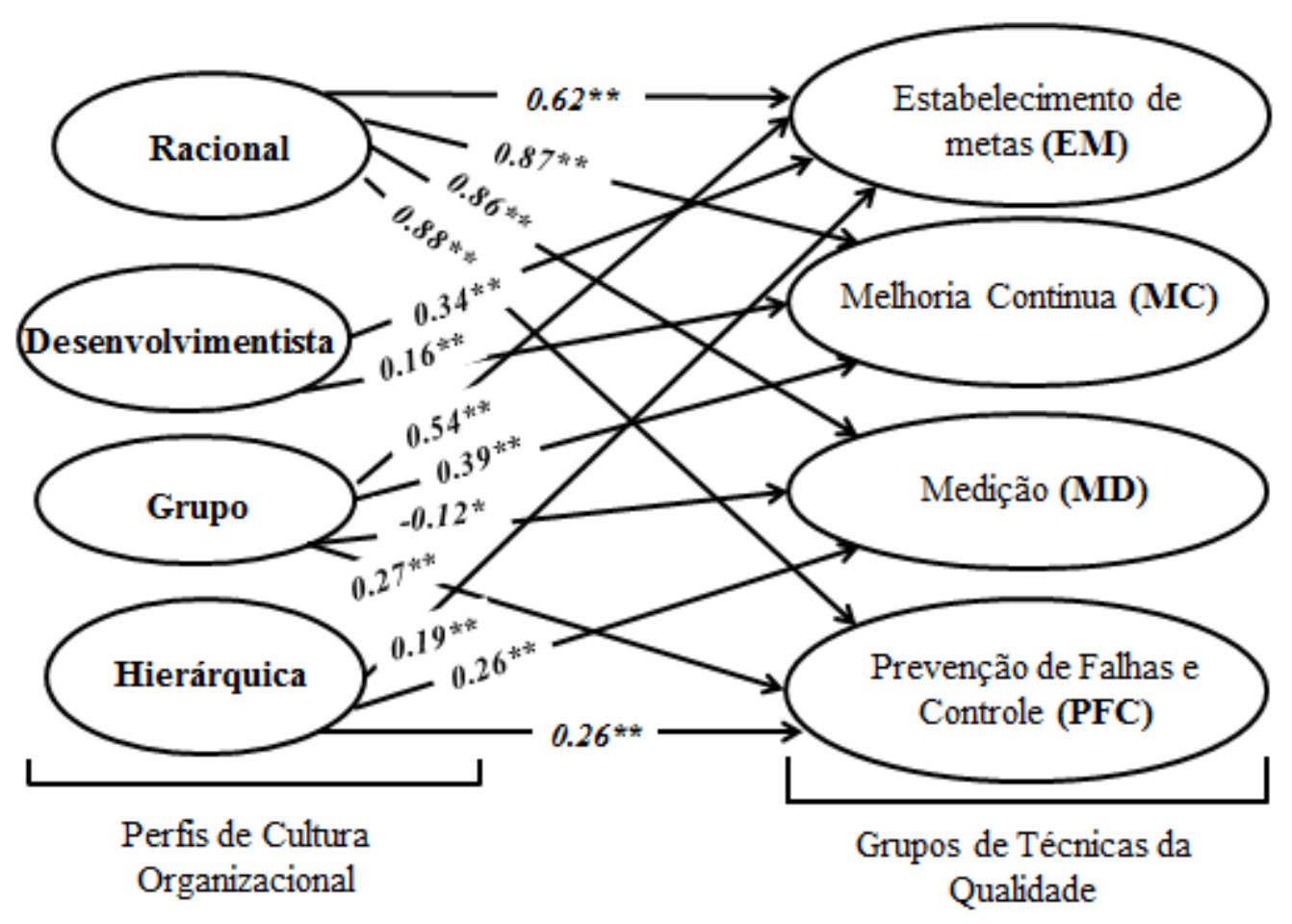

Nota: $* * \mathrm{p}<0,01, * \mathrm{p}<0,05$

Figura 9. Modelo estrutural das relações entre perfis de cultura organizacional e grupos de técnicas da qualidade

- A cultura desenvolvimentista está positivamente relacionada aos grupos de técnicas de estabelecimento de metas e melhoria contínua. Os caminhos representando as relações entre essa cultura e os grupos de técnicas de medição e prevenção de falhas e controle não foram estatisticamente significantes $(p>0,10)$, sendo retirados do modelo. Em outras palavras, empresas com características da cultura desenvolvimentista, orientadas para inovação, tendem a usar as técnicas da qualidade dos grupos de estabelecimento de metas e melhoria contínua. Essa cultura não está associada ao uso de técnicas dos grupos de medição e prevenção de falhas e controle.

- A cultura de grupo está positivamente relacionada ao uso de técnicas do grupo de estabelecimento de metas, melhoria contínua e prevenção de falhas e controle, e negativamente relacionada ao grupo de técnicas de medição. Em outras palavras, empresas com características da cultura de grupo, orientadas para a colaboração, tendem a usar as técnicas da qualidade dos grupos de estabelecimento de metas, melhoria contínua, e prevenção de falhas e controle. A relação negativa entre essa cultura e o uso de técnicas do grupo de medição significa que quanto mais forte as 
características dessa cultura numa organização, menor sua tendência em usar técnicas da qualidade desse grupo.

- A cultura hierárquica está positivamente relacionada ao uso de técnicas da qualidade do grupo de estabelecimento de metas, medição e prevenção de falhas e controle. O caminho representando a relação entre essa cultura e os grupos de técnicas de melhoria contínua não foi estatisticamente significante $(p>0,10)$, sendo retirado do modelo. Ou seja, empresas com características da cultura hierárquica, orientadas para o controle, tendem a usar as técnicas da qualidade dos grupos de estabelecimento de metas, medição e prevenção de falhas e controle. Essa cultura não está associada ao uso de técnicas de melhoria contínua.

Em resumo, empresas com características da cultura racional, tendem a usar todos os grupos de técnicas da qualidade, e em maior intensidade quando comparada aos demais perfis culturais. As culturas de grupo e desenvolvimentista usam técnicas pertencentes ao grupo de estabelecimento de metas e melhoria contínua mais que a cultura hierárquica que, por sua vez, é mais propensa a usar técnicas de medição que as culturas de grupo e desenvolvimentista. A Figura 10 resume os resultados apresentados anteriormente.

Teste da H2. A H2: A combinação entre o conjunto de técnicas da qualidade adotada por uma organização e sua cultura organizacional afeta o desempenho

foi testada baseando-se no modelo estrutural geral apresentado na Figura 8 (página 63). Esse modelo considerou também o desempenho. Dessa forma, pares de perfis culturais e grupos de técnicas da qualidade foram testados para avaliar se a combinação de determinadas características culturais com um grupo específico de técnicas da qualidade afeta o desempenho. Considerando quatro perfis de cultura organizacional e quatro grupos de técnicas da qualidade foram testados ao todo dezesseis modelos. Os índices de ajuste geral dos modelos testados, bem como os efeitos estão apresentados no Apêndice G. Os índices de ajuste geral dos modelos mantido mostram ajuste satisfatório de todos os modelos $x 2 / \mathrm{df}<2,00, \mathrm{CFI}>0,89$, IFI $>$ 0,89 , TLI $>0,88$ e RMSEA $<0,06$. 


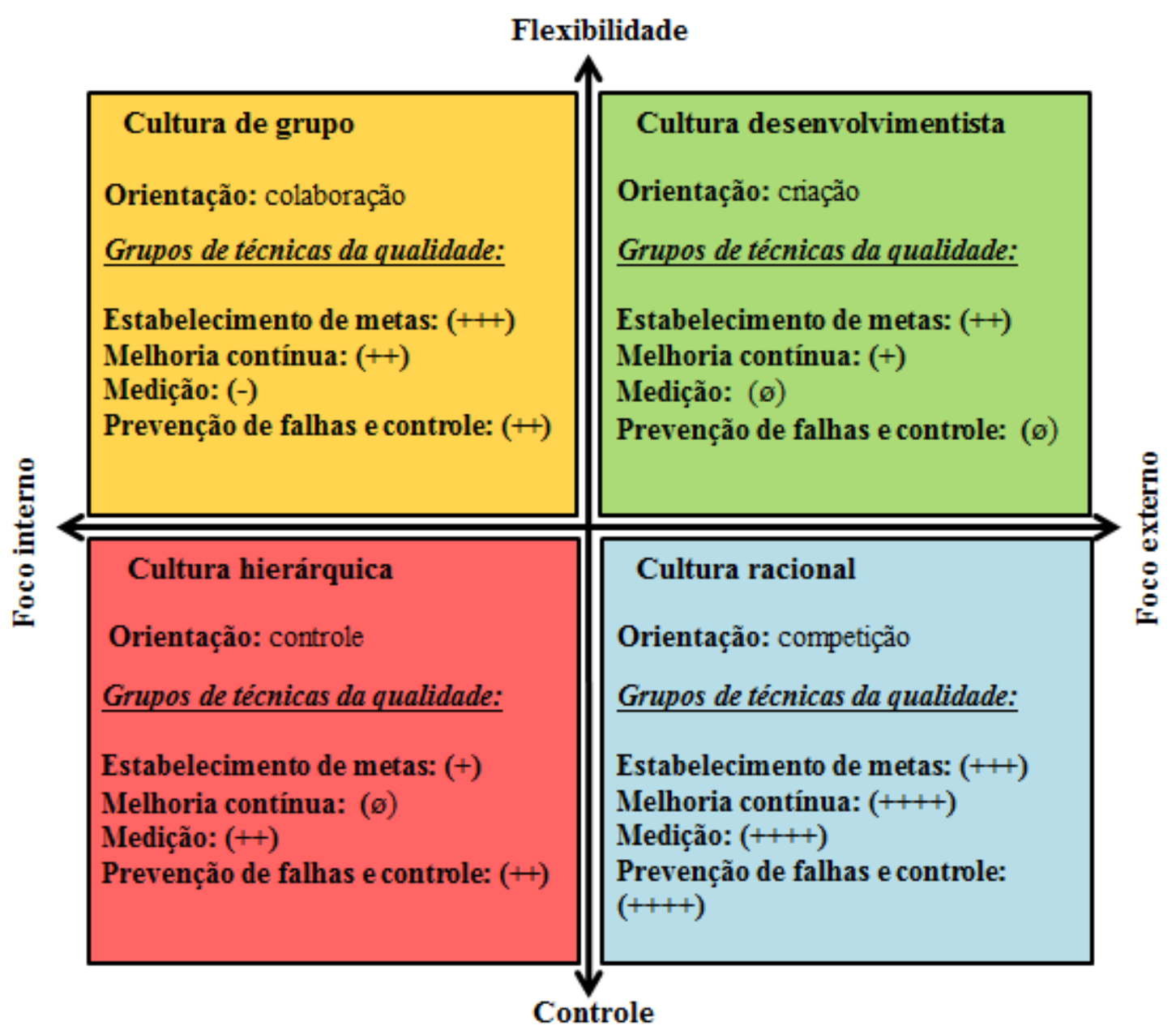

Figura 10. Relacionamento entre cultura organizacional e grupos de técnicas da qualidade (Notas: $(\varnothing)$ não relacionada, $(+)$ relacionada positivamente, $(-)$ relacionada negativamente)

A Tabela 7 apresenta o efeito direto dos diferentes perfis culturais (caminho (a) na Figura 8), o efeito direto dos grupos de técnicas da qualidade (caminho (c)) no desempenho, o efeito indireto da cultura organizacional por mediação dos grupos de técnicas da qualidade (caminho (b) + (c)) no desempenho, bem como o efeito total da cultura organizacional (efeitos direto e indireto) no desempenho. 
Tabela 7. Efeitos do relacionamento entre cultura organizacional e grupos de técnicas da qualidade no desempenho

\begin{tabular}{|c|c|c|c|c|c|c|c|c|}
\hline \multicolumn{9}{|c|}{ Efeitos no desempenho } \\
\hline & EM & Desenv. & $\mathbf{E M}$ & Grupo & EM & Hie rárquica & $\mathbf{E M}$ & Racional \\
\hline Direto & $0,39 *$ & $0,34^{* *}(51 \%)$ & $0,39 *$ & $0,33^{* *}(50 \%)$ & $0,52 * *$ & $0,18^{\mathrm{ns}}$ & $0,17^{\mathrm{ns}}$ & 0,60 ** \\
\hline Indireto & & $0,33 * *(49 \%)$ & & $0,33 * *(50 \%)$ & & $0,41 * *(100 \%)$ & & $0,14^{\mathrm{ns}}$ \\
\hline \multirow[t]{2}{*}{ Total } & $0,39 *$ & $0,67 * *(100 \%)$ & $0,39 *$ & $0,66^{* *}(100 \%)$ & $0,52 * *$ & $0,41 * *(100 \%)$ & & $0,60 * *(100 \%)$ \\
\hline & MC & Desenv. & MC & Grupo & MC & Hie rárquica & MC & Racional \\
\hline ireto & $0,41^{* * *}$ & $0,35^{* *}(53 \%)$ & $0,40 * *$ & $0,35^{* *}(53 \%)$ & $0,49 * *$ & $0,23^{\mathrm{ns}}$ & $0,08^{\mathrm{ns}}$ & $0,67^{* *}$ \\
\hline Indireto & & $0,31^{* *}(47 \%)$ & & $0,31 * *(47 \%)$ & & $0,36^{* *}(100 \%)$ & & $0,07^{\mathrm{ns}}$ \\
\hline \multirow[t]{2}{*}{ Total } & $0,41 * *$ & $0,66^{* *}(100 \%)$ & $0,40 * *$ & $0,66 * *(100 \%)$ & $0,49 * *$ & $0,36 * *(100 \%)$ & & $0,67 * *(100 \%)$ \\
\hline & MD & Deseniv. & NOID & 0 & MD & uica & MD & Kactonial \\
\hline Direto & $0,31 * *$ & $0,48 * *(75 \%)$ & $0,33 * *$ & $0,50 * *(77 \%)$ & $0,29 * *$ & $0,39 * *(66 \%)$ & $0,02^{\mathrm{ns}}$ & $0,70 * *$ \\
\hline Indireto & & $0,16^{* *}(25 \%)$ & & $0,15^{* *}(23 \%)$ & & $0,20 * *(33 \%)$ & & \\
\hline \multirow[t]{2}{*}{ Total } & $0,31^{* *}$ & $0,64 * *(100 \%)$ & $0,33^{* *}$ & $0,65^{* *}(100 \%)$ & $0.29 * *$ & $0,59 * *(100 \%)$ & & $0,70 * *(100 \%)$ \\
\hline & PFC & & PFC & & PFC & Hie rárquica & PFC & Racional \\
\hline Direto & $0,39 * *$ & $0,40 * *(60 \%)$ & $0,38^{* *}$ & $0,38 * *(58 \%)$ & $0,49 * *$ & $0,21^{\mathrm{ns}}$ & $0,15^{\mathrm{ns}}$ & $0,61 * *$ \\
\hline Indireto & & $0,26^{* *}(40 \%)$ & & $1,7 \%)$ & & $0,39 * *(100 \%)$ & & $0,13^{\mathrm{ns}}$ \\
\hline Total & $0,39 * *$ & $0,66^{* *}(100 \%)$ & $0,38 * *$ & $0,65^{* *}(100 \%)$ & $0,49 * *$ & $0,39 * *(100 \%)$ & & $0,61 * *(100 \%)$ \\
\hline
\end{tabular}

Nota - EM: Técnicas de estabelecimento de metas; MC: Técnicas de melhoria contínua; MD:

Técnicas de medição de desempenho; PFC: Técnicas de prevenção de falha e controle; ** $p<0,01$, ${ }^{*} p<0,05 ;{ }^{\text {ns }}$ não significante $(p>0,05)$

Os dados da Tabela 7 mostram que a H2 é confirmada para a cultura desenvolvimentista e a de grupo, uma vez que essas duas culturas contribuem para um aumento do efeito no desempenho quando são combinadas com os quatro grupos de técnicas da qualidade. Ainda, esse mesmo efeito é percebido quando a cultura hierárquica e o grupo de técnicas de medição são combinados. Já a combinação dessa cultura com os demais grupos de técnicas da qualidade (estabelecimento de metas, melhoria contínua, e prevenção de falhas e controle) contribui para redução do efeito total no desempenho. Já a cultura racional explica $100 \%$ do efeito no desempenho, independente de quais grupos de técnicas da qualidade esteja combinado com esse perfil cultural. A Figura 11 resume os resultados apresentados anteriormente. 


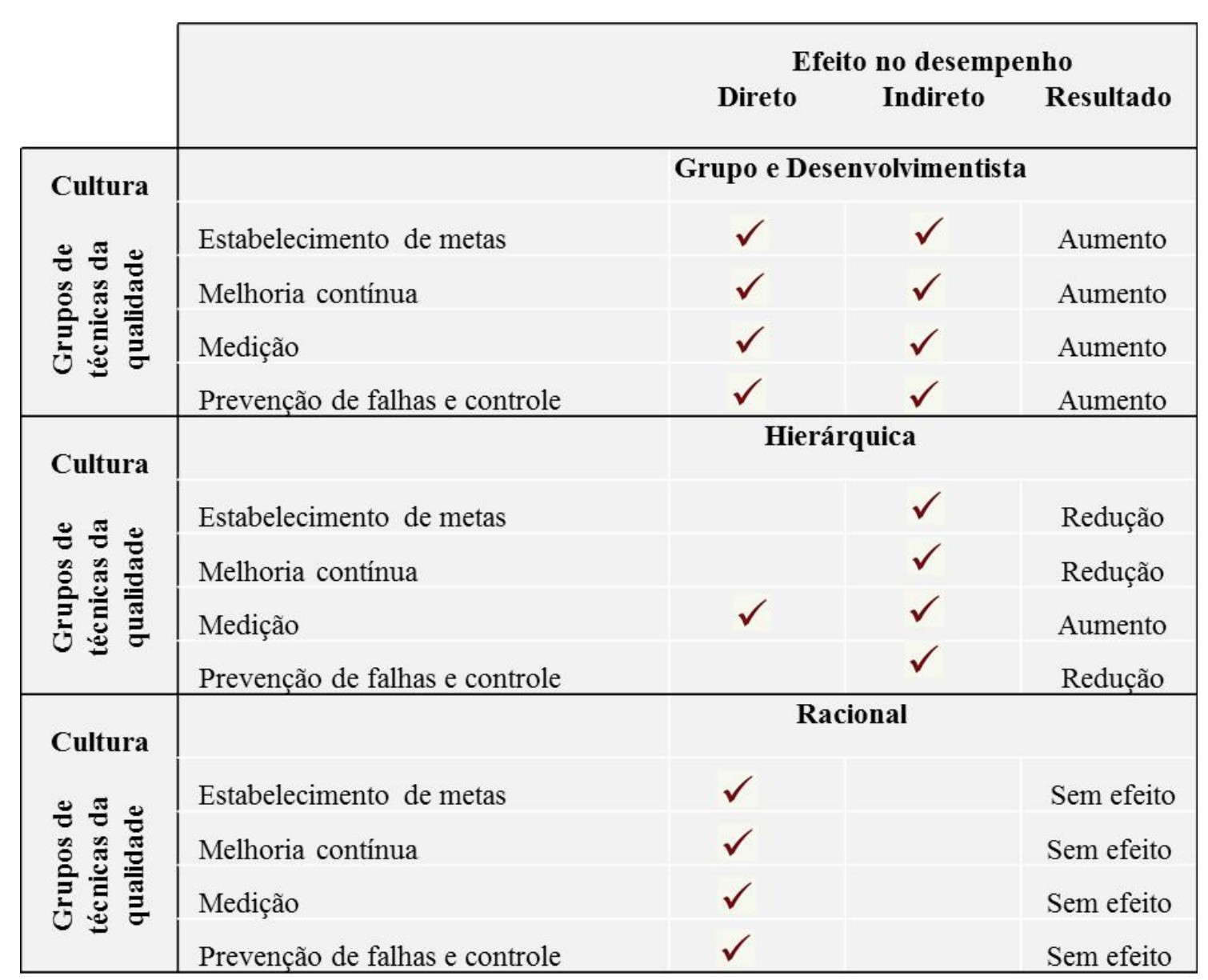

Quadro 5. Efeitos da combinação entre cultura e técnicas da qualidade no desempenho 


\section{Discussão}

\subsection{Hipótese 1. Associação entre cultura organizacional e o uso de técnicas da qualidade}

A Figura 9 (página 84) apresenta um conjunto de relações significantes entre cultura organizacional e o uso de técnicas da qualidade, confirmando a H1: A cultura de uma organização influencia o conjunto de técnicas da qualidade que ela adota.

A cultura racional foca no ambiente externo e é orientada para o controle. Dentre os perfis culturais considerados nesse estudo, a cultura racional é a que mostra relações mais fortes com todos os grupos de técnicas da qualidade. Esses resultados são esperados para o grupo de técnicas da qualidade: de Medição, Prevenção de Falhas e Controle, e Estabelecimento de Metas, uma vez que essas técnicas estão relacionadas a características da cultura racional como: foco nas tarefas, orientação para os objetivos e metas, liderança orientada para resultados, eficiência e produtividade (CAMERON; QUINN, 2006; DENISON; SPREITZER, 1991; PRAJOGO; McDERMOTT, 2005; 2011; ZU; ROBBINS; FREDENDALL, 2010).

No entanto, a relação significante entre essa cultura e o grupo de técnicas de Melhoria Contínua é bastante interessante. Como esse grupo se relaciona a técnicas como brainstorming e evento kaizen, que são mais orientadas para o envolvimento das pessoas (BAYO-MORIONES; BELLO-PINTADO; CERIO, 2010; GLOVER et al., 2013), seria esperado que a associação entre a cultura de grupo e as técnicas de melhoria contínua apresentassem uma relação mais forte que a relação entre esse grupo de técnicas e a cultura racional. Porém, esses resultados reforçam as conclusões de Prajogo e McDermott (2005) que sugerem que práticas orientadas ao controle e práticas orientadas às pessoas podem coexistir em harmonia. Os resultados aqui mostram que isso também é válido para o nível das técnicas de qualidade.

A cultura de grupo foca no ambiente interno da organização e é orientada para a flexibilidade. Essa cultura está positivamente associada com o uso de técnicas do grupo de Estabelecimento de Metas, Melhoria Contínua, e Prevenção de Falhas e Controle. A relação entre a cultura de grupo e das técnicas de Medição é negativa. Assim, quanto mais forte as características associadas a essa cultura, menor é o uso das técnicas do grupo de medição. 
Esses resultados sugerem que as empresas com características da cultura de grupo adotam técnicas orientadas às pessoas (grupo de técnicas de Melhoria Contínua), e técnicas que são orientadas ao planejamento (grupo de técnicas de Estabelecimento de Metas), e controle (grupo de Prevenção de Falhas e Controle), mas não as técnicas pertencentes ao grupo de Medição.

Trabalho em equipe, liderança participativa, empowerment, confiança, desenvolvimento do potencial humano e comprometimento dos funcionários são características da cultura de grupo (CAMERON; QUINN, 2006; DENISON; SPREITZER, 1991; PRAJOGO; McDERMOTT, 2005, 2011; ZU; ROBBINS; FREDENDALL, 2010). Considerando essas características, o relacionamento positivo das técnicas do grupo de Estabelecimento de Metas e Melhoria Contínua, e o efeito negativo das técnicas do grupo de Medição e essa cultura são esperados. A relação positiva entre a cultura de grupo e as técnicas de Prevenção de Falhas e Controle é interessante uma vez que as características desse grupo de técnicas não estão alinhadas às características dessa cultura, mais orientada para as relações humanas que para aspectos de controle e eficiência.

A cultura hierárquica também foca no ambiente externo da organização, porém é orientada ao controle. Essa cultura não tem uma relação significante com as técnicas de Melhoria Contínua, o que pode ser explicado pelo fato de que essa cultura é caracterizada pelo foco na eficiência interna e previsibilidade nas entregas, controle, estabilidade, uniformidade, características alinhadas à formalização, centralização e às regras (CAMERON; QUINN, 2006; DENISON; SPREITZER, 1991; PRAJOGO; McDERMOTT, 2005, 2011; ZU; ROBBINS; FREDENDALL, 2010) que, de certa forma, contrapõem às características desse grupo de técnicas que são mais orientadas às pessoas e enfatizam a participação e envolvimento dos funcionários.

Considerando esse conjunto de características, a cultura hierárquica seria mais adequada ao uso de técnicas do grupo de Estabelecimento de Metas e, especialmente, ao uso de técnicas do grupo de Medição, e Prevenção de Falha e Controle. Os resultados estatísticos apresentados na Figura 9 claramente dão suporte a esses argumentos.

A cultura desenvolvimentista foca no ambiente externo e é orientada à flexibilidade. Os resultados sugerem que existe um relacionamento positivo entre essa cultura e o uso de técnicas como QFD e benchmarking (grupo de Estabelecimento de Metas). O relacionamento dessa cultura com as técnicas do grupo de Melhoria Contínua também é positivo, porém mais fraco. Já os resultados do relacionamento entre essa 
cultura e os demais grupos de técnicas da qualidade (Medição, e Prevenção de Falhas e Controle) mostraram-se insignificantes. Esses resultados também são consistentes com as características da cultura desenvolvimentista uma vez que ela é orientada à flexibilidade, criatividade e adaptação ao ambiente externo (CAMERON; QUINN, 2006; DENISON; SPREITZER, 1991), valores centrais que contrapõem às características desses grupos de técnicas que se relacionam principalmente à estabilidade e controle.

Em suma, a cultura racional cuja orientação é voltada à produtividade, desempenho, alcance das metas e eficiência fornecem características adequadas para o uso de técnicas de todos os grupos investigados nesse estudo. Já as características da cultura de grupo propiciam o uso de técnicas mais voltadas a aspectos sociais da empresa que favorecem o envolvimento e participação dos funcionários (como as técnicas do grupo de Melhoria Contínua e Estabelecimento de Metas). Em menor intensidade, essa cultura também prediz o uso de técnicas de Prevenção de Falhas e Controle, e não mostra relação com o uso das técnicas de Medição. A cultura hierárquica mostra-se adequada para uso de técnicas dos grupos de Estabelecimento de Metas, Medição, e do grupo de Prevenção de Falhas e Controle. Por fim, as características da cultura desenvolvimentista favorecem o uso de técnicas do grupo de Estabelecimento de Metas e Melhoria Contínua.

O conjunto de técnicas da qualidade adotadas por cada um dos quatro perfis culturais e a magnitude das relações entre cultura e técnicas varia. Dessa forma, a H1 de que a cultura de uma organização influencia nas técnicas da qualidade que ela adota é confirmada. Esses resultados também mostram que a visão pluralista da qualidade não só é válida para as práticas de gestão da qualidade, mas também se estende para o nível das técnicas. Entretanto, a adoção das técnicas da qualidade pelas empresas não implica que estas sejam usadas de forma eficaz. A H2 aborda essa questão ao investigar a influência do relacionamento entre cultura e técnicas da qualidade no desempenho. 


\subsection{Hipótese 2. Associação entre cultura organizacional, técnicas da qualidade e desempenho}

Os resultados descritos na Tabela 7 parcialmente suportam a $\mathrm{H} 2$ de que $a$ combinação entre o conjunto de técnicas da qualidade adotada por uma organização e sua cultura organizacional afeta o desempenho.

A cultura desenvolvimentista e a cultura de grupo contribuem direta e indiretamente para melhoria no desempenho independente do grupo de técnicas da qualidade consideradas. Nos oito modelos testados considerando esses dois perfis culturais e os quatro grupos de técnicas da qualidade (Apêndice G), todos os grupos de técnicas da qualidade exercem um efeito direto no desempenho. Entretanto, o efeito direto (caminho (a) na Figura 8) da cultura de grupo e desenvolvimentista são consideravelmente maiores que seus efeitos indiretos (caminho (b) + (c)) se essas culturas são combinadas com grupos de técnicas que possuem características não alinhadas às características desses perfis culturais.

Por exemplo, no modelo que considera o relacionamento entre cultura desenvolvimentista e o grupo de técnicas de Medição, a cultura contribui diretamente com $75 \%$ do efeito total no desempenho, enquanto o efeito indireto (através do grupo de técnicas de Medição) contribui com 25\% para o efeito total. O mesmo ocorre quando a cultura de grupo é combinada com as técnicas de Medição. Nesse caso, o efeito direto da cultura contribui com $77 \%$ do efeito total, enquanto seu efeito indireto (através do grupo de técnicas de Medição) contribui somente com 23\%. Também para o grupo de técnicas de prevenção de falhas e controle, o efeito direto da cultura desenvolvimentista e de grupo é consideravelmente maior, embora menor que nas combinações discutidas anteriormente, que seus efeitos indiretos: $60 \%$ versus $40 \%$, e $58 \%$ versus $42 \%$, respectivamente (Tabela 7).

Esses resultados são consistentes com a natureza desses perfis culturais e dos grupos de técnicas da qualidade considerados nas discussões anteriores. Técnicas do grupo de Estabelecimento de Metas e de Melhoria Contínua estão relacionadas à flexibilidade, que é uma das orientações das culturas de grupo e desenvolvimentista. Em contraste, as técnicas da qualidade dos grupos de medição e de prevenção de falhas e controle estão mais alinhadas à orientação voltada ao controle que é típica das culturas hierárquica e racional (CAMERON; FREEMAN, 1991; CAMERON; QUINN, 2006). 
A cultura hierárquica contribui para o aumento do efeito no desempenho quando combinada com apenas um (grupo de técnicas de Medição) dos quatro grupos de técnicas da qualidade. Essa cultura enfatiza eficiência interna, uniformidade, coordenação, controle e avaliação (DENISON; SPREITZER, 1991), características alinhadas à função de medição que tem o objetivo de assegurar respostas rápidas para ações necessárias proporcionando, consequentemente, um processo de produção estável.

Conforme apresentado na Tabela 7 (vide também Quadro 5, página 88), a cultura hierárquica afeta o desempenho indiretamente por meio de todos os demais grupos de técnicas da qualidade (Estabelecimento de Metas, Melhoria Contínua, Prevenção de Falhas e Controle), mas não exerce efeito direto no desempenho. Em empresas com características da cultura hierárquica, o efeito que essa cultura exerce no desempenho através dos grupos de técnicas de Estabelecimento de Metas, Melhoria Contínua, e Prevenção de Falhas e Controle contribui, de fato, para redução do efeito no desempenho de 0,52 para 0,41 , de 0,47 para 0,34 e de 0,49 para 0,39 , respectivamente. Esse resultado é interessante, visto a popularidade das técnicas de qualidade desses grupos de qualidade em empresas com características da cultura hierárquica (vide Figura 9).

Esses resultados são esperados quando as técnicas dos grupos de estabelecimento de metas e melhoria contínua são consideradas, já que essas técnicas se relacionam à um ambiente com características mais flexíveis que de controle, típico da cultura hierárquica. Entretanto, esse resultado é interessante quando as técnicas da qualidade do grupo de prevenção de falhas e controle são consideradas, já que essas técnicas contribuem para um fluxo produtivo controlado e estável estando, de fato, bastante alinhadas às características da cultura hierárquica que possui valores como a estabilidade, previsibilidade e eficiência (CAMERON; FREEMAN, 1991; CAMERON; QUINN, 2006; DENISON; SPREITZER, 1991).

Uma justificativa para esse resultado pode recair no fato de que é possível que as empresas com características de cultura hierárquica usem de forma mais eficaz as técnicas de qualidade relacionadas a um controle de medição (por ex. medição de indicadores de qualidade) que as técnicas relacionadas ao controle como prevenção (por ex. manutenção preventiva).

A cultura racional possui apenas um efeito direto no desempenho, não exercendo efeito indireto por meio de quaisquer dos grupos de técnicas de gestão da qualidade. Nos quatro modelos testados com essa cultura, nenhum dos grupos de técnicas da 
qualidade apresentou efeito direto no desempenho. Esses resultados podem ser explicados pelo fato de que a cultura racional, dentre todos os perfis culturais estudados, apresenta a relação mais intensa com todos os grupos de técnicas da qualidade (vide Figura 9).

A cultura racional é uma cultura orientada para a competição e controle e tem como um de sues critérios de eficiência o alcance das metas como um de seus critérios de eficiência. Dessa forma, os resultados sugerem que o uso de todos os grupos de técnicas da qualidade por empresas com características predominantes da cultura racional, de forma mais intensa do que empresas com os demais perfis culturais, é decorrente das próprias características centrais desta cultura. Em outras palavras, o uso de todos os grupos de técnicas está tão fortemente relacionado às características da cultura racional que nenhum efeito indireto desta cultura, por meio dos grupos de técnicas da qualidade, foi percebido no desempenho operacional.

Em suma, os resultados sugerem que a cultura organizacional afeta o desempenho por meio das técnicas de qualidade adotadas para a maioria das combinações de perfis culturais e grupos de técnicas da qualidade consideradas nesse estudo, confirmando parcialmente a H2. A única exceção recai sobre a cultura racional, já que o efeito indireto no desempenho foi insignificante para todas as combinações dessa cultura com os grupos de técnicas da qualidade estudados.

\subsection{Discussão geral}

Como discutido na revisão bibliográfica, a maioria das pesquisas em gestão da qualidade tem focado no nível das práticas da qualidade e estudado o efeito delas no desempenho (por ex. Kaynak, 2003, Samson e Terzioviski, 1999), sua interação com a cultura (por ex. Wu, Zhang e Schroeder, 2011), ou considerando práticas, cultura e desempenho conjuntamente (por ex. Baird, Hu e Reeve, 2011). Em alguns desses estudos, as técnicas da qualidade são incluídas no conjunto das práticas consideradas (por ex. Naor et al., 2008).

De fato, são poucos os estudos que focam somente nas técnicas da qualidade, como é o caso, por exemplo, dos estudos de Handfield, Jayaram e Gosh (1999). Embora esses autores tenham concluído que as técnicas da qualidade afetam diferentes níveis de desempenho, outros estudos mais recentes, como os de Naor et al., (2008) sugerem que 
os elementos técnicos da gestão da qualidade não estão diretamente associados ao desempenho. Dentro desse contexto, o presente estudo fornece uma contraprova a esses estudos mais recentes sugerindo que, de fato, o uso de técnicas da qualidade afeta o desempenho, direta e indiretamente por meio da interação com a cultura organizacional.

Esses resultados confirmam tanto os resultados dos estudos de Handfiel, Jayaram e Gosh (1999) como os de Sitkin, Sutcliffe e Schroeder (1994), Dean e Bowen (1994) e Rahman e Bullock (2005) que sugerem ser importante considerar a interação entre os elementos técnicos (hard) e sociais (soft) da gestão da qualidade de forma a se obter melhores resultados de desempenho.

$\mathrm{O}$ teste da $\mathrm{H} 1$ mostra que os perfis culturais se relacionam de forma diferente a diversas técnicas da qualidade sugerindo que, assim como as práticas, as técnicas também são compatíveis com diferentes perfis culturais. Outra questão recai sobre o efeito que esse relacionamento entre qualidade e cultura exerce no desempenho, testada na $\mathrm{H} 2$.

Os resultados do teste da $\mathrm{H} 2$ sugerem que empresas com cultura de grupo e desenvolvimentista poderiam usar todos os grupos de técnicas da qualidade efetivamente - essas técnicas afetam o desempenho positivamente e esse efeito é aumentado pela combinação dessas técnicas com a cultura de grupo e desenvolvimentista. Em empresas com uma cultura hierárquica, as técnicas da qualidade afetam o desempenho. Porém, o efeito positivo no desempenho ocorre somente quando essa cultura é combinada com as técnicas do grupo de medição. Por fim, em empresas com cultura racional o efeito no desempenho não é influenciado pelos grupos de técnicas da qualidade.

Dessa forma, as técnicas da qualidade contribuem para melhoria do desempenho quando combinadas à cultura desenvolvimentista e de grupo, mas não à cultura hierárquica (exceção das técnicas de Medição) e racional. Aparentemente, as características da cultura racional e hierárquica, por exemplo, sua orientação dominante, valores centrais, estilo de liderança e prioridades de desempenho, podem reduzir ou até mesmo anular os efeitos das técnicas da qualidade.

Enquanto alguns estudos mostram que os elementos sociais da gestão da qualidade podem contribuir para melhoria do desempenho até mesmo sem os elementos técnicos (por ex., Samson e Terziovski, 1999; Naor et al., 2008), esse estudo mostra que as técnicas da qualidade contribuem para a melhoria do desempenho, desde que estejam alinhadas a características culturais apropriadas. 
Dentro desse contexto, não é surpresa que as empresas têm modificado sua compreensão sobre gestão da qualidade como um sistema técnico, focado exclusivamente no uso de técnicas da qualidade, para um sistema que considere também aspectos sociais alinhados a esses aspectos técnicos, conforme sugerido pelos estudos de Maull, Brown e Cliffe (2001). 


\section{Conclusão}

O presente estudo teve como objetivo investigar se determinadas características culturais da organização favorecem o uso de técnicas específicas da qualidade, e se a cultura organizacional combinada ao uso de técnicas da qualidade influencia nos resultados de desempenho da empresa. Para isso, foram testadas duas hipóteses que possibilitaram responder aos questionamentos previamente levantados, a saber:

- A cultura organizacional influencia na adoção de técnicas da gestão da qualidade?

- Determinadas técnicas de gestão da qualidade se adequam melhor a certas organizações dependendo de suas características culturais?

- O efeito do uso das técnicas da qualidade no desempenho é influenciado pela combinação entre essas técnicas e a cultura organizacional?

Assim, por meio dos resultados é possível concluir que, de fato, a cultura organizacional influencia na adoção de técnicas da gestão da qualidade. Dessa forma, empresas com características da cultura racional, tendem a usar todos os grupos de técnicas da qualidade, e em maior intensidade quando comparada aos demais perfis culturais. Já as empresas com características das culturas de grupo e desenvolvimentista usam técnicas pertencentes ao grupo de Estabelecimento de Metas e Melhoria Contínua mais que aquelas empresas com características da cultura hierárquica que, por sua vez, é mais propensa a usar técnicas de Medição que as culturas de grupo e desenvolvimentista.

Esses resultados também permitem conclusões referentes ao questionamento se determinadas técnicas da gestão da qualidade se adequam melhor a certas empresas dependendo de suas características culturais. Por meio desse estudo, conclui-se que todos os grupos de técnicas da qualidade considerados nesse estudo são adequados às empresas com características da cultura racional. Assim, dentre os perfis culturais estudados, empresas com cultura racional apresentam um ambiente que suporta o uso das técnicas da qualidade de melhor maneira que os demais perfis culturais.

Considerando as características da cultura desenvolvimentista, orientadas para flexibilidade, ambiente externo e inovação, é possível concluir que o uso de técnicas da qualidade do grupo de Estabelecimento de Metas que enfatizam o desenvolvimento de 
produtos e processos e auxiliam as empresas a definirem metas que direcionam a melhores resultados e o uso de técnicas do grupo de Melhoria Contínua que enfatizam um ambiente flexível se adequam melhor a essa cultura. De forma oposta, conclui-se que as técnicas da qualidade dos grupos de Medição e de Prevenção de Falhas e Controle que possuem características relacionadas à estabilidade e controle, não se adequam às características da cultura desenvolvimentista.

Referente à cultura de grupo, dentre todos os grupos de técnicas da qualidade, somente as técnicas pertencentes ao grupo de Medição não são adequadas às características dessa cultura. Para as empresas com características da cultura hierárquica, orientadas para o controle, apenas as técnicas do grupo de Melhoria Contínua mostraram não adequadas a esse perfil cultural.

Por fim, referente ao questionamento se o desempenho da empresa é influenciado pela combinação entre cultura organizacional e técnicas da qualidade, foi possível concluir que técnicas da qualidade contribuem para melhoria do desempenho desde que suportadas por características culturais apropriadas.

Em outras palavras, a cultura desenvolvimentista e de grupo exercem uma influência positiva, ou seja, contribui para um aumento do efeito no desempenho quando combinada aos quatro grupos de técnicas da qualidade consideradas nesse estudo. Já a cultura hierárquica reduz esse efeito para a maioria dos grupos de técnicas (Estabelecimento de Metas, Melhoria Contínua, e de Prevenção de Falhas e Controle), enquanto contribui para um aumento no desempenho, quando combinada às técnicas do grupo de Medição. Para a combinação da cultura racional com todos os grupos de técnicas considerados nesse estudo, não houve efeito algum no desempenho.

\subsection{Implicações teóricas}

Esse estudo apresenta uma contribuição teórica importante, pois, enquanto os estudos anteriores focam no estudo do relacionamento entre cultura organizacional e gestão da qualidade no nível de práticas da qualidade, ele estende essa análise para o nível das técnicas, considerando também a influência desse relacionamento no desempenho da empresa.

Assim, como implicações teóricas, ele confirma a visão pluralista da gestão da qualidade também nesse nível de análise e, além disso, fornece maior evidência 
empírica sobre a influência que a cultura organizacional exerce na gestão da qualidade e o impacto desse relacionamento no desempenho organizacional uma vez que os resultados mostram que, de forma a se obter melhores resultados a partir do uso dessas técnicas, é fundamental que elas estejam alinhadas a características culturais apropriadas.

\subsection{Implicações práticas}

Em geral, as técnicas da qualidade são consideradas como facilmente aplicáveis em qualquer empresa. Entretanto, como demonstrado nesse estudo, para obter os melhores resultados a partir do uso dessas técnicas, elas precisam estar alinhadas a características culturais apropriadas. Os resultados mostram que características culturais influenciam quais técnicas são mais adequadas para uma empresa e que o desempenho é melhorado quando existe uma combinação entre as técnicas da qualidade usada e as características culturais da empresa. Isso significa que a abordagem tradicional de se considerar as técnicas da qualidade igualmente aplicáveis a qualquer empresa independente de suas características não é adequada.

Dessa forma, essa pesquisa tem implicações práticas importantes para os gerentes no sentido de que eles precisam conhecer as características culturais de suas organizações para alcançar os melhores resultados a partir do uso das técnicas de qualidade. Por exemplo, para uma organização com características principalmente da cultura de grupo, seria muito mais difícil se beneficiar de técnicas relacionadas à medição do que de técnicas que são orientadas para as pessoas, tais como brainstorming e evento kaizen. Em contrapartida, para uma organização que enfatiza uma cultura desenvolvimentista, seria mais provável que a empresa alcançasse maiores benefícios a partir do uso de técnicas relacionadas ao desenvolvimento e melhoria de produtos e processos que a partir do uso de técnicas que estão, por exemplo, mais relacionadas a evitar as incertezas como aquelas pertencentes ao grupo de Prevenção de Falhas e Controle.

Além disso, espera-se com esse estudo fornecer diretrizes às empresas sobre quais técnicas seriam mais aplicáveis numa organização considerando suas características culturais e, assim, contribuir para melhoria dos casos de sucesso das iniciativas de gestão da qualidade. 


\subsection{Limitações do trabalho e pesquisas futuras}

Este estudo possui algumas limitações relacionadas ao método de pesquisa. Por exemplo, a coleta de dados via email apresenta limitações como auto compreensão das questões pelos respondentes e falta de controle sobre quem, de fato, participa da pesquisa. Além disso, a própria forma qualitativa na qual os itens foram medidos, principalmente, no que se refere aos indicadores de desempenho, acaba representando uma limitação para esse estudo.

Esta pesquisa teve, principalmente, uma abordagem descritiva cujo objetivo primário foi estudar a relação entre a cultura organizacional e o uso de técnicas da qualidade e o impacto desse relacionamento no desempenho operacional. Entretanto, para investigar os mecanismos que explicam as relações encontradas nesse estudo é necessário complementá-la utilizando outros métodos de pesquisa.

Assim, pesquisas futuras deveriam considerar a realização de entrevistas, pesquisa de campo e estudos longitudinais, com o objetivo de desenvolver uma compreensão profunda dos mecanismos por trás dos resultados estatísticos apresentados nesse trabalho. Isso permitiria investigar o mecanismo que explicaria, por exemplo, de que forma a cultura organizacional influencia na adoção de técnicas da qualidade e como essa influência afeta o desempenho operacional da empresa.

Essa pesquisa apresenta resultados interessantes como o que mostra que, dentre os perfis culturais estudados, a cultura racional está mais fortemente relacionada a todos os grupos de técnicas da qualidade considerados e que esta cultura não exerce efeito no desempenho operacional através dessas técnicas.

Dentro desse contexto, pesquisas utilizando abordagem qualitativa exploratória poderiam ser desenvolvidas para investigar, por exemplo, quais elementos (internos e externos) presentes numa organização com características predominantes da cultura racional contribuem para a adoção de todos os grupos de técnicas da qualidade investigadas nesse estudo de forma mais intensa que empresas com predominância de características de outros perfis culturais. Uma vez identificado esses elementos, realizar estudos qualitativos em outras empresas, também com características da cultura racional, de forma a comparar esses elementos ao longo de empresas com o mesmo perfil cultural, e identificar que mecanismos explicariam um efeito direto dessa cultura 
no desempenho operacional, mas não um efeito indireto por meio do uso de técnicas da qualidade.

Ainda, considerando que uma empresa não possui apenas um único e exclusivo perfil cultural, seria interessante estudar também qual seria a melhor combinação entre características de diferentes perfis culturais que contribuiria para um melhor resultado no desempenho a partir do uso de técnicas da qualidade. Essa consideração de culturas mistas poderia contribuir para eventuais diferenças de resultados apresentadas no desempenho operacional a partir do uso de técnicas da qualidade, por exemplo, em empresas que apresentam o mesmo perfil cultural predominante.

Além disso, outras variáveis contextuais poderiam afetar os resultados desse trabalho, caso outras variáveis fossem consideradas. Assim, em trabalhos futuros, é interessante explorar se os efeitos no desempenho seriam diferentes se variáveis como, por exemplo, estratégia competitiva, estratégia de manufatura ou mesmo o setor industrial fossem considerados.

Estudos cross-country também constituem oportunidades de realização de pesquisas futuras. Assim, estudos com o objetivo de identificar características peculiares e semelhantes entre diferentes países no que diz respeito a perfil cultural e práticas de gestão mostram-se interessantes. Considerando a amostra utilizada neste trabalho, novos estudos poderiam ser realizados separadamente de forma a identificar o perfil cultural das empresas estudadas na Dinamarca e as práticas e técnicas de gestão adotadas por elas, e no Brasil. Por fim, a amostra poderia ser expandida além desses dois países de forma a favorecer generalizações dos resultados. 


\section{Referências}

ANDERSON, J.C.; RUNGTUSANATHAN, M.; SCHROEDER, R.G.; DEVARAJ. S. (1995). A path analytic model of theory of quality management underlying the Deming Management method: preliminary empirical findings. Decision Sciences, v. 26, p. 637-658.

AHIRE, S. L.; DREYFUS, P. (2000). The impact of design management and process management on quality: an empirical investigation. Journal of Operations Management, $v$. 18 , p. 549-575.

AHIRE, S. L.; GOLHAR, D. Y.; WALLER, M. A. (1996). Development and Validation of TQM Implementation Constructs. Decision Sciences, v. 27, n. 1, p. 23-56.

AHUJA, I.P.S.; KHAMBA, J.S. (2008). Total productive maintenance: literature review and directions. International Journal of Quality \& Reliability Management, Bradford, v.25, n.7, p.709-756.

AKAO, Y. (1990). Quality Function Deployment, Productivity Press, Cambridge, MA.

ASIF, M.; DE BRUIJN, E.J.; DOUGLAS, A.; FISSCHER, O.A.M. (2009). Why quality management programs fail. International Journal of Quality \& Reliability Management, v.26, n.8, p. $778-794$.

BAIRD, K.; HU, K.; REEVE, R. (2011). The relationships between organizational culture, total quality management practices and operational performance. International Journal of Operations and Production Management, v.31, n.7, p. 789-814.

BAYO-MORIONES, A.; BELLO-PINTADO, A.; CERIO, J.M.D. (2010). 5S use in manufacturing plants: contextual factors and impact on operating performance, International Journal of Quality \& Reliability Management, v. 27, n. 2, p. 217-230.

BEER, M. (2003). Why TQM programs do not persist: the role of management quality and implications for leading a TQM transformation, Decision Sciences, v. 34, n. 4, p. 623-642.

BODEK, N. (2002). Kaizen: kaZam!. Training and Development, Alexandria, v.56, n.1, p.60.

BRIGHT, K.; COOPER, C. L. (1993). Organizational culture and the management of quality, Journal of Management Psycology, v.8, n.6, p. 21-27.

CAMERON, K.S.; FREEMAN, S.J. (1991). Cultural congruence, strength, and type: relationships to effectiveness, Research in Organizational Change and Development, v. 5, p. 23-58.

CAMERON, K. S.; QUINN, R. E. (2006). Diagnosing and changing organizational culture: based on the competing values framework, sl, Revised ed.

CÂNDIDO, C. J. F.; SANTOS, S. P. (2011). Is TQM more difficult to implemente than other transformational strategies? Total Quality Management. v. 22, n. 11, p. 1139-1164. 
CARPINETTI, L.C.R. (2012) Gestão da qualidade: conceitos e técnicas. São Paulo: Atlas. $2^{\mathrm{a} e d .}$

CARNEVAlLI, J. A.; MIGUEL, P. C. (2008). Review, analysis and classification of the literature on QFD - Types of research, difficulties and benefits. Internacional Journal of Production Economics, v. 114, n. 2, p.737-754.

CASSANElli, G.; MURA, G.; FANTINI, F.; VANZI, M.; PlANO, B. (2006). Failure Analysis-assisted FMEA. Microeletronics Reliability, v. 46, n. 9-11, p. 1795-1799.

CRONBACH, L. J. (1951). Coefficient alpha and the internal structure of tests. Psychometrika, v. 16, n. 3, p. 297-334.

DEAN, J.W.J.; BOWEN, D.E. (1994). Management theory and total quality: improving research and practice through theory development. Academy of Management Review, v. 19, p. $392-418$.

DENISON, D. R.; SPREITZER, G. M. (1991). Organizational culture and organizational development: a competing values approach. Research in Organizational Change and Development, v. 5, p. 1-21.

DETERT, J. R.; SCHROEDER, R. G.; MAURIEL, J. J. (2000). A framework for linking culture and improvement initiatives in Organizations. Academy of Management Review, v. 25 , n. 4 , p. $850-863$.

DEVELIN, N. (1995). Kaizen II: acelerando a melhoria contínua, uma corrida sem linha de chegada. São Paulo: IMAM.

DILLMAN, D. A. (1978). A Mail and telephone surveys: the total design method. Wiley, New York.

DILLMAN, D. A. (1991). The design and administration of mail survey. Annual Review of Sociology, v. 17. p. 225-249.

DOUGLAS, T. J.; JUDE JR, W. Q. (2001). Total quality management implementation and competitive advantage: the role of structural control and exploration, Academy of Management Journal. v. 44, n. 1, p. 158-169.

DOW, D., SAMSON, D.; FORD, S. (1999). Exploding the myth: do all quality management practices contribute to superior quality performance? Production and Operations Management, v. 8, n. 1, p. 1-27.

EBRAHIMI, M.; SADEGHI, M. (2013). Quality management and performance: an annotated review. International Journal of Production Research. v. 51, n. 18, p. 5625-5643.

FLYNN, B. B.; SCHOEDER, R. G.; SAKAKIBARA, S. (1994). A framework for quality management research and associated measurement instrument. Journal of Operations Management, v. 11, p. 339-366.

FLYNN, B. B.; SCHOEDER, R. G.; SAKAKIBARA, S. (1995). The impact of quality management practices on performance and competitive advantage. Decision Sciences, v. 26, n. 5, p. 659-691.

FORZA, C. (2008). Surveys. In. Researching Operations Management. Edited by Christen Karlsson, 1 edition. Routledge. 
FORKER, L. B.; VICKERY, S. K.; DROOGE, C. L. (1996). The contribution of quality to business performance. International Journal of Operations and Production Management, v. 16 , n. 8, p. 44-62.

FROHLICH, M.T. (2002). Techniques for improving response rates in OM survey research. Journal of Operations Management, v. 20, n. 1, p. 53-62.

GIMENEZ-ESPIN， J.A.; JIMÉNEZ-JIMÉNEZ， D.; MATÍNEZ-COSTA， M. (2012) Organizational culture for total quality management, Total Quality Management \& Business Excellence, v. 24, n. 5-6, p. 678-692.

GLOVER, W.J.; LIU, W. H.; FARRIS, J.A.; VAN AKEN, E.M. (2013). Characteristics of established kaizen event programs: an empirical study, International Journal of Operations \& Production Management, v. 33, n. 9, p. 1166-1201.

GUNASEKARAN, A. (1999). Enablers of total quality management implementation on manufacturing: a case study. Total quality management, v. 10, n. 7, p. 987-996.

HACKMAN, J. R; WAGEMAN, R. (1995). Total Quality Management: Empirical, conceptual, and practical issues. Administrative Science Quartely, v. 40, n. 2, 1995, p. 309-342.

HAIR, J.F.; BLACK, W.C.; BABIN, B.J.; ANDERSON, R.E. (2009). Análise Multivariada de Dados. $6^{\mathrm{a}}$ ed. Porto Alegre: Bookman.

HANDFIELD, R.; JAYARAM, J.; GHOSH, S. (1999). An empirical examination of quality tool deployment patterns and their impact on performance. International Journal of Production Research, v. 37, n. 6, p. 1403-1426.

HARARI, O. (1993). Ten reasons why TQM doesn't work. Management Review, v. 82, n. 1, p. 33-38.

HOFSTEDE, G. (2001). Culture's Consequence, $2^{\text {nd }}$ ed. Sage, Beverly Hills, CA.

HUBIAK, W. A.; O'DONNEL, S.J. (1996). Do Americans have their minds set against TQM? National Productivity Review, v.15, p. 19-20.

IRANI, Z., BESKESE, A.; LOVE, P.E.D. (2004). Total quality management and corporate culture: constructs of organisational excellence, Technovation, v.24, p. 643-650.

ISHIKAWA, K. (1985). What is Total Quality Control? The Japanese Way, Prentice-Hall, Englewood Cliffs, NJ.

JAYARAM, J.; AHIRE, S. L.; DREYFUS, P. (2010). Contingency relationships of firm size, TQM duration, unionization, and industry context on TQM implementation - A focus on total effects. Journal of Operations Management. v.28, p. 345-356.

KAYNAK, H. (2003). The relationship between total quality management practices and their effects on firm performance. Journal of Operations Management, v. 21, p. 405-435.

KLINE, R. B. (2011). Principles and Practice of Structural Equation Modeling, The Guilford Press, New York, NY.

KUJALA, J.; LILLRANK, P. (2004). Total quality management as a cultural phenomenon, Quality Management Journal, v. 11 n. 4, p. 43-55. 
KULL, T. J.; WACKER, J. G. (2010). Quality management effectiveness in Asia: The influence of culture. Journal of Operations Management, v. 28, p. 223-239.

KUTNER, M.H.; NACHTSHEIM, C.J.; NETER, J. (2004). Applied Linear Regression Models, McGraw-Hill Irwin, New York, NY.

LIKER, J.K. (2005). O Modelo Toyota: 14 princípios de gestão do maior fabricante do mundo. Porto Alegre: Bookman.

MAULL, R.; BROWN, P.; CLIFFE, R. (2001). Organisational culture and quality improvement. International Journal of Operations and Production Management, v.21, n. 3, p. 302-312.

McQUATER, R.E.; SCURR, C.H.; DALE, B.G.; HILLMAN, P.G. (1995). Using quality tools and techniques successfully. The TQM Magazine, v. 7, n. 6, p. 37-42.

MEHRA, S.; HOFFMAN, J.M.; SIRIAS, D. (2001). TQM as a management strategy for the next millennia, International Journal of Operations \& Production Management, v. 21, n. $5 / 6$, p. 855-877.

MODARESS, B.; ANSARI, A. (1989). Quality control techniques in US firms: a survey. Production and Inventory Management Journal, v. 30, p. 58-62.

MOLINA, L.M.; MONTES, J.M.; MORENO, A.R. (2007). Relationship between quality management practices and knowledge transfer. Journal of Operations Management, v. 25, n. 3, p. 682-701.

MOOSA, K.; SAJID, A.; KHAN, R. A.; MUGHAL, A. (2010). An empirical study of TQM implementation: examination of aspects versus impacts. Asian Business \& Management, v. 9, n. 4 , p. 525-551.

NAOR, M.; GOLDSTEIN, S.M.; LINDERMAN, K.W.; SCHROEDER, R.G. (2008). The role of culture as driver of quality management and performance infrastructure versus core quality practices. Decision Sciences, v. 39, n. 4, p. 671-702.

NEELY, A.; GREGORY, M.; PLATTS, K. (2005). Performance measurement system design: a literature review and research agenda, International Journal of Operation \& Production Management, v. 25, n.12, p. 1228-1263.

O'REILLY III, C.A.; CHATMAN, J.; CALDWELL, D.F. (1991). People and Organizational culture: a profile comparison approach to assessing person-organization fit. Academy of Management Journal, v. 34, n. 3, p. 487-516.

PINTO, S. H. B.; CARVALHO, M. M.; HO, L. L. (2006). Implementação de programas de qualidade: um survey em empresas de grande porte no Brasil. Gestão e Produção, v. 13, n. 2, p.191-203.

POWELL, T. (1995). TQM as competitive advantage: a review and empirical study, Strategic Management Journal, v.16, n. 1, p. 15-37.

PRAJOGO, D. I.; McDERMOTT, C. M. (2005). The relationship between total quality management practices and organizational culture. International Journal of Operation and Production Management, v.25, n.11, p. 1101-1122. 
PRAJOGO, D. I.; McDERMOTT, C. M. (2011). The relationship between multidimensional organization culture and performace. International Journal of Operation and Production Management, v.31, n.7, p. 712-735.

QUINN, R.E.; ROHRBAUGH, J. (1981). A competing values approach to organizational effectiveness, Public Productivity Review, v. 5, pp. 122-140.

QUINN, R; ROHRBAUGH, J. (1983). A Spatial model of effectiveness criteria: towards a competing values approach to Organizational Analysis, Management Science, v. 29, p. 363377.

RAD, A. M. M. (2006). The impact of organizational culture on the successful implementation of total quality management. The TQM Magazine. v. 18, n. 6, p. 606-625.

RAHMAN, S.; BULLOCK, P. (2005). Soft TQM, hard TQM, and organisational performance relationships: an empirical investigation, Omega, v.33, p.73-83.

SAMSON, D.; TERZIOVSKI, M. (1999). The relationship between total quality management practices and operational performance. Journal of Operations Management, v. 17, n. 4, p. 393-409.

SARAPH, J. V.; BENSON, P. G.; SCHROEDER, R. G. (1989). An instrument for measuring the critical factors of quality management. Decision Sciences, v. 20, n. 4, p. 810-829.

SCHEIN, E. H. (1984). Coming to a new awareness of organizational culture, Sloan Management Review, v.25, p. 3-16.

SHAEFFER, D. R.; DILLMAN, D. A. (1998). Development of a standard e-mail methodology: results from an experiment. Public Opinion Quarterly. V. 62, p. 378-397.

SHAH, R; GOLDSTEIN, S. M. (2006). Use of structural equation modeling in operations management research: looking back and forward. Journal of Operations Management, v. 24, p. $148-169$.

SILA, I. (2007). Examining the effects of contextual factors on TQM and performance through the lens of organizational theories: an empirical study. Journal of Operations Management, v. 25 , p. 83-109.

SILA, I.; EBRAHIMPOUR, M. (2005). Critical linkages among TQM factors and business results. International Journal of Operations and Production Management. v. 25, n. 11, p. 1123-1155.

SINGH, L.P.; BHARDWAJ, A.; SACHDEVA, A. (2009). The impact of quality management tools on performance: an exploratory study on SMEs, IUP Journal of Operations Management, v. 8, n. 3-4, p. 61-70.

SITKIN, S. B.; SUTCLIFFE, K. M.; SCHROEDER, R. G. (1994). Distinguishing control from learning in Total Quality Management: a contingency perspective. Academy of Management Review, v. 19, n. 3, p. $537-564$.

STEWART, D.M.; GROUT, J. R. (2001). The human side of mistake proofing, Production and Operations Management, v. 10, n. 4, p. 440-459. 
SUN, H.; YAM, R.; WAI-KEUNG, N. (2003). The implementation and evaluation of total productive maintenance (TPM) - an action case study in a Hong Kong manufacturing company. International Journal of Advanced Manufacturing Technology, v.22, n.3/4, p.224-228.

SOHAL, A.S.; TERZIOVSKI, M.; (2000). TQM in Australian manufacturing: Factors critical to success. International Journal of Quality \& Reliability Management v.17, n. 2, p. 158-167.

SOUSA R.; VOSS C. A. (2001). Quality Management: universal or context dependent? Production and Operations Management. v. 10, n. 4, p.383-404.

SOUSA, R.; VOSS, C. (2002). Quality management re-visited: a reflective review and agenda for future research. Journal of Operations Management, v. 20, n.1, p. 91-109.

STREINER, D. L. (2003) Being inconsistent about consistency: when coefficient alpha does and doesn't matter. Journal of Personality Assessment, v.80, n. 3, p. 217-222.

TABACHNIK, B.G.; FIDELL, L.S. (2007). Using Multivariate Statistics, Pearson, NY.

TARÍ, J.J.; SABATER, V. (2004). Quality tools and techniques: are they necessary for quality management? International Journal of Production Economics, v. 29, n. 3, p. 267-280.

TARÍ, J.J.; MOLINA, J.F.; CASTEJÓN, J.L. (2007). The relationship between quality management practices and their effects on quality outcomes. European Journal of Operational Research, v.183, n. 2, p. 483-501.

TATA, J.; PRASAD, S. (1998). Cultural and structural constraints on total quality management implementation. Total Quality Management, v. 9, n.8, p. 703-710.

TSOU, J.C.; CHEN, J.M. (2005). Dynamic model for a defective production system with pokayoke. The Journal of the Operational Research Society, v.56, n. 7, p. 799-803.

UNDERDOWN, R.; TALLURI, S. (2002). Cycle of success: a strategy for becoming agile through benchmarking. Benchmarking: An International Journal, v. 9, n. 3, p. 278-292.

UNGAN, M. (2004). Factors affecting the adoption of manufacturing best practices. Benchmarking: An Internacional Journal, v. 11, n. 5, p. 504-520.

WATSON, J. G.; KORUKONDA, A. R. (1995). The TQM jungle: a dialectical analysis, International Journal of Quality \& Reliability Management, v.7, n.9, p.100-109.

WOMACK, J.P; JONES, D.T.; ROOS, D. (1990). The Machine that Changed the World, Rawson Associates, New York, NY.

WU, S. J; ZHANG, D.; SCHROEDER, R. G. (2011). Customization of quality practices: the impact of quality culture. International Journal of Quality \& Reliability Management, v. 28, n. 3, p. 263-279.

WU, S.; ZUO, M.J. (2010). Linear and nonlinear preventive maintenance models. IEE Transactions on Reliability, v. 59, n. 1, p. 242-249.

ZEITZ, G.; JOHANNENSE, R.; RITCHIE, J. J. E. (1997). An employee survey measuring total quality management practices and culture. Group and Organizational Management, v. 22, n. 4, p. 414-444. 
ZU, X.; ROBBINS, T. L.; FREDENDALL, L. D. (2010). Mapping the critical links between organizational culture and TQM/Six Sigma practices. International Journal of Production Economics, v. 123, p. 86-106. 


\section{APÊNDICE A - Elementos de gestão da qualidade identificados na revisão da literatura}

\begin{tabular}{|c|c|c|}
\hline $\begin{array}{c}\text { Termos identificados na revisão da } \\
\text { literatura } \\
\end{array}$ & Autores & Elemento da qualidade \\
\hline Suporte da alta direção & Flynn et al (1994), Naor et al (2008), Zu et al (2009) & \multirow{4}{*}{ Liderança } \\
\hline Envolvimento da alta direção & Douglas \& Judge (2001) & \\
\hline Comprometimento da alta direção & Ahire et al (1996), Jayaram et al (2010) & \\
\hline Liderança & Beer (2003), Sila \& Ebrahimpour (2005), Prajogo \& McDermott (2005) & \\
\hline Foco nos recursos humanos & Mehra et al (2001) & \multirow{4}{*}{ Gestão das pessoas } \\
\hline Gestão da força de trabalho & Flynn et al (1994), Naor et al (2008), Zu et al (2009) & \\
\hline Gestão das pessoas & Prajogo \& McDermott (2005) & \\
\hline Gestão dos recursos humanos & Sila \& Ebrahimpour (2005) & \\
\hline Treinamento & $\begin{array}{l}\text { Ahire et al (1996), Douglas \& Judge (2001), Flynn et al (1994), } \\
\text { Hackman \& Wageman (1995), Jayaram et al (2010), Rahman \& } \\
\text { Bullock (2005); Wu et al (2010) }\end{array}$ & Treinamento \\
\hline Uso de times & Rahman \& Bullock (2005) & \multirow{3}{*}{ Trabalho em times } \\
\hline Trabalho em times & Beer (2003), Flynn et al (1994), Wu et al (2010) & \\
\hline Times cross funcionais & Beer (2003), Hackman \& Wageman (1995) & \\
\hline Empowerment & Ahire et al (1996), Jayaram et al (2010), Wu et al (2011) & Empowerment \\
\hline Envolvimento dos funcionários & Ahire et al (1996) & Comprometimento dos \\
\hline Comprometimento da força de trabalho & Rahman \& Bullock (2005) & funcionários \\
\hline Gestão da qualidade dos fornecedores & $\begin{array}{l}\text { Ahire et al (1996), Baird et al (2011), Jayaram et al (2010), Sila \& } \\
\text { Ebrahimpour (2005), Zu et al (2009) }\end{array}$ & \multirow{6}{*}{$\begin{array}{l}\text { Gestão da qualidade do } \\
\text { fornecedor }\end{array}$} \\
\hline Relacionamento com os fornecedores & Rahman \& Bullock (2005), Zu et al (2009) & \\
\hline Desempenho do fornecedor & Ahire et al (1996) & \\
\hline Suporte dos fornecedores & Mehar el al (2001) & \\
\hline Seleção dos fornecedores & Beer (2003) & \\
\hline Envolvimento dos fornecedores & Flynn et al (1994), Naor et al (2008) & \\
\hline Foco no consumidor & $\begin{array}{l}\text { Ahire et al (1996), Douglas \& Judge (2001), Hackman \& Wageman } \\
\text { (1995), Jayaram et al (2010), Rahman \& Bullock (2005), Sila \& } \\
\text { Ebrahimpour (2005), Wu et al (2010), Prajogo \& McDermott (2005) }\end{array}$ & \multirow{5}{*}{ Foco no consumidor } \\
\hline Orientação para o consumidor & Mehra et al (2001) & \\
\hline Relacionamento com o consumidor & Zu et al (2009) & \\
\hline Criação de parcerias com o consumidor & Hackman \& Wageman (1995) & \\
\hline Envolvimento dos consumidores & Flynn et al (1994), Naor et al (2008) & \\
\hline Princípios do Just in time & Rahman \& Bullock (2005) & Excluído \\
\hline Visão compartilhada & Rahman \& Bullock (2005) & \multirow{2}{*}{ Relação ganha-ganha } \\
\hline Colaboração & Beer (2003) & \\
\hline Melhoria contínua & Douglas \& Judge (2001), Hackman \& Wageman (1995) & \multirow{2}{*}{ Melhoria contínua } \\
\hline Possibilitadores de melhoria contínua & Rahman \& Bullock (2005) & \\
\hline Uso de informações da qualidade & $\begin{array}{l}\text { Ahire et al (1996), Flynn et al (1994), Jayaram et al (2010), Naor et al } \\
\text { (2008), Sila \& Ebrahimpour (2005) }\end{array}$ & \multirow[t]{2}{*}{ Uso de dados da qualidade } \\
\hline Qualidade dos dados e relatórios & Baird et al (2011), Zu et al (2009) & \\
\hline Gestão baseada em fatos & Douglas \& Judge (2001) & \multirow{2}{*}{ Decisão baseada em dados } \\
\hline Uso da abordagem científica & Beer (2003), Hackman \& Wageman (1995) & \\
\hline Gestão dos processos & $\begin{array}{l}\text { Baird et al (2011), Beer (2003), Flynn et al (1994), Hackman \& } \\
\text { Wageman (1995), Jayaram et al (2010), Naor et al (2008), Sila \& } \\
\text { Ebrahimpour (2005), Wu et al (2010), Zu et al (2009), Prajogo } \\
\text { McDermott (2005) }\end{array}$ & Gestão dos processos \\
\hline Filosofia da qualidade & Douglas \& Judge (2001) & Excluído \\
\hline Desenvolvimento produto & $\begin{array}{l}\text { Baird et al (2011), Flynn et al (1994), Naor et al (2008), Zu et al (2009), } \\
\text { Prajogo \& McDermott (2005) }\end{array}$ & \multirow[t]{2}{*}{ Desenvolvimento do produto } \\
\hline Qualidade do produto & Ahire et al (1996) & \\
\hline Benchmarking & $\begin{array}{l}\text { Ahire et al (1996), Hackman \& Wageman (1995), McQuarter et al } \\
\text { (1995) }\end{array}$ & Benchmarking \\
\hline Resultado dos negócios & Sila \& Ebrahimpour (2005) & Excluído \\
\hline Planejamento estratégico & Prajogo \& McDermott (2005), Sila \& Ebrahimpour (2005) & Excluído \\
\hline
\end{tabular}


Conclusão

\begin{tabular}{|c|c|c|}
\hline $\begin{array}{l}\text { Termos identificados na revisão da } \\
\text { literatura }\end{array}$ & Autores & Elemento da qualidade \\
\hline Desempenho da gestão do estoque & Mehra et al (2001) & \multirow{3}{*}{ Medição de desempenho } \\
\hline Desempenho da qualidade & Mehra et al (2001) & \\
\hline Foco na métrica & Zu et al (2009) & \\
\hline Sistemas de medição de desempenho & Carpinetti (2012) & $\begin{array}{l}\text { Sistema de medição de } \\
\text { desempenho }\end{array}$ \\
\hline Uso de tecnologia & Rahman \& Bullock (2005) & \multirow{2}{*}{ Excluído } \\
\hline Uso de tecnologia de informação & Rahman \& Bullock (2005) & \\
\hline DMAIC & Pinto et al (2006), Zu et al (2009) & \multirow{2}{*}{$\begin{array}{l}\text { Métodos estruturados para } \\
\text { melhoria contínua }\end{array}$} \\
\hline PDCA & Carpinetti (2012), Pinto et al (2006) & \\
\hline Procedimento Operacional Padrão (POP) & Flynn et al (1994) & $\begin{array}{l}\text { Procedimento Operacional } \\
\text { Padrão (POP) }\end{array}$ \\
\hline $\begin{array}{l}\text { Análise do Modo e Efeito da Falha } \\
\text { (FMEA) }\end{array}$ & $\begin{array}{l}\text { Carpinetti (2012), Handfield (1999), McQuarter et al (1995), Pinto et al } \\
\text { (2006) }\end{array}$ & $\begin{array}{c}\text { Análise do Modo e Efeito da } \\
\text { Falha (FMEA) }\end{array}$ \\
\hline Delineamento de experimentos (DOE) & Handfield et al (1999), McQuarter et al (1995), Pinto et al (2006) & \multirow{4}{*}{ Uso de técnicas estatísticas } \\
\hline Método Taguchi & Ahire et al (1996) & \\
\hline Controle Estatístico do Processo (CEP) & Ahire et al (1996), Carpinetti (2012), Handfield et al (1999) & \\
\hline Design for Six Sigma (DFSS) & Carpinetti (2012), Pinto et al (2006), Zu et al (2009) & \\
\hline Dispositivo a prova de erros & Ahire et al (1996), McQuarter et al (1995) & Poka Yoke \\
\hline Gestão da qualidade do projeto & Ahire et al (1996), Jayaram et al (2010) & \multirow{3}{*}{$\begin{array}{l}\text { Desdobramento da Função } \\
\text { Qualidade (QFD) }\end{array}$} \\
\hline $\begin{array}{l}\text { Identificação de requerimentos dos } \\
\text { consumidores }\end{array}$ & Beer (2003) & \\
\hline $\begin{array}{l}\text { Desdobramento da Função Qualidade } \\
\text { (QFD) }\end{array}$ & $\begin{array}{l}\text { Ahire et al (1996), Carpinetti (2012), Handfield et al (1999), McQuarter } \\
\text { et al (1995) }\end{array}$ & \\
\hline $5 \mathrm{~S}$ & Carpinetti (2012), Pinto et al (2006) & \multirow{2}{*}{$5 \mathrm{~S}$} \\
\hline Limpeza e Organização & Flynn et al (1994) & \\
\hline Programas de sugestões & Handfield et al (1999), Pinto et al (2006) & \multirow{2}{*}{ Evento Kaizen } \\
\hline Programas de melhoria contínua & Handfield et al (1999) & \\
\hline Ferramentas da qualidade & $\begin{array}{l}\text { Carpinetti (2012), Douglas \& Judge (2001), Handfield et al (1999), } \\
\text { McQuarter et al (1995), Mehra et al (2001) }\end{array}$ & Ferramentas da qualidade \\
\hline Brainstorming & McQuarter et al (1995) & Brainstorming \\
\hline Manutenção preventiva & Handfield et al (1999) & Manutenção preventiva \\
\hline Manutenção Produtiva Total (TPM) & Pinto et al (2006) & Manutenção Produtiva Total \\
\hline Seis Sigma & Carpinetti (2012), Pinto et al (2006), Zu et al (2009) & Seis Sigma \\
\hline Inspeção da qualidade & Handfield (1999), Naor et al (2008) & Inspeção da qualidade \\
\hline Certificação de fornecedores & Naor et al (2008) & Certificação de fornecedores \\
\hline
\end{tabular}




\section{APÊNDICE B - Variáveis utilizadas em pesquisas survey para medição de cultura organizacional}

\begin{tabular}{|c|c|c|}
\hline & Variáveis medidas para Cultura Organizacional & Autores \\
\hline \multirow{14}{*}{ 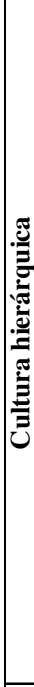 } & Mesmo decisões simples precisam ser levadas a um nível mais alto para uma resposta final & \multirow{4}{*}{ Naor et al ., 2008} \\
\hline & Qualquer decisão que eu tome precisa ter a aprovação do meu chefe & \\
\hline & Pouca atenção é dada até que um supervisor aprove uma decisão & \\
\hline & Nossa organização é muito hierárquica & \\
\hline & Controle, centralização & \multirow{4}{*}{$\begin{array}{c}\text { Prajogo \& } \\
\text { McDermott, 2011, } \\
\text { Zu et al, 2010 }\end{array}$} \\
\hline & Rotina, formalização e estrutura & \\
\hline & Estabilidade, continuidade e ordenação & \\
\hline & Resultados de desempenho previsíveis & \\
\hline & Os líderes da organização são geralmente considerados coordenadores, organizadores ou técnicos eficientes & \multirow{6}{*}{$\begin{array}{l}\text { Cameron \& } \\
\text { Quinn, } 2006\end{array}$} \\
\hline & $\begin{array}{l}\text { A organização enfatiza a continuidade e a estabilidade. Eficiência, controle e funcionamento sem transtornos são } \\
\text { importantes }\end{array}$ & \\
\hline & $\begin{array}{l}\text { A organização define sucesso com base na eficiência. Cumprir prazos, seguir a programação facilmente e produzir a } \\
\text { baixos custos são fatores críticos }\end{array}$ & \\
\hline & $\begin{array}{l}\text { O que mantém a organização unida são regras formais e políticas estabelecidas. Manter a organização funcionando sem } \\
\text { conflitos é importante }\end{array}$ & \\
\hline & \multirow{2}{*}{$\begin{array}{l}\text { O estilo gerencial na organização é caracterizado por estabilidade no emprego, conformidade, previsibilidade e } \\
\text { estabilidade nas relações } \\
\text { A organização é um lugar controlado e estruturado. Procedimentos formais geralmente governam o que as pessoas } \\
\text { fazem }\end{array}$} & \\
\hline & & \\
\hline \multirow{14}{*}{ 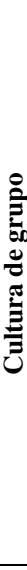 } & Supervisores encorajam as pessoas a trabalharem em times & \multirow{4}{*}{ Naor et al , 2008} \\
\hline & Supervisores encorajam os funcionários a trocarem experiências, opiniões e ideias & \\
\hline & Os funcionários podem discutir abertamente sobre suas opiniões e ideias com seus chefes & \\
\hline & Equipes para solução de problemas são formadas em nossa empresa & \\
\hline & Participação e discussão aberta & \multirow{4}{*}{$\begin{array}{c}\text { Prajogo \& } \\
\text { McDermott, 2011, } \\
\text { Zu et al, 2010 }\end{array}$} \\
\hline & Os funcionários são encorajados a tomarem decisões & \\
\hline & As ideias e preocupações dos funcionários são avaliadas & \\
\hline & Relações humanas, trabalho em equipe e coesão & \\
\hline & A organização enfatiza o desenvolvimento humano. Alta confiança, transparência e participação persistem & \multirow{6}{*}{$\begin{array}{l}\text { Cameron \& } \\
\text { Quinn, } 2006\end{array}$} \\
\hline & $\begin{array}{l}\text { A organização é um lugar muito pessoal, como uma familia. As pessoas repartem suas experiências tanto pessoais } \\
\text { como de trabalho }\end{array}$ & \\
\hline & O que mantém a organização unida é a lealdade e a confiança mútua. O comprometimento com a organização é alto & \\
\hline & $\begin{array}{l}\text { A organização define sucesso com base no desenvolvimento de recursos humanos, trabalho em equipe, } \\
\text { comprometimento com o emprego e a preocupação com as pessoas }\end{array}$ & \\
\hline & O estilo gerencial da organização é caracterizado por trabalho em equipe, consenso e participação & \\
\hline & Os líderes da organização são geralmente considerados mentores, facilitadores e estimuladores & \\
\hline \multirow{14}{*}{ 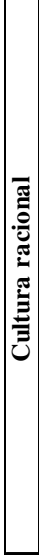 } & Nosso sistema de incentivo nos encoraja vigorosamente a perseguir os objetivos da planta & \multirow{4}{*}{ Naor et al., 2008} \\
\hline & O sistema de incentivo da empresa é satisfatório em recompensar as pessoas que cumprem os objetivos da empresa & \\
\hline & Nosso sistema de recompensa realmente recompensa as pessoas que mais contribuem para a empresa & \\
\hline & Nosso sistema de incentivo nos encoraja a alcançar as metas da empresa & \\
\hline & Foco na tarefa, realização e alcance das metas & \multirow{4}{*}{$\begin{array}{c}\text { Prajogo \& } \\
\text { McDermott, 2011, } \\
\text { Zu et al, } 2010\end{array}$} \\
\hline & Direção, estabelecimento de objetivos e claridade das metas & \\
\hline & Eficiência, produtividade e lucratividade & \\
\hline & Excelência nos resultados, qualidade & \\
\hline & Os líderes da organização são geralmente considerados exemplos de seriedade, ambição e orientação para resultados & \multirow{6}{*}{$\begin{array}{l}\text { Cameron \& Quinn, } \\
2006\end{array}$} \\
\hline & O estilo gerencial na organização é caracterizado por uma competitividade energética, exigências e realização & \\
\hline & $\begin{array}{l}\text { A organização define sucesso com base no ganho e na liderança de mercado. A liderança no mercado competitivo é conceito } \\
\text { chave }\end{array}$ & \\
\hline & $\begin{array}{l}\text { A organização enfatiza a ação competitiva e o alcance dos resultados. Atingir metas difíceis e satisfazer o mercado são } \\
\text { prioridades }\end{array}$ & \\
\hline & $\begin{array}{l}\text { A organização é orientada para resultados. A maior preocupação é concluir o trabalho a ser realizado. As pessoas são } \\
\text { competitivas e buscam realização profissional }\end{array}$ & \\
\hline & A ênfase em resultados e realização de metas mantêm a organização unida. Agressividade & \\
\hline
\end{tabular}


Conclusão

\begin{tabular}{|c|c|c|}
\hline & Variáveis medidas para Cultura Organizacional & Autores \\
\hline \multirow{13}{*}{ 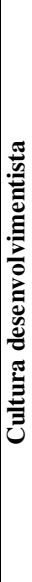 } & Nós buscamos programas de longo alcance de forma a obter condições de manufatura antecipadas às nossas necessidades & \multirow{4}{*}{ Naor et al, 2008} \\
\hline & Nós nos esforçamos em antecipar potenciais novas práticas e tecnologias de manufatura & \\
\hline & Nossa empresa ocupa posição de ponta em nova tecnologia na nossa indústria & \\
\hline & Nós estamos constantemente pensando na próxima geração de tecnologia de produção & \\
\hline & Flexibilidade, descentralização & \\
\hline & Expansão, crescimento e desenvolvimento & McDermott 2011. \\
\hline & Inovação e mudança & Zu et al, 2010 \\
\hline & Processos criativos de solução de problemas & \\
\hline & O estilo gerencial na organização é caracterizado por ac eitar riscos individualmente, inovação, liberdade e singularidade & \multirow{5}{*}{$\begin{array}{l}\text { Cameron \& Quinn, } \\
2006\end{array}$} \\
\hline & $\begin{array}{l}\text { O que mantém a organização unida é o comprometimento com a inovação e desenvolvimento. Há uma ênfase em estar na } \\
\text { vanguarda }\end{array}$ & \\
\hline & A organização define sucesso com base em ter os produtos mais novos ou diferenciados. É uma líder e inovadora de produtos & \\
\hline & $\begin{array}{l}\text { A organização enfatiza a obtenção de novos recursos e a criação de novos desafios. Experimentar coisas novas e buscar } \\
\text { oportunidades são ações valorizadas }\end{array}$ & \\
\hline & A organização define sucesso com base em ter os produtos mais novos ou diferenciados. É uma líder e inovadora de produtos & \\
\hline
\end{tabular}




\section{APÊNDICE C - Variáveis utilizadas em pesquisas survey para medição de elementos da qualidade}

\begin{tabular}{|c|c|}
\hline Variáveis medidas para as técnicas de Gestão da Qualidade & Autores \\
\hline O CEP é utilizado extensivamente em nossa empresa & \multirow{17}{*}{ Ahire et al, 1996} \\
\hline O CEP tem sido efetivo na melhoria da qualidade dos nossos produtos & \\
\hline Nós continuaremos a usar o CEP na fabricação de nossos produtos & \\
\hline Os funcionários da produção são bem treinados em CEP & \\
\hline A maioria dos funcionários é treinada no uso de ferramentas da qualidade como diagrama de causa-e-efeito & \\
\hline O progresso em direção as metas relacionadas à qualidade está disponível na nossa empresa & \\
\hline Os funcionários da linha de produção são encorajados a corrigir os erros que eles encontram & \\
\hline Os funcionários da linha de produção possuem assistência técnica disponível para solução de problemas & \\
\hline Nós usamos técnicas de prevenção de erros no desenho dos processos de manufatura & \\
\hline O QFD é utilizado no desenvolvimento de nossos produtos & \\
\hline Nós estamos engajados em fazer benchmarking dos processos de negócios de outras empresas & \\
\hline Nossas atividades de benchmarking têm reduzido nossos custos & \\
\hline $\begin{array}{l}\text { Nós estamos engajados em comparar nossos produtos com produtos semelhantes aos de nossos } \\
\text { competidores }\end{array}$ & \\
\hline Benchmarking tem ajudado na melhoria dos nossos produtos & \\
\hline Os funcionários são encorajados a darem sugestões & \\
\hline Times "cross functional" são frequentemente utilizados & \\
\hline Todas as sugestões dadas pelos funcionários são avaliadas & \\
\hline Grande parte dos equipamentos ou processos no chão de fábrica estão sob controle estatístico da qualidade & \multirow{3}{*}{$\begin{array}{c}\text { Flynn et al ., 1998, Naor } \\
\text { et al. } 2008, \mathrm{Zu} \text { et al } \\
2010\end{array}$} \\
\hline Nós fazemos uso extensivo de técnicas estatísticas para reduzir a variação no processo & \\
\hline Nós somos orgulhosos em manter nossa área de trabalho limpa e arrumada & \\
\hline Nossa empresa enfatiza manter o ambiente de trabalho organizado, tendo para cada coisa um local apropriado & \multirow{4}{*}{$\begin{array}{l}\text { Flynn et al ., 1994, Naor } \\
\quad \text { et al } 2008\end{array}$} \\
\hline Nossa área de trabalho é mantida limpa todo o tempo & \\
\hline Eu geralmente tenho problemas em encontrar os materiais que eu preciso & \\
\hline Nosso ambiente de trabalho é sujo e desorganizado & \\
\hline Nós monitoramos o processo usando CEP & \multirow[b]{2}{*}{ Naor et al 2008} \\
\hline $\begin{array}{l}\text { Em nossa organização, trazer uma variedade de perspectivas para solução de problemas direciona a melhores } \\
\text { soluções }\end{array}$ & \\
\hline Gráficos que apresentam a taxa de defeitos estão disponíveis no chão de fábrica & \multirow{5}{*}{ Flynn et al 1994} \\
\hline Gráficos mostram a frequência de paradas das máquinas & \\
\hline Informações de produtividade estão prontamente disponíveis aos funcionários & \\
\hline Nossa empresa forma times para solucionar problemas & \\
\hline $\begin{array}{l}\text { Durante as sessões de solução de problemas, nós fazemos um esforço para conseguir as opiniões e ideias de } \\
\text { todos os membros do grupo antes que a decisão seja tomada }\end{array}$ & \\
\hline $\begin{array}{l}\text { Dados de qualidade (taxa de erros, defeitos, refugos custo da qualidade, etc) estão prontamente disponíveis } \\
\text { em nossa empresa }\end{array}$ & $\begin{array}{l}\text { Ahire et al. 1996, Zu et } \\
\text { al. } 2010 \\
\end{array}$ \\
\hline Os dados de qualidade estão disponíveis aos gerentes, supervisores, engenheiros e demais funcionários & \multirow{11}{*}{ Zu et al. 2010} \\
\hline $\begin{array}{l}\text { Nós incluímos no planejamento de nossas atividades, tempo destinado somente para manutenção dos } \\
\text { equipamentos }\end{array}$ & \\
\hline Nossa empresa faz manutenção preventiva dos equipamentos & \\
\hline $\begin{array}{l}\text { Os processos em nossa empresa são desenhados para serem "a prova de erros", ou seja, minimizarem as } \\
\text { chances de ocorrência dos erros }\end{array}$ & \\
\hline $\begin{array}{l}\text { Nossa empresa estabelece metas estratégicas para a melhoria da qualidade de forma a melhorar seu } \\
\text { desempenho financeiro }\end{array}$ & \\
\hline Em nossa empresa as metas da qualidade são desafiadoras & \\
\hline Em nossa empresa as metas da qualidade são claras e específicas & \\
\hline $\begin{array}{l}\text { Nossa empresa faz uma revisão completa do desenvolvimento de novos produtos/serviços antes de eles serem } \\
\text { produzidos }\end{array}$ & \\
\hline Nós desenvolvemos produtos para serem "manufaturáveis" & \\
\hline Nós fazemos um esforço para listar especificações que são claramente necessárias & \\
\hline Nossa empresa traduz as necessidades e expectativas dos clientes em metas da qualidade & \\
\hline Gráficos mostrando o acompanhamento da produção estão disponíveis no chão de fábrica & $\begin{array}{l}\text { Flynn et al ., 1994, Zu et } \\
\text { al. } 2010 \\
\end{array}$ \\
\hline Informações sobre o desempenho da qualidade é prontamente disponível para os funcionários & $\begin{array}{c}\text { Ahire et al. 1996, Flynn } \\
\text { et al ., } 1994\end{array}$ \\
\hline Nós trabalhamos em times, com funcionários de diferentes áreas para o desenvolvimento de novo & \begin{tabular}{|l} 
Naor et al 2008, Zu et al. \\
2010
\end{tabular} \\
\hline
\end{tabular}




\section{APÊNDICE D - Variáveis utilizadas em pesquisas survey para medição de desempenho}

\begin{tabular}{|c|c|}
\hline Variáveis medidas para as técnicas de Desempenho & Autores \\
\hline Turnover do estoque & \multirow{7}{*}{ Naor et al. (2008) } \\
\hline Tempo do ciclo (do recebimento do material até o carregamento) & \\
\hline Custo unitário da manufatura & \\
\hline Desempenho e confiabilidade do produto & \\
\hline Velocidade da entrega & \\
\hline Flexibilidade para mudar a variedade do produto & \\
\hline Flexibilidade para mudar o volume & \\
\hline Entrega no tempo & $\begin{array}{c}\text { Naor et al. (2008); } \\
\text { Samson \& Terziovski }\end{array}$ \\
\hline Turnover do material comprado e do material total & \multirow{5}{*}{ Baird et al. (2011) } \\
\hline Redução dos custos de estoque obsoleto & \\
\hline Aumento da produtividade & \\
\hline Redução das reclamações dos consumidores & \\
\hline Redução do número de reclamações no prazo da garantia & \\
\hline Redução dos custos de defeitos, refugo e retrabalho & \multirow{3}{*}{$\begin{array}{l}\text { Baird et al. (2011), } \\
\text { Kaynak (2003) }\end{array}$} \\
\hline Melhoria da qualidade dos produtos/serviços & \\
\hline Redução do leadtime de entrega de produtos/serviços aos consumidores & \\
\hline Satisfação do consumidor & \multirow{4}{*}{$\begin{array}{c}\text { Samson \& Terziovski } \\
\text { (1999) }\end{array}$} \\
\hline Unidades defeituosas em \% de produção & \\
\hline Custo de reclamações de garantia em $\%$ das vendas & \\
\hline Moral dos funcionários & \\
\hline Os processos são projetados para sem a prova de erros (orientados à prevenção) & \multirow{14}{*}{$\begin{array}{c}\text { Prajogo \& McDermott } \\
\text { (2011) }\end{array}$} \\
\hline $\begin{array}{l}\text { Nós temos instruções de processos claros, padronizados e documentados que são bem compreendidos por } \\
\text { nossos clientes }\end{array}$ & \\
\hline Nós fazemos uso extensivo de técnicas estatísticas para melhoria do processo e redução da variação & \\
\hline Desempenho dos nossos produtos & \\
\hline Confiabilidade dos nossos produtos & \\
\hline Durabilidade dos nossos produtos & \\
\hline Nível de inovação dos novos produtos & \\
\hline Velocidade do desenvolvimento de novos produtos & \\
\hline Número de novos produtos que temos colocado no mercado & \\
\hline Número de novos produtos colocados primeiro no mercado & \\
\hline Competitividade tecnológica & \\
\hline Velocidade de adoção das útlimas inovações tecnológicas em nosso processo & \\
\hline Nível de atualização das tecnologias usadas em nossos processos & \\
\hline Taxa de mudança em nossos processos, técnicas e tecnologia & \\
\hline Conformidade às especificações do produto & $\begin{array}{c}\text { Naor et al. (2008), } \\
\text { Prajogo \& McDermott }\end{array}$ \\
\hline Market share & \multirow{5}{*}{$\begin{array}{l}\text { Handfield et al. (1999), } \\
\text { Kaynak (2003) }\end{array}$} \\
\hline Retorno sobre investimento total (Return on total assets) & \\
\hline Média anual do crescimento do market share (últimos 3 anos) & \\
\hline Média anual do crescimento de vendas (últimos 3 anos) & \\
\hline Qualidade do produto (geral) & \\
\hline Custo médio do crescimento do retorno sobre investimento (últimos 3 anos) & \multirow{4}{*}{ Handfield et al (1999) } \\
\hline Custo médio de produção & \\
\hline Nível do serviço ao consumidor (geral) & \\
\hline Posição competitiva (geral) & \\
\hline Produtividade & \multirow{2}{*}{$\begin{array}{c}\text { Kaynak (2003); Samson } \\
\text { \& Terziovski (1999) }\end{array}$} \\
\hline Custo da qualidade (erros, retrabalho, refugo, inspeção) em \% total das vendas & \\
\hline Crescimento dos lucros & \multirow{3}{*}{ Kaynak (2003) } \\
\hline Crescimento das vendas & \\
\hline Leadtime de entrega dos produtos comprados & \\
\hline
\end{tabular}


APÊNDICE E - Variáveis utilizadas em pesquisas survey para medição de elementos da qualidade

\footnotetext{
Prezado participante,

O objetivo dessa pesquisa é estudar o relacionamento entre diferentes culturas organizacionais e o uso de técnicas de gestão da qualidade, investigando se determinadas características culturais da organização favorecem a implementação de técnicas específicas da qualidade de forma a potencializar a contribuição delas para melhoria do desempenho organizacional.

Como resultados, espera-se melhorar a compreensão sobre a influência que a cultura organizacional exerce na gestão da qualidade e sobre quais técnicas seriam mais aplicáveis numa organização considerando suas características culturais, contribuindo para melhoria dos casos de sucesso nas iniciativas de gestão da qualidade.

O tempo médio para responder o questionário é de 10 minutos. Para respondê-lo, clique no link disponível neste email.

Os resultados serão usados para fins acadêmicos, não sendo possível a identificação dos respondentes.

Agradecemos sua atenção e participação em nossa pesquisa Grupo de Pesquisa em Gestão da Qualidade e Mudança Escola de Engenharia de São Carlos/ Universidade de São Paulo

Este é um convite para preencher o formulário Pesquisa "Cultura Organizacional e Gestão da Qualidade". Para preenchê-lo, visite:
}

https://docs.google.com/spreadsheet/viewform?formkey=dF9DRExkcGJPTIZjYjJzaFVROEdNeVE6MQ

\section{Cultura organizacional}

Por favor, avalie em qual extensão as afirmações seguintes caracterizam sua organização. Adote o seguinte critério para escala:

$$
\begin{aligned}
& 1 \text { - Discordo totalmente } \\
& 2 \text { - Discordo parcialmente } \\
& 3 \text { - Nem discordo nem concordo } \\
& 4 \text { - Concordo parcialmente } \\
& 5 \text { - Concordo totalmente }
\end{aligned}
$$

1) Em nossa organização, mesmo decisões simples precisam ser levadas a um nível hierárquico mais alto para uma resposta final.

2) Em nossa organização, as atividades são caracterizadas por formalização, rotina e controle.

3) Nossa organização possui resultados de desempenho previsíveis, dificilmente ocorre algo diferente do planejado.

4) Em nossa organização cumprir prazos, seguir a programação e produzir a baixos custos são fatores críticos.

5) O estilo gerencial em nossa organização é caracterizado por conformidade, previsibilidade e estabilidade nas relações.

6) Em nossa organização, o desenvolvimento de recursos humanos e a preocupação com as pessoas são fatores críticos.

7) Em nossa organizaçao, os funcionários são encorajados a trabalhar em equipe, trocar experiências, opiniões e ideias.

8) Em nossa organização, os funcionários podem discutir abertamente sobre suas opiniões e ideias com seus superiores.

9) Em nossa organização, os funcionários são encorajados a tomarem decisões. 
10) O estilo gerencial da organização é caracterizado por trabalho em equipe, consenso e participação.

11) Nossa organização define sucesso com base no ganho e na liderança de mercado.

12) Para nossa organização o mais importante é a realização das tarefas e alcance das metas.

13) Nossa organização é orientada para resultados, as pessoas são competitivas e buscam realização profissional.

14) Em nossa organização, os objetivos e metas são definidos de forma clara e comunicados a todos os envolvidos.

15) O estilo gerencial na organização é caracterizado por competitividade e exigências de realização.

16) Nossa organização enfatiza a obtenção de novos recursos, a busca de oportunidades e a criação de novos desafios.

17) Nossa organização se esforça em antecipar potenciais novas práticas e tecnologias de manufatura.

18) Nossa organização é um lugar dinâmico onde as pessoas estão dispostas a ousar e correr riscos.

19) O estilo gerencial na organização é caracterizado pela liberdade dada aos funcionários para assumirem riscos e inovarem.

20) Nossa organização define sucesso baseando-se na inovação e diferenciação de seus produtos.

\section{Técnicas de gestão da qualidade}

Por favor, avalie em qual extensão as afirmações seguintes caracterizam sua organização. Adote o seguinte critério para escala:

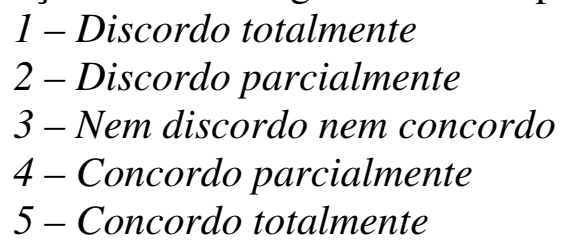

1 - Discordo totalmente

2 - Discordo parcialmente

3 - Nem discordo nem concordo

4 - Concordo parcialmente

5 - Concordo totalmente

1) Nossa organização se empenha em identificar as falhas, suas possíveis causas e os meios existentes para sua detecção em nossos produtos/processos. 
2) Nossa empresa possui planos de ação que visam eliminar as possíveis falhas que possam ocorrer em nossos produtos/processos.

3) Nossa empresa faz uma revisão completa do desenvolvimento de novos produtos/processos antes que eles sejam fabricados/utilizados.

4) Nossa empresa se empenha em identificar os desejos dos clientes e se preocupa em considerá-los no desenvolvimento dos nossos produtos.

5) Nossa organização traduz as necessidades e expectativas dos clientes em metas da qualidade.

6) Em nossa organização, trabalhamos em times, com funcionários de diferentes áreas para o desenvolvimento de novos produtos/processos.

7) Nossa organização está engajada em comparar nossos produtos/processos aos de nossos concorrentes.

8) Nossa organização identifica melhores práticas existentes entre suas diferentes áreas e buscam disseminá-las por toda organização.

9) Em nossa organização, os funcionários são estimulados a conhecer as atividades realizadas em outras áreas.

10) Em nossa organização, o benchmarking tem ajudado na melhoria dos nossos produtos/processos.

11) Em nossa organização, é frequente que os funcionários se juntem para identificação e solução de causas-raízes de problemas.

12) Durante as reuniões de soluções de problemas, é feito um esforço para conseguir as opiniões e ideias de todos os membros do grupo antes que a decisão seja tomada.

13) Em nossa organização, trazer uma variedade de perspectivas para solução de problemas direciona a melhores soluções.

14) Em nossa organização, os funcionários pensam em melhorias no seu dia-a-dia de trabalho.

15) Em nossa organização, a maioria das sugestões de melhorias dadas pelos funcionários são avaliadas.

16) Em nossa organização, existem ações focadas e estruturadas para se alcançar melhorias específicas num intervalo de tempo reduzido.

17) Em nossa organização é comum que uma equipe multifuncional trabalhe para alcançar metas específicas num intervalo de tempo reduzido.

18) Em nossa organização, utilizamos frequentemente métodos estruturados (PDCA, DMAIC, MASP) para melhoria contínua. 
19) Em nossa organização, a maioria dos funcionários são treinados no uso de ferramentas da qualidade (por ex. diagrama de causa-efeito, pareto, histograma).

20) Em nossa organização, utilizamos extensivamente métodos para identificação e priorização de problemas.

21) Nossa organização enfatiza manter o ambiente de trabalho organizado, tendo um local apropriado para cada coisa.

22) Em nossa organização, os funcionários costumam manter suas áreas de trabalho limpas e organizadas.

23) Em nossa organização, os dados de qualidade (por ex. taxa de erros, defeitos, refugos, custo de qualidade) estão prontamente disponíveis para todos os funcionários.

24) Em nossa organização, gráficos mostrando o acompanhamento da produção estão disponíveis no chão de fábrica.

25) Em nossa organização, as informações de produtividade estão prontamente disponíveis aos funcionários.

26) Em nossa organização fazemos uso extensivo de técnicas estatísticas para reduzir a variação nos processos.

27) Grande parte dos equipamentos e processos no chão de fábrica são monitorados por meio de controle estatístico.

28) Os funcionários do chão de fábrica são bem treinados em controle estatístico do processo.

29) Nós incluímos no planejamento de nossas atividades, tempo destinado somente para manutenção dos equipamentos,

30) Em nossa organização os funcionários da linha de produção tentam corrigir os erros que eles identificam antes de recorrerem a seus superiores.

31) Os funcionários da linha de produção possuem assistência técnica disponível para solução dos problemas.

32) Os processos em nossa organização são desenhados de forma a minimizarem as chances de ocorrência de erros.

33) $\mathrm{Na}$ maioria dos nossos equipamentos existem dispositivos que alertam quando algum erro é detectado no processo.

34) Nossa organização estabelece metas estratégicas para a melhoria da qualidade e monitora essas metas por meio de indicadores de desempenho.

35) Nossa organização utiliza de indicadores (por ex. taxa de erros, defeitos, refugos, custo da qualidade) para mensurar o desempenho da qualidade. 
36) Informações sobre o desempenho da qualidade são utilizadas para avaliar o progresso em nossa organização.

\section{Avaliação do desempenho organizacional}

Por favor, indique o nível de desempenho para cada um dos aspectos listados:

1) Considerando a satisfação dos consumidores, nossa organização:

(Raramente/às vezes/frequentemente/sempre) atende as expectativas dos consumidores.

2) Em nossa organização, a produtividade está:

Diminuindo de forma (significativa/moderada)

Estática

Melhorando de forma (significativa/moderada)

3) Em nossa organização, as unidades fabricadas com defeitos representam:

(Menos que 0,1\%/ Entre 0,1 - 0,49\%/Entre 0,5 - 1,99\%/ Entre 2,0 - 5,0\%/Mais de $5,0 \%$ ) do volume produzido).

4) Em nossa organização, o custo unitário de manufatura está:

Diminuindo de forma (significativa/moderada)

Estático

Aumentando de forma (significativa/moderada)

5) Nosso leadtime está:

(Considere o leadtime o tempo decorrido desde o início do processamento da matéria prima até a expedição do produto final)

Diminuindo de forma (significativa/moderada)

Estático

Aumentando de forma (significativa/moderada)

6) O número de reclamações dos clientes está:

Diminuindo de forma (significativa/moderada)

Estático

Aumentando de forma (significativa/moderada)

7) As unidades defeituosas, refugadas ou retrabalhadas estão:

Diminuindo de forma (significativa/moderada)

Estático

Aumentando de forma (significativa/moderada) 
8) Os produtos entregues aos consumidores dentro do prazo definido representam: (Menos de 50\%/ De 50 - 80\%/ De 81 - 90\%/ De 91 - 96\%/ De 97 - 100\%)

\section{Informações demográficas}

As informações seguintes são importantes para consideração de diferentes perfis de respostas.

1) Setor Industrial da empresa

2) Cargo ocupado pelo respondente

3) Tempo no cargo (até 1 ano/ entre 1 e 3 anos/mais de 3 anos)

4) Tamanho da empresa (até 19/ De 20 a 99/ De 100 a 499/ Igual ou superior a 500 funcionários)

\section{Informações sobre o questionário}

1) Você teve dificuldade em responder alguma das questões desse questionário? (Se sim, por favor, indique qual(is) questão(ões) e o motivo).

2) Em sua opinião, faltou clareza no enunciado de alguma das questões? (Se sim, por favor, indique qual(is) questão(ões) e o motivo).

3) Escreva críticas ou sugestões para melhoria do questionário. 
APÊNDICE F - Questionário Final

\section{Gestăo da Qualidade e Cultura Organizacional}

\section{Gestão da Qualidade \& Cultura Organizacional}

Por favor, avalie em qual extensão as afirmaçōes seguintes caracterizam sua organização.

1. Em minha organização, mesmo decisões simples precisam ser levadas a um nível hierárquico mais alto para uma resposta final.

Discordo totalmente

Discordo parcialmente

Nem concordo, nem discordo

Concordo parcialmente

Concordo totalmente

2. Em minha organização, procedimentos formalizados geralmente governam o que as pessoas fazem.

Discordo totalmente

Discordo parcialmente

Nem concordo, nem discordo

Concordo parcialmente

Concordo totalmente

$$
\text { c }
$$

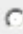

6

3. Minha organização enfatiza eficiência e controle para alcançar resultados previsíveis de desempenho.

Discordo totalmente

Discordo parcialmente

Nem concordo, nem discordo

Concordo parcialmente

Concordo totalmente $c$ c c C

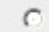

4. Em minha organização, cumprir prazos, seguir a programação e produzir a baixos custos é o foco principal.

Discordo Nem concordo, nem

Concordo parcialmente Concordo totalmente 6

5. 0 estilo gerencial em minha organização prioriza conformidade, previsibilidade e estabilidade.

Discordo totalmente

Discordo parcialmente
Nem concordo, nem discordo

Concordo parcialmente

Concordo totalmente

6. Em minha organização, o desenvolvimento de recursos humanos e a preocupação com as pessoas são muito valorizados.

Discordo totalmente

Discordo parcialmente

Nem concordo, nem discordo

Concordo parcialmente

Concordo totalmente

7. Em minha organização, os funcionários são encorajados a trabalhar em equipe, trocar experiências, opiniões e ideias.

Discordo totalmente

Discordo parcialmente

Nem concordo, nem discordo

Concordo parcialmente

Concordo totalmente 


\section{Gestão da Qualidade e Cultura Organizacional}

8. Em minha organização, os funcionários podem discutir abertamente sobre suas opinióes e ideias com seus superiores.

Discordo totalmente

Discordo parcialmente Nem concordo, nem
discordo Concordo parcialmente Concordo totalmente 6

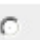
$c$

9. Em minha organização, os funcionários são encorajados a tomarem decisões.
Discordo totalmente
Discordo parcialmente
Nem concordo, nem discordo
Concordo parcialmente
Concordo totalmente o

10. 0 estilo gerencial da minha organização é caracterizado por trabalho em equipe, consenso e participação.

Discordo totalmente

Discordo parcialmente

Nem concordo, nem discordo

Concordo parcialmente

Concordo totalmente c

11. Minha organização define sucesso com base no ganho e liderança de mercado.

Discordo totalmente Discordo parcialmente Nem concordo, nem discordo

Concordo parcialmente

Concordo totalmente c

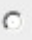

$$
6
$$

\section{Gestão da Qualidade \& Cultura Organizacional}

12. Em minha organização, nosso sistema de recompensa nos encoraja a alcançar as metas da empresa.

Discordo totalmente

Discordo parcialmente

Nem concordo, nem discordo

Concordo parcialmente

Concordo totalmente

6

13. Minha organização é orientada para resultados; as pessoas são competitivas e buscam realização profissional.

Discordo totalmente

Discordo parcialmente

Nem concordo, nem discordo

Concordo parcialmente

Concordo totalmente c

14. Em minha organização, os objetivos e metas estão claramente definidos.

\begin{tabular}{|c|c|c|c|c|}
\hline Discordo totalmente & Discordo parcialmente & $\begin{array}{l}\text { Nem concordo, nem } \\
\text { discordo }\end{array}$ & Concordo parcialmente & Concordo totalmente \\
\hline 6 & $c$ & $c$ & 6 & 6 \\
\hline
\end{tabular}

15. O estilo gerencial na minha organização é caracterizado por competitividade e exigência de realização.

Discordo totalmente

Discordo parcialmente

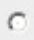

Nem concordo, nem discordo

Concordo parcialmente

Concordo totalmente $c$ 


\section{Gestão da Qualidade e Cultura Organizacional}

16. Minha organização enfatiza a busca de oportunidades e a criação de novos desafios.

$\begin{array}{ccccc}\text { Discordo totalmente } & \text { Discordo parcialmente } & \begin{array}{c}\text { Nem concordo, nem } \\ \text { discordo }\end{array} & \text { Concordo parcialmente } & \text { Concordo totalmente } \\ C & 6 & 6 & 6 & 6\end{array}$

17. Minha organização se esforça em antecipar novas práticas e tecnologias de manufatura.

$\begin{array}{ccccc}\text { Discordo totalmente } & \text { Discordo parcialmente } & \begin{array}{c}\text { Nem concordo, nem } \\ \text { discordo }\end{array} & \text { Concordo parcialmente } & \text { Concordo totalmente }\end{array}$

18. Minha organização é um lugar dinâmico que estimula as pessoas a ousarem profissionalmente.

Discordo totalmente

Discordo parcialmente
Nem concordo, nem discordo

Concordo parcialmente

Concordo totalmente

19. O estilo gerencial em minha organização é caracterizado pela liberdade dada aos funcionários para assumirem riscos e inovarem em suas decisões profissionais.

Discordo totalmente Discordo parcialmente Nem concordo, nem

discordo

Concordo parcialmente

Concordo totalmente

20. Minha organização define sucesso baseando-se na inovação e diferenciação de seus produtos.

Discordo totalmente

Discordo parcialmente Nem concordo, nem
discordo

Concordo parcialmente

Concordo totalmente
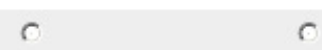

6

21. Em minha organização usamos métodos para identificar as falhas, suas possíveis causas e os meios existentes para sua detecção nos produtos/processos.

Discordo totalmente

Discordo parcialmente

Nem discordo, nem concordo

Concordo parcialmente

Concordo totalmente

6

C

22. Em minha organização implementamos planos de ação para melhoria dos produtos/processos a partir da análise detalhada de possíveis falhas e suas causas.

Discordo totalmente

Discordo parcialmente

Nem concordo, nem discordo

Concordo parcialmente

Concordo totalmente c

$$
\text { c }
$$$$
\text { c }
$$$$
\text { c }
$$

3. Gestão da Qualidade \& Cultura Organizacional 


\section{Gestão da Qualidade e Cultura Organizacional}

23. Em minha organização registramos o histórico de falhas dos produtos/processos e as ações para redução dessas falhas.

$\begin{array}{ccccc}\text { Discordo totalmente } & \text { Discordo parcialmente } & \text { Nem concordo, nem } & \text { Concordo parcialmente } & \text { Concordo totalmente } \\ 6 & 6 & \text { discordo } & 6 & 6\end{array}$

24. Minha empresa usa método sistemático para identificar os desejos dos clientes e se preocupa em considerá-los no desenvolvimento dos nossos produtos.

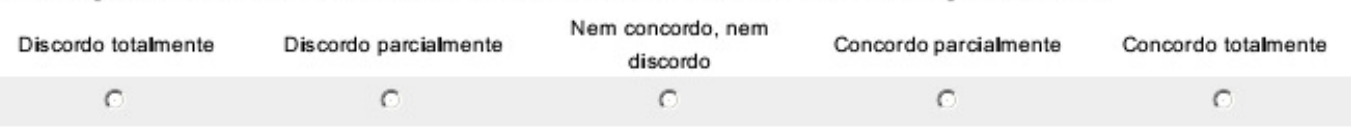

25. Minha organização traduz as necessidades e expectativas dos clientes em características técnicas do produto.

Discordo totalmente

Discordo parcialmente
Nem concordo, nem discordo

C
Concordo parcialmente

Concordo totalmente

26. Em minha organização, trabalhamos em equipes multifuncionais para identificar as expectativas dos clientes e considerá-las no desenvolvimento de nossos produtos.

Discordo totalmente

Discordo parcialmente
Nem concordo, nem discordo

Concordo parcialmente

Concordo totalmente

27. Minha organização compara nossos produtos/processos aos produtos/processos similares de nossos concorrentes.

Discordo totalmente

Discordo parcialmente

Nem concordo, nem discordo

Concordo parcialmente

Concordo totalmente

28. Em minha organização identificamos melhores práticas existentes entre as diferentes áreas e buscamos disseminá-las por toda organização.

Discordo totalmente

Discordo parcialmente

Nem concordo, nem

Concordo parcialmente

Concordo totalmente

29. Em minha organização, os funcionários são encorajados a conhecerem as atividades realizadas em outras áreas.

Discordo totalmente

Discordo parcialmente

Nem concordo, nem discordo

Concordo parcialmente

Concordo totalmente

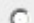

30. Em minha organização, melhores práticas tem ajudado na melhoria dos nossos produtos/processos.

Discordo totalmente

Discordo parcialmente

Nem concordo, nem discordo

Concordo parcialmente

Concordo totalmente 


\section{Gestão da Qualidade e Cultura Organizacional}

31. Em minha organização, os funcionários frequentemente se juntam para discutir problemas e suas causas-raízes.

Discordo totalmente

Discordo parcialmente
Nem concordo, nem discordo

Concordo parcialmente

Concordo totalmente

32. Durante as reuniões para solução de problemas, busca-se as opiniões e ideias da maioria dos membros do grupo antes que a decisão seja tomada.

Discordo totalment

Discordo parcialmente

Nem concordo, nem

33. Em minha organização, levantar uma variedade de perspectivas para solução de problemas direciona a melhores soluções.

Discordo totalmente

Discordo parcialmente
Nem concordo, nem discordo

Concordo parcialmente

Concordo totalmente

\section{Gestão da Qualidade \& Cultura Organizacional}

34. Em minha organização, os funcionários são incentivados a pensarem em melhorias no seu dia-a-dia de trabalho.

Discordo totalmente

Discordo parcialmente

Nem concordo, nem discordo

Concordo parcialmente

Concordo totalmente

35. Em minha organização, a maioria das sugestões de melhoria dadas pelos funcionários é transformada em projetos de melhoria.

Discordo totalmente

Discordo parcialmente

Nem concordo, nem discordo

Concordo parcialmente

Concordo totalmente
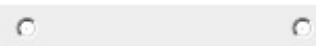

$c$

36. Em minha organização, existem ações focadas e estruturadas para se alcançar melhorias especificas num intervalo de tempo definido.

Discordo totalmente

Discordo parcialmente

Nem concordo, nem discordo

Concordo parcialmente

Concordo totalmente

37. Em minha organização, é comum que uma equipe multifuncional trabalhe para alcançar metas de melhoria num intervalo de tempo definido.

Dis cordo totalmente

Discordo parcialmente

Nem concordo, nem discordo

Concordo parcialmente

Concordo totalmente
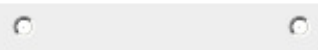

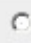




\section{Gestão da Qualidade e Cultura Organizacional}

38. Em minha organização, é comum seguirmos métodos estruturados (por ex., PDCA, DMAIC, MASP) para melhoria contínua.

Discordo totalmente

Discordo parcialmente

Nem

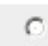

Nem concordo, nem discordo
Concordo parcialmente

Concordo totalmente

39. Em minha organização, a maioria dos funcionários são treinados no uso de ferramentas da qualidade (por ex., diagrama de causa-e-efeito, pareto, histograma).

Discordo totalmente

Discordo parcialmente discordo

Concordo parcialmente

Concordo totalmente

40. Em minha organização, fazemos uso extensivo de métodos para identificação e priorização dos problemas.

Discordo totalmente

Discordo parcialmente

Nem concordo, nem discordo

Concordo parcialmente

Concordo totalmente c

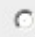

41. Em minha organização, enfatizamos manter o ambiente de trabalho organizado, tendo um local apropriado para cada coisa.

$\begin{array}{ccccc}\text { Discordo totalmente } & \text { Discordo parcialmente } & \begin{array}{c}\text { Nem concordo, nem } \\ \text { discordo }\end{array} & \text { Concordo parcialmente } & \text { Concordo totalmente }\end{array}$

42. Em minha organização, na rotina do dia a dia, os funcionários mantêm suas áreas de trabalho limpas e organizadas.

Discordo totalmente Discordo parcialmente

Nem concordo, nem discordo 6
Concordo parcialmente

Concordo totalmente

$$
6
$$

43. Em minha organização, os dados de qualidade (por ex. taxa de erros, de defeitos, de refugos, custos da qualidade) estão prontamente disponíveis para os funcionários.

Discordo totalmente

Discordo parcialmente

Nem concordo, nem discordo

Concordo parcialmente

Concordo totalmente

44. Em minha organização, gráficos mostrando o acompanhamento da produção estão visíveis no chão de fábrica.

Discordo totalmente

Discordo parcialmente

Nem concordo, nem

discordo

Concordo parcialmente

Concordo totalmente

45. Em minha organização, informações de produtividade estão prontamente disponíveis para os funcionários.

Discordo totalmente

Discordo parcialmente

Nem concordo, nem discordo

Concordo parcialmente

Concordo totalmente 


\section{Gestão da Qualidade e Cultura Organizacional}

46. Em minha organização, fazemos uso extensivo de técnicas estatísticas para analisar a variação nos processos.

Discordo totalmente

Discordo parcialmente

Nem concordo, nem discordo

Concordo parcialmente

Concordo totalmente
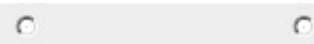

C.

47. Em minha organização, o controle estatístico do processo tem contribuído para melhoria da qualidade de nossos produtos.

Discordo totalmente

Discordo parcialmente

Nem concordo, nem discordo

Concordo parcialmente

Concordo totalmente

6

48. Em minha organização, os funcionários do chão de fábrica são bem treinados em controle estatístico do processo.

Discordo totalmente

Discordo parcialmente

Nem concordo, nem discordo

Concordo parcialmente

Concordo totalmente 6

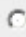

$c$

6

\section{c}

49. Em minha organização, nós incluímos tempo destinado para manutenção dos equipamentos no planejamento de nossas atividades.

Discordo totalmente

Discordo parcialmente

Nem concordo, nem discordo

Concordo parcialmente

Concordo totalmente 6

c

50. Em minha organização, nós enfatizamos a manutenção preventiva como uma estratégia para se ter uma produção conforme ao cronograma planejado.

Discordo totalmente Discordo parcialmente Nem concordo, nem

discordo Concordo parcialmente Concordo totalmente

51. Em minha organização, a área de manutenção dá suporte aos funcionários da linha produção para que eles executem manutenção preventiva nos equipamentos que eles operam.

Discordo totalmente

Discordo parcialmente

Nem concordo, nem discordo

Concordo parcialmente

Concordo totalmente

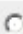

6

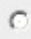

52. Em minha organização, os processos são projetados de forma a minimizarem as chances de ocorrência de erros. 


\section{Gestão da Qualidade e Cultura Organizacional}

53. Em minha organização, a maioria dos equipamentos possui dispositivos que indicam quando algum erro acontece no processo.

Discordo totalmente

Discordo parcialmente

Nem concordo, nem discordo

Concordo parcialmente

Concordo totalmente

6

c

54. Em minha organização, estabelecemos metas para a melhoria da qualidade e monitoramos essas metas por meio de indicadores de desempenho.

Discordo totalmente

Discordo parcialmente

Nem concordo, nem

Concordo parcialmente

Concordo totalmente

6

55. Em minha organização, utilizamos indicadores (por ex., taxa de erros, defeitos, refugos, custo da qualidade) para medir o desempenho da qualidade.

iscordo totalmente

Dis cordo parcialmente

Nem concordo, nem discordo

Concordo parcialmente

Concordo totalmente
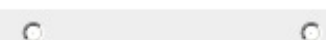

56. Em minha organização, utilizamos informações sobre o desempenho da qualidade para avaliar melhorias na empresa.

Discordo totalmente

Discordo parcialmente

Nem concordo, nem discordo

Concordo parcialmente

Concordo totalmente

\section{Desempenho}

\section{Considerando a satisfação dos consumidores, minha organização:}

$\begin{array}{cccccc}\begin{array}{c}\text { Raramente atende as } \\ \text { expectativas dos } \\ \text { consumidores }\end{array} & \begin{array}{c}\text { As vezes atende as } \\ \text { expectativas dos } \\ \text { consumidores }\end{array} & \begin{array}{c}\text { Frequentemente } \\ \text { atende as expectativas } \\ \text { dos consumidores }\end{array} & \begin{array}{c}\text { Sempre atende as } \\ \text { expectativas dos } \\ \text { consumidores }\end{array} & \begin{array}{c}\text { Excede as expectativas } \\ \text { dos consumidares }\end{array} & \text { Não tenho certeza } \\ \text { C } & 6 & 6 & 6 & 6 & 6\end{array}$

\section{Em minha organização, a produtividade está:}

$\begin{array}{cccccc}\begin{array}{c}\text { Diminuindo de forma } \\ \text { significativa }\end{array} & \begin{array}{c}\text { Diminuindo de forma } \\ \text { moderada }\end{array} & \text { Estática } & \begin{array}{c}\text { Melhorando de forma } \\ \text { moderada }\end{array} & \begin{array}{c}\text { Melhorando de forma } \\ \text { significativa }\end{array} \text { Não tenho certeza } \\ 6 & C & 6 & 6 & 6 & C\end{array}$

\section{Em minha organização, o custo unitário da manufatura está:}

$\begin{array}{cccccc}\begin{array}{c}\text { Aumentando de forma Aumentando de forma } \\ \text { significativa } \\ \text { moderada }\end{array} & \text { Estático } & \begin{array}{c}\text { Diminuindo de forma } \\ \text { moderada }\end{array} & \begin{array}{c}\text { Diminuindo de forma } \\ \text { significativa }\end{array} \text { Não tenho certeza } \\ & 6 & C & C & C\end{array}$

60. Em minha organização, nosso leadtime está:

$\begin{array}{cccccc}\begin{array}{c}\text { Aumentando de forma Aumentando de forma } \\ \text { significativa }\end{array} & \text { Estático } & \begin{array}{c}\text { Diminuindo de forma } \\ \text { moderada }\end{array} & \begin{array}{c}\text { Diminuindo de forma } \\ \text { significativa }\end{array} \text { Não tenho certeza }\end{array}$




\section{Gestão da Qualidade e Cultura Organizacional}

61. Em minha organização, o número de reclamações dos clientes está:

$\begin{array}{cccccc}\begin{array}{c}\text { Aumentando de forma } \\ \text { significativa }\end{array} & \text { Estático } & \begin{array}{c}\text { Diminuindo de forma } \\ \text { moderada }\end{array} & \begin{array}{c}\text { Diminuindo de forma } \\ \text { significativa }\end{array} & \text { Não tenho certeza } \\ 6 & 0 & 0 & 6 & 6 & 0\end{array}$

62. Em minha organização, o número de unidades defeituosas, refugadas ou retrabalhadas estão:

Aumentando de forma Aumentando de forma significativa moderada

Estático

Diminuindo de forma Diminuindo de forma moderada significativa

Não tenho certeza C 


\section{Gestăo da Qualidade e Cultura Organizacional}

\section{Tamanho da empresa:}

C. Até 19 funcionários

C. De 20 a 99 funcionários

C De 100 a 499 funcionários

C. Igual ou superior a 500 funcionários

\section{Indique a principal estratégia de manufatura de sua organização:}

Produzir para estoque (alto volume, alta padronizaçāo dos produtos)

Montagem sob encomenda (alto volume, baixa variedade de produtos)

C Fabricação sob encomenda (baixo volume, alta variedade de produtos)

C Projeto sob encomenda (baixo volume, alta customização dos produtos)

Não tenho certeza

\section{Indique a principal estratégia competitiva de sua organização:}

A Alta qualidade

B Baixo custo

Velocidade (resposta rápida aos pedidos)

6 Confiabilidade na entrega

6 Lançamento de novos produtos

Não tenho certeza

\section{Caso tenha quaisquer comentários, escreva-os aqui:}




\section{APÊNDICE G - Resultados dos testes dos modelos estruturais}

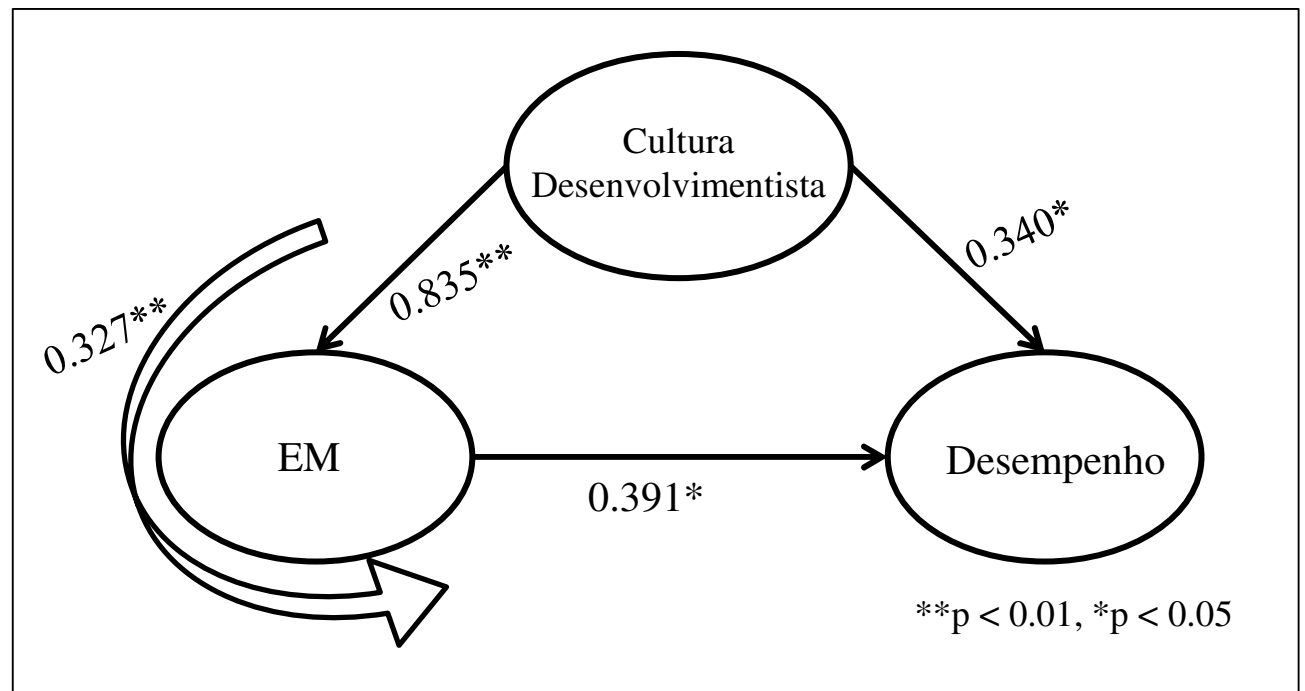

Indices de ajuste geral: $\mathrm{x}^{2} / \mathrm{df}=1.78, \mathrm{CFI}=0.92, \mathrm{IFI}=0.92, \mathrm{TLI}=0.91, \mathrm{RMSEA}=0.06$

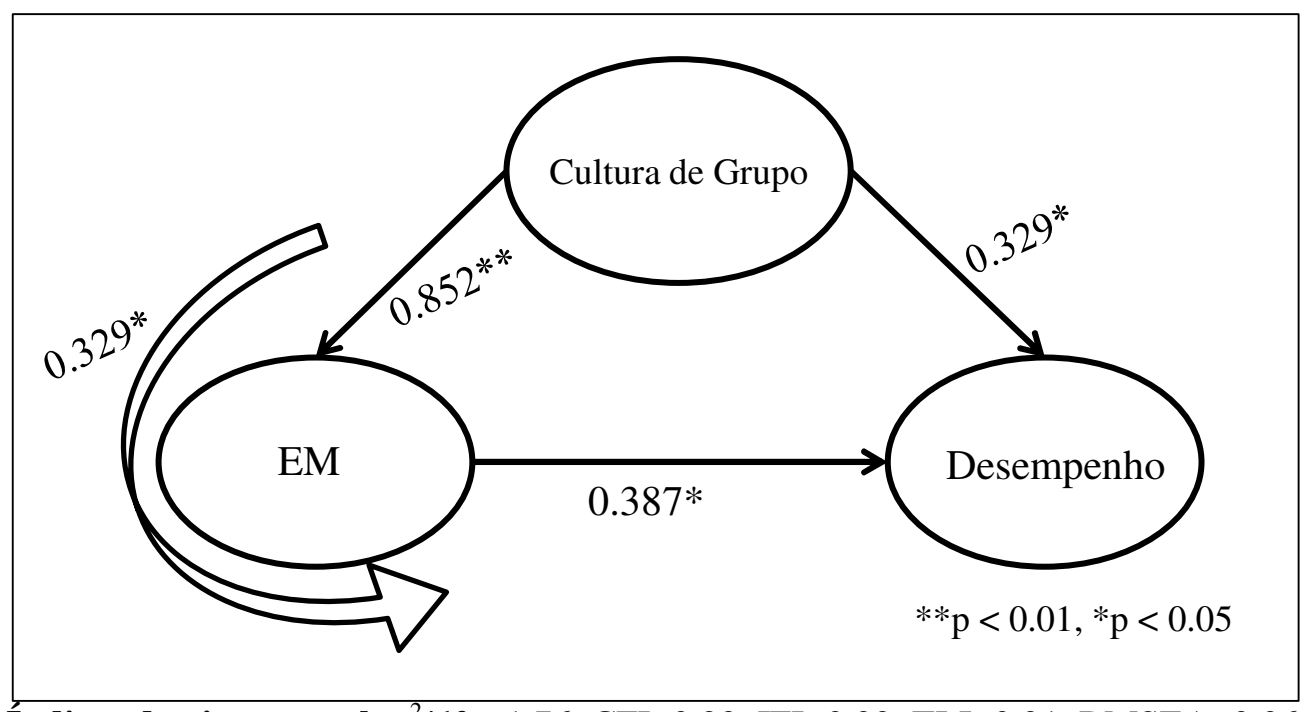

Indices de ajuste geral: $\mathrm{x}^{2} / \mathrm{df}=1.76, \mathrm{CFI}=0.92, \mathrm{IFI}=0.92, \mathrm{TLI}=0.91, \mathrm{RMSEA}=0.06$

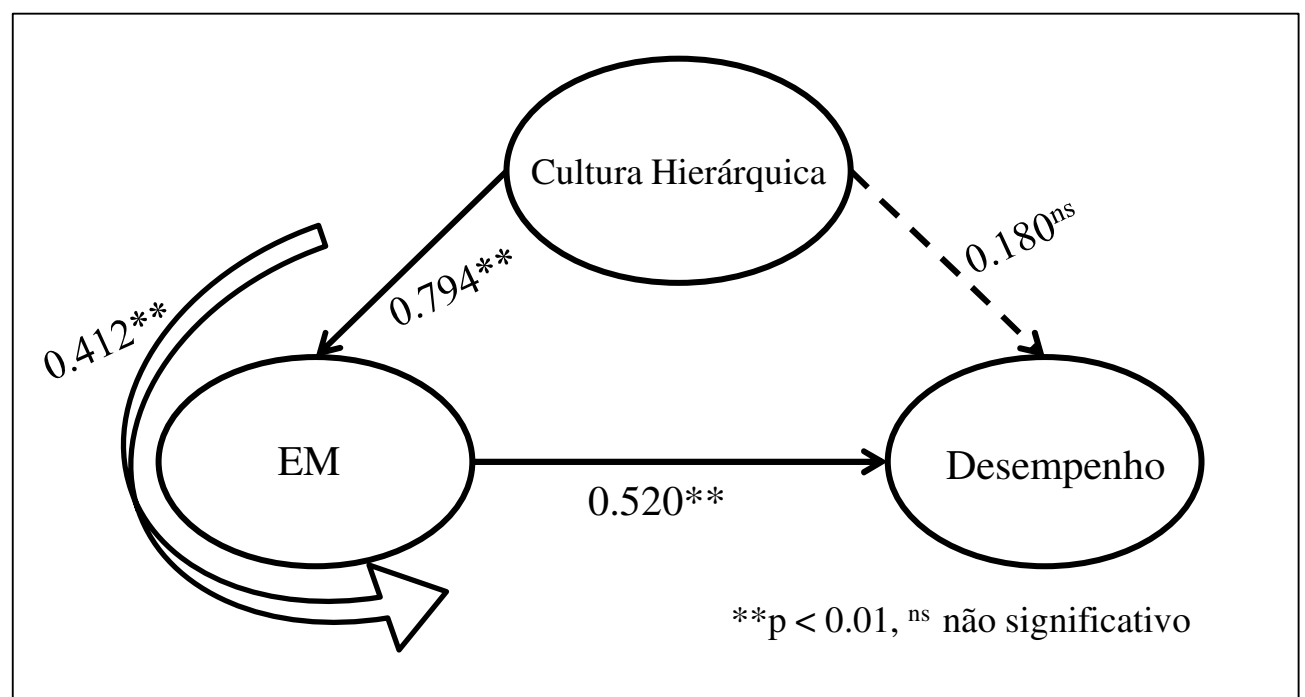

Îndices de ajuste geral: $\mathrm{x}^{2} / \mathrm{df}=1.83, \mathrm{CFI}=0.91, \mathrm{IFI}=0.91, \mathrm{TLI}=0.90, \mathrm{RMSEA}=0.06$ 


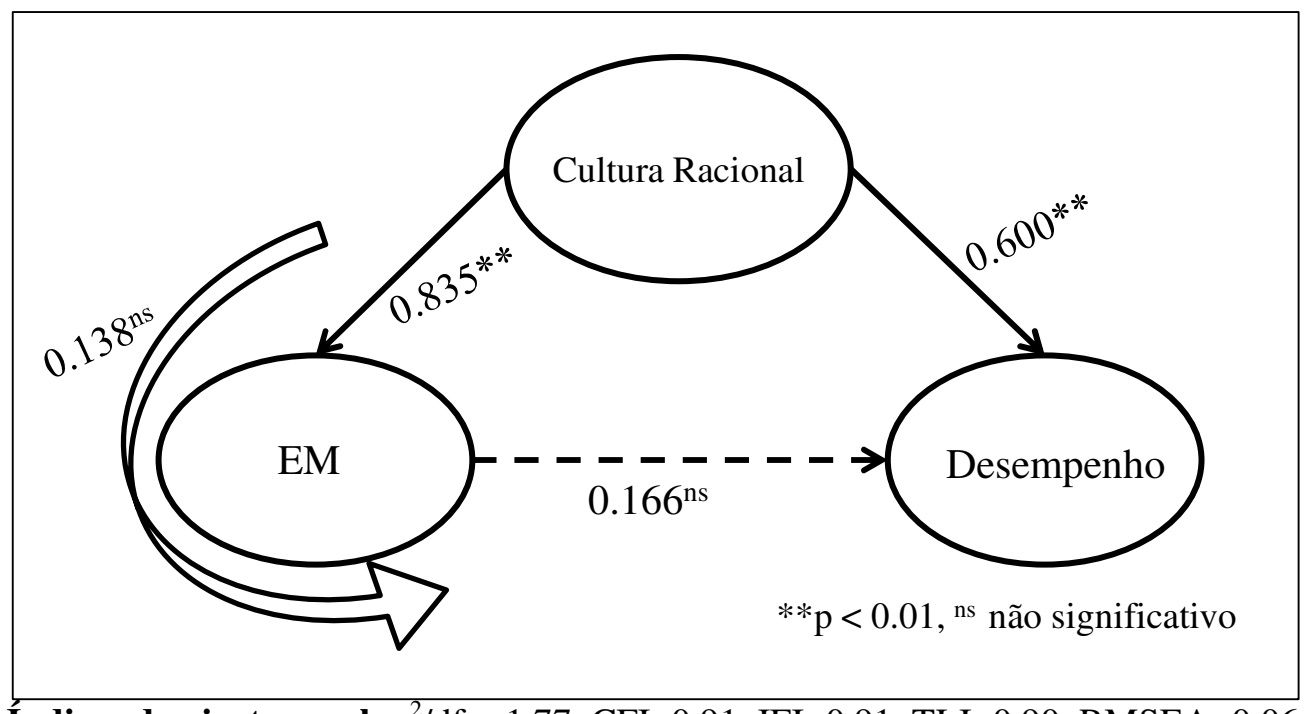

Indices de ajuste geral: $\mathrm{x}^{2} / \mathrm{df}=1.77, \mathrm{CFI}=0.91, \mathrm{IFI}=0.91, \mathrm{TLI}=0.90, \mathrm{RMSEA}=0.06$

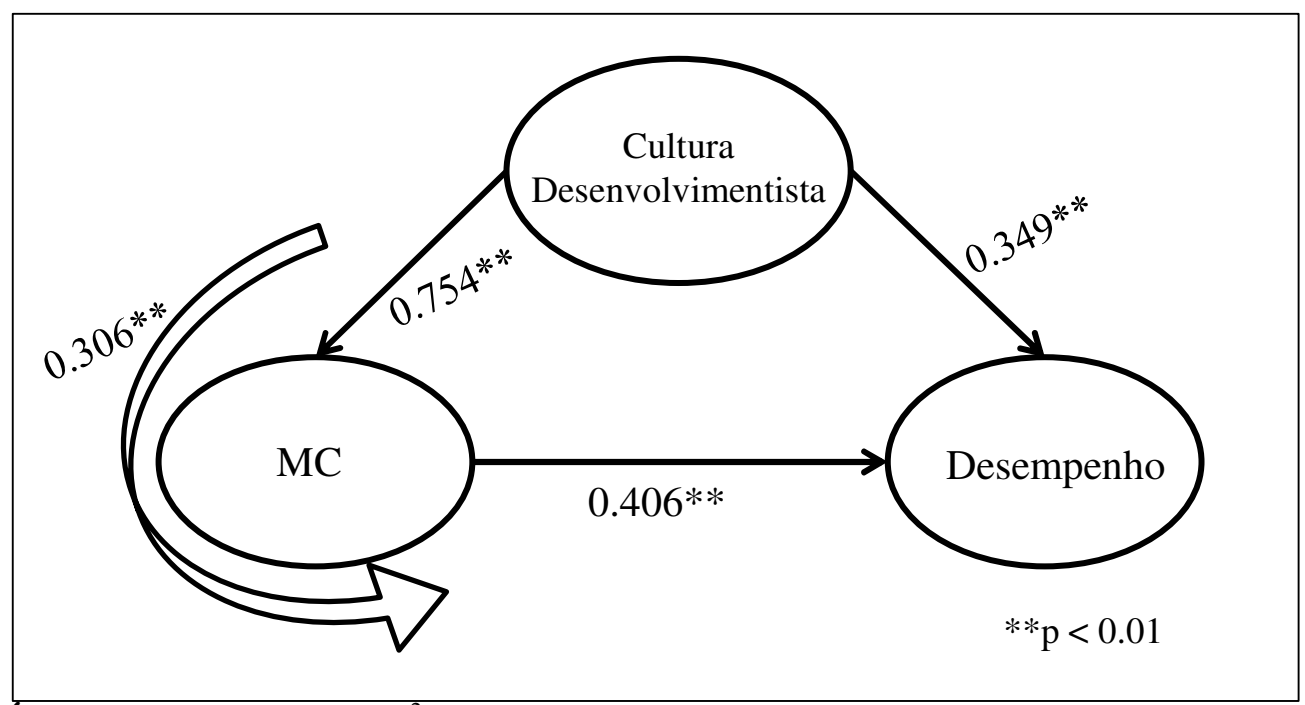

Indices de ajuste geral: $\mathrm{x}^{2} / \mathrm{df}=2.01, \mathrm{CFI}=0.87, \mathrm{IFI}=0.88, \mathrm{TLI}=0.86, \mathrm{RMSEA}=0.06$

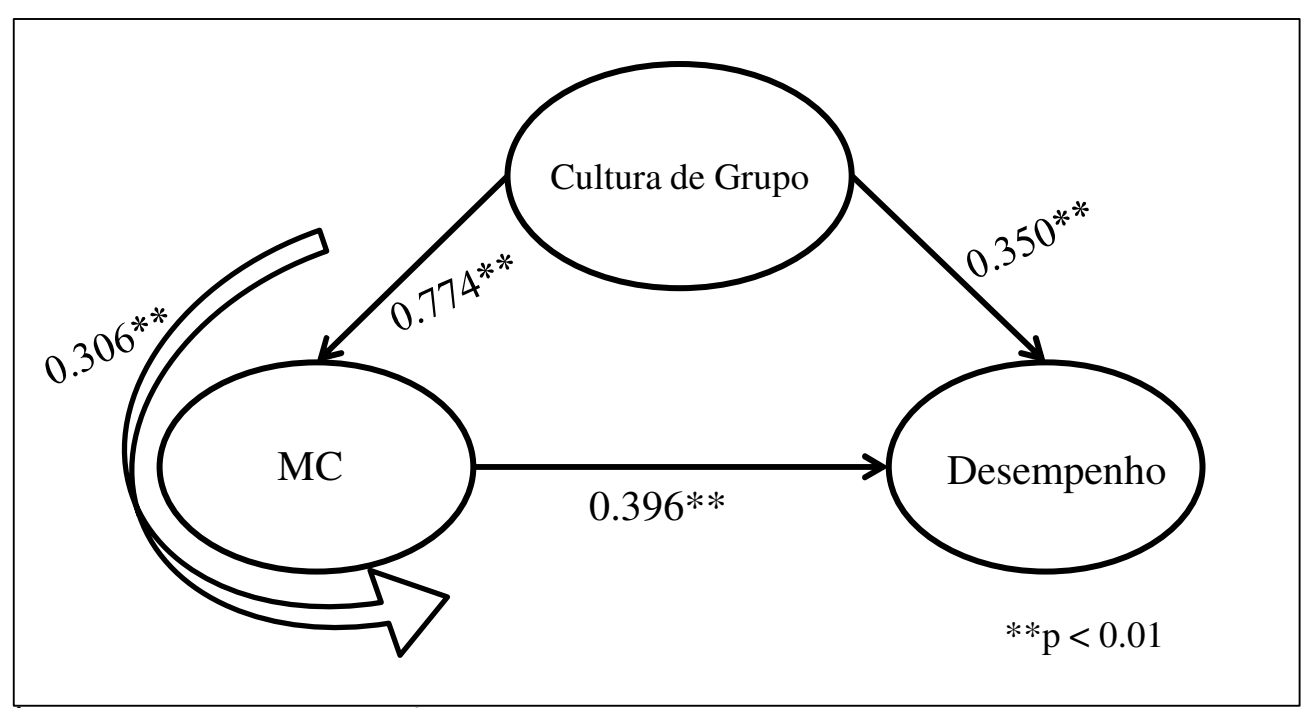

Índices de ajuste geral: $\mathrm{x}^{2} / \mathrm{df}=1.91, \mathrm{CFI}=0.89, \mathrm{IFI}=0.89, \mathrm{TLI}=0.88, \mathrm{RMSEA}=0.06$ 


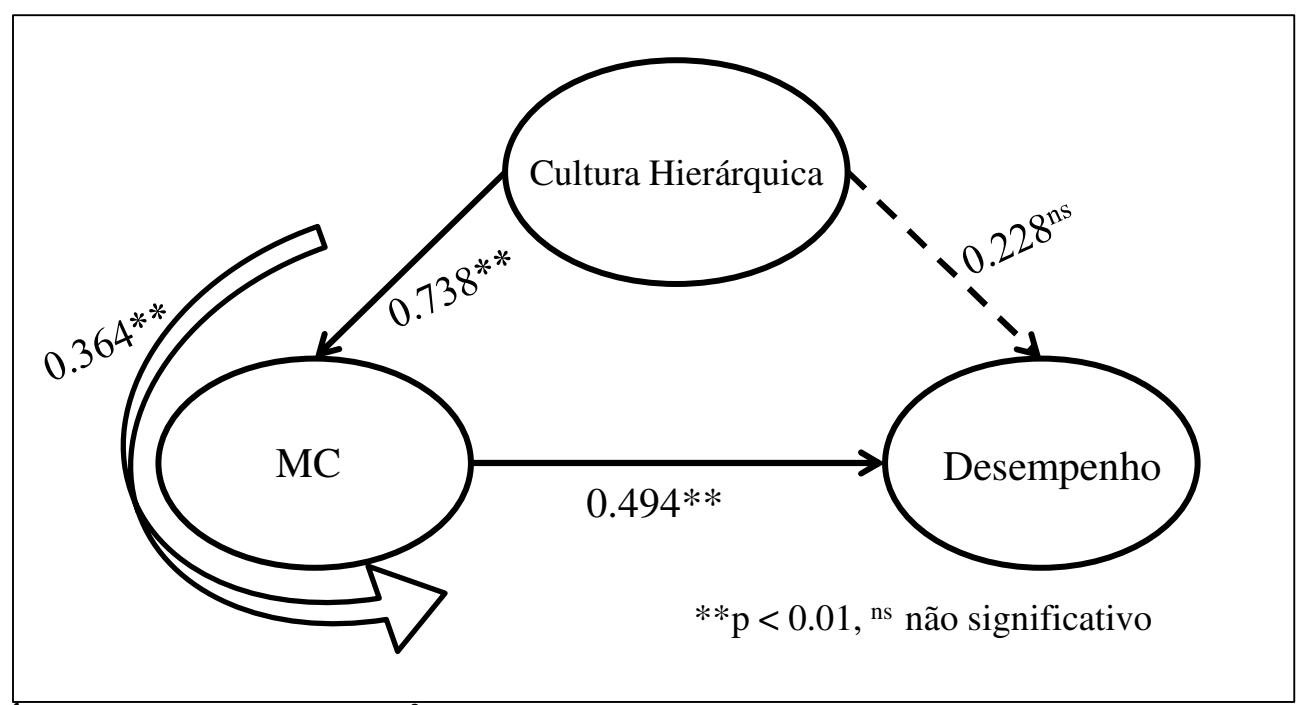

Indices de ajuste geral: $\mathrm{x}^{2} / \mathrm{df}=1.90, \mathrm{CFI}=0.88, \mathrm{IFI}=0.88, \mathrm{TLI}=0.87, \mathrm{RMSEA}=0.06$

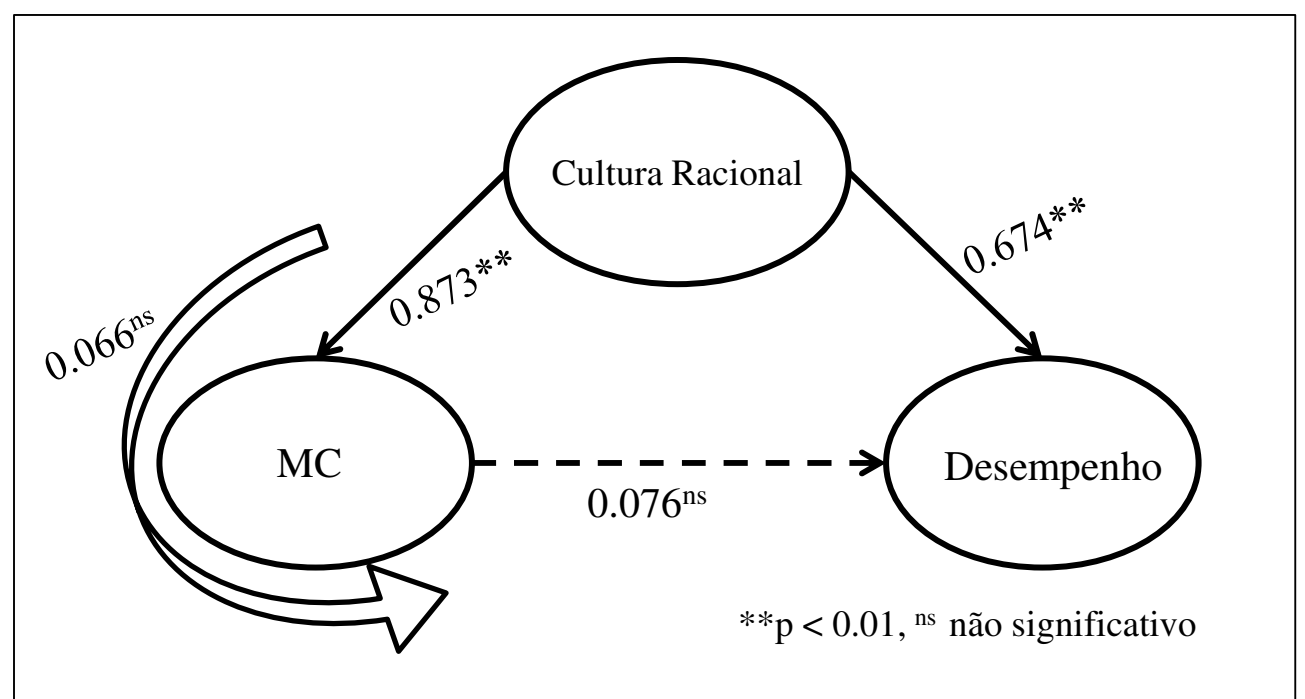

Indices de ajuste geral: $\mathrm{x}^{2} / \mathrm{df}=1.88, \mathrm{CFI}=0.88, \mathrm{IFI}=0.89, \mathrm{TLI}=0.87, \mathrm{RMSEA}=0.06$

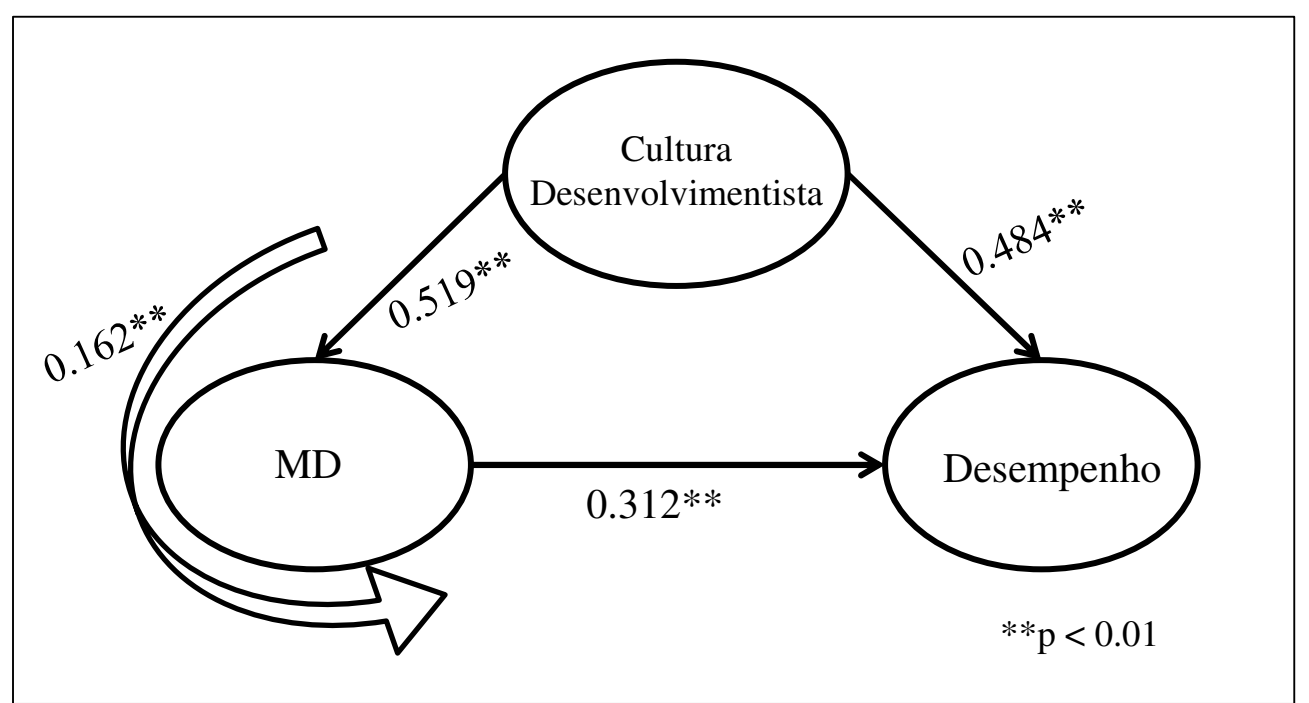

Indices de ajuste geral: $\mathrm{x}^{2} / \mathrm{df}=1.80, \mathrm{CFI}=0.91, \mathrm{IFI}=0.92, \mathrm{TLI}=0.90, \mathrm{RMSEA}=0.06$ 


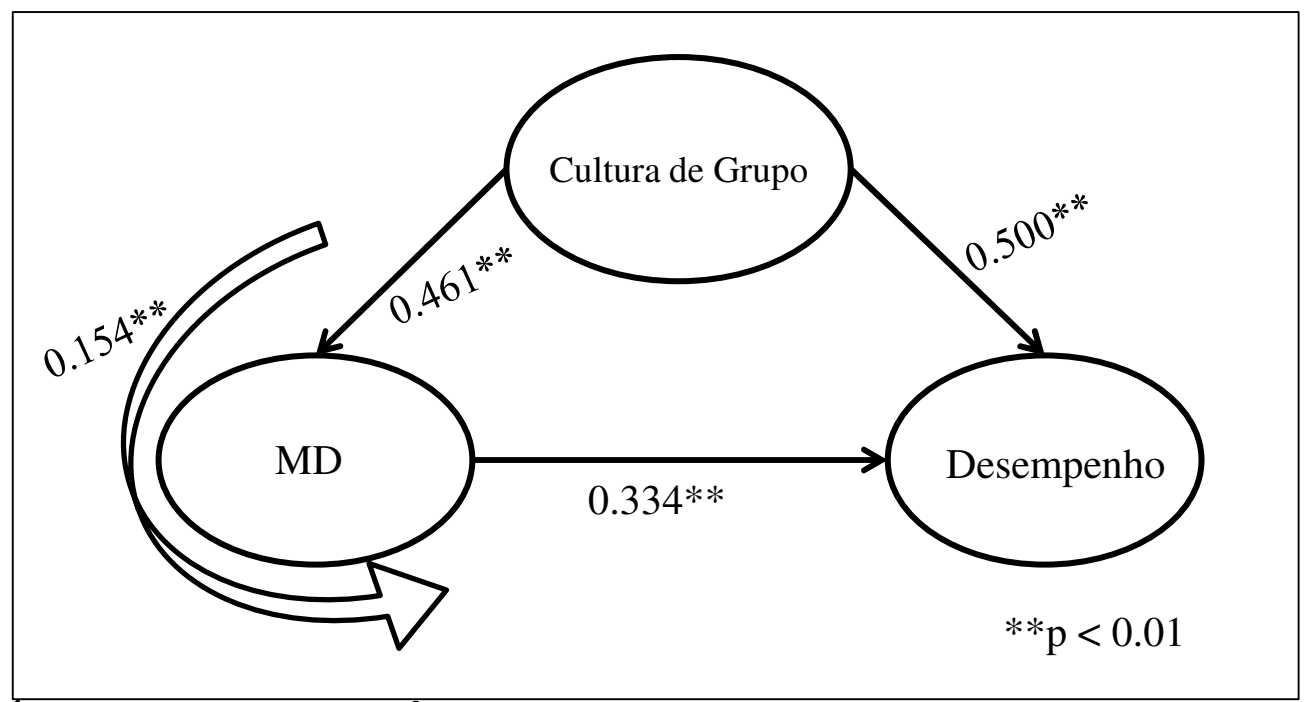

Indices de ajuste geral: $\mathrm{x}^{2} / \mathrm{df}=1.61, \mathrm{CFI}=0.94, \mathrm{IFI}=0.94, \mathrm{TLI}=0.92, \mathrm{RMSEA}=0.05$

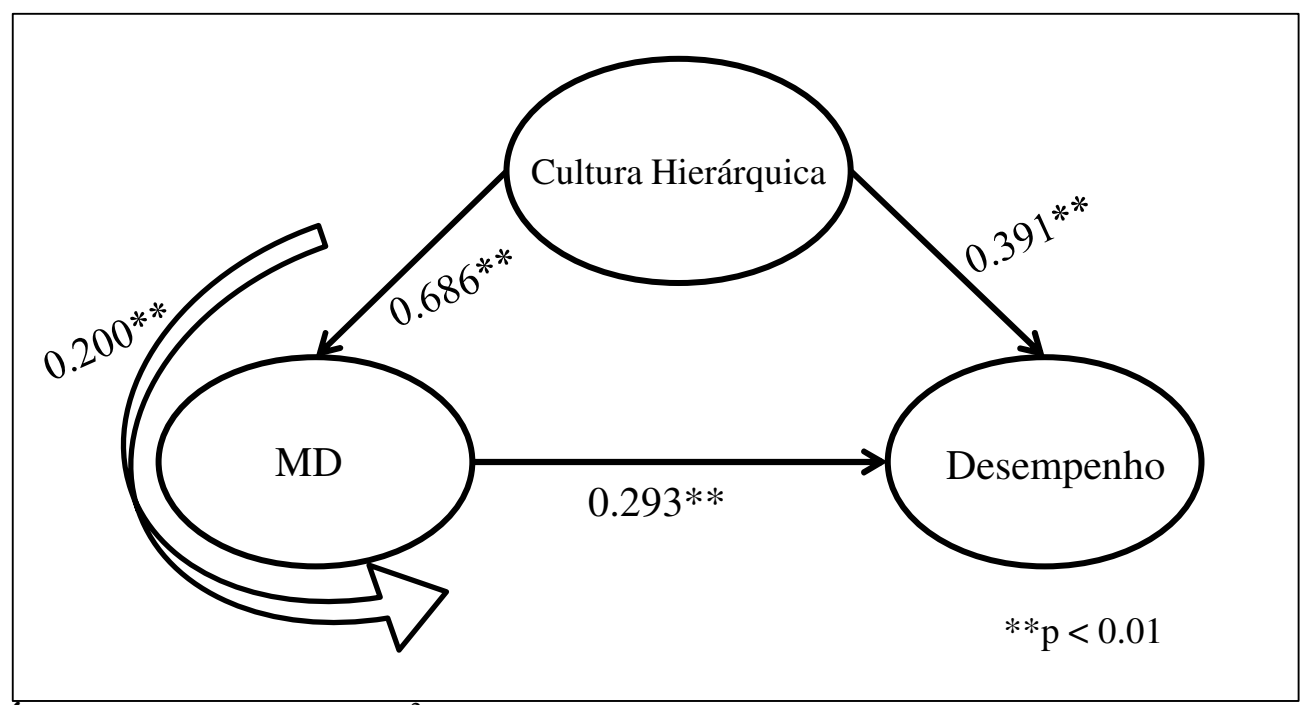

Indices de ajuste geral: $\mathrm{x}^{2} / \mathrm{df}=1.79, \mathrm{CFI}=0.91, \mathrm{IFI}=0.91, \mathrm{TLI}=0.90, \mathrm{RMSEA}=0.06$

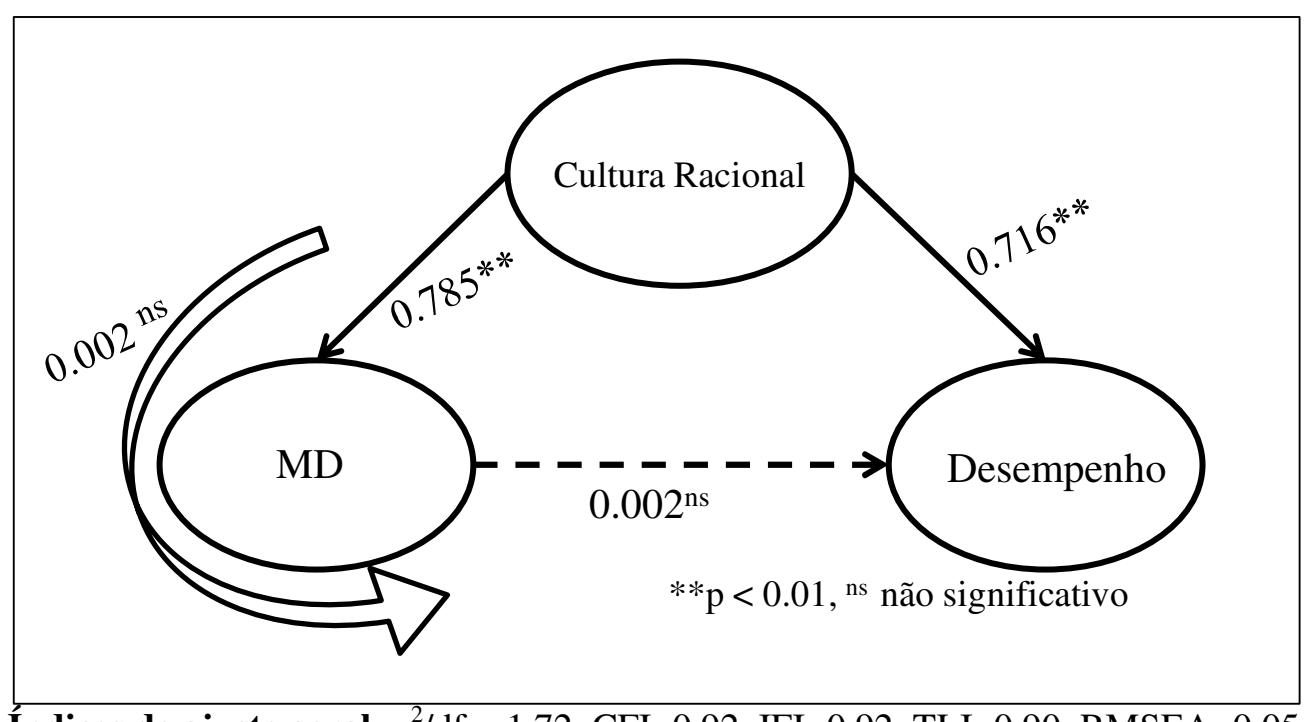

Indices de ajuste geral: $\mathrm{x}^{2} / \mathrm{df}=1.72, \mathrm{CFI}=0.92, \mathrm{IFI}=0.92, \mathrm{TLI}=0.90, \mathrm{RMSEA}=0.05$ 


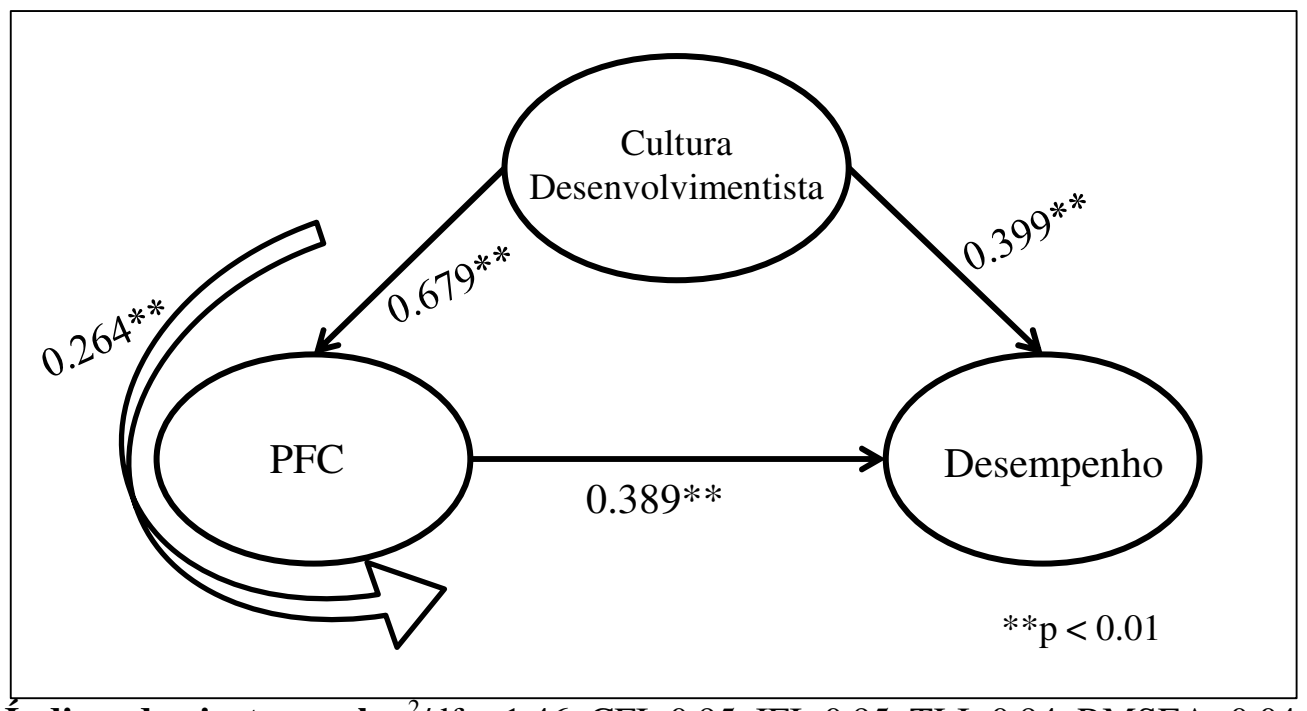

Indices de ajuste geral: $\mathrm{x}^{2} / \mathrm{df}=1.46, \mathrm{CFI}=0.95, \mathrm{IFI}=0.95, \mathrm{TLI}=0.94, \mathrm{RMSEA}=0.04$

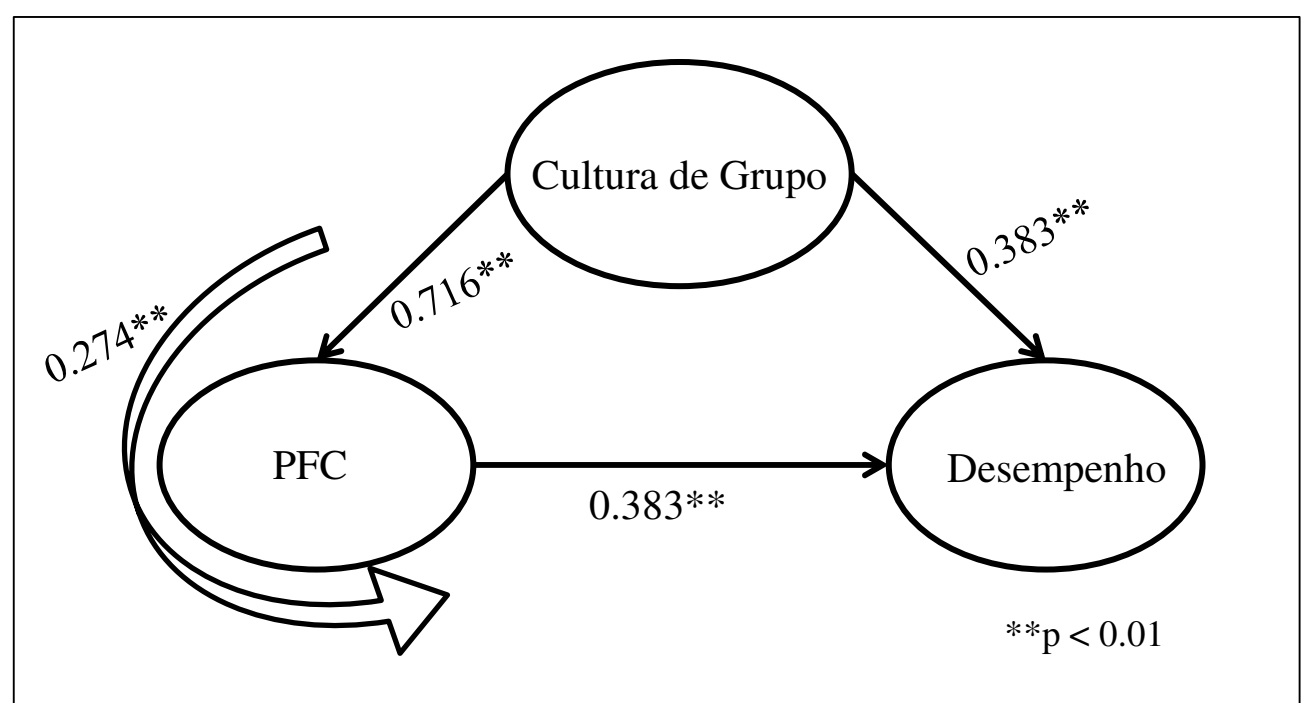

Indices de ajuste geral: $\mathrm{x}^{2} / \mathrm{df}=1.48, \mathrm{CFI}=0.95, \mathrm{IFI}=0.95, \mathrm{TLI}=0.94, \mathrm{RMSEA}=0.05$

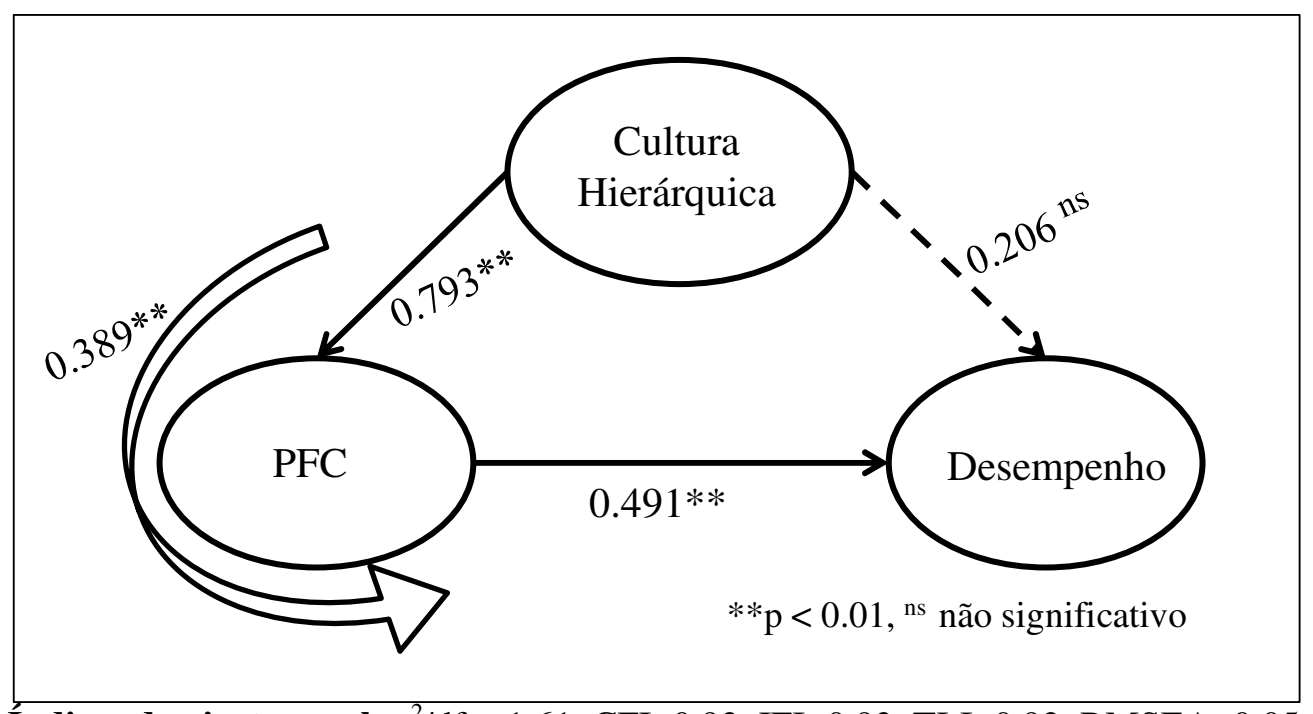

Indices de ajuste geral: $\mathrm{x}^{2} / \mathrm{df}=1.61, \mathrm{CFI}=0.93, \mathrm{IFI}=0.93, \mathrm{TLI}=0.92, \mathrm{RMSEA}=0.05$ 


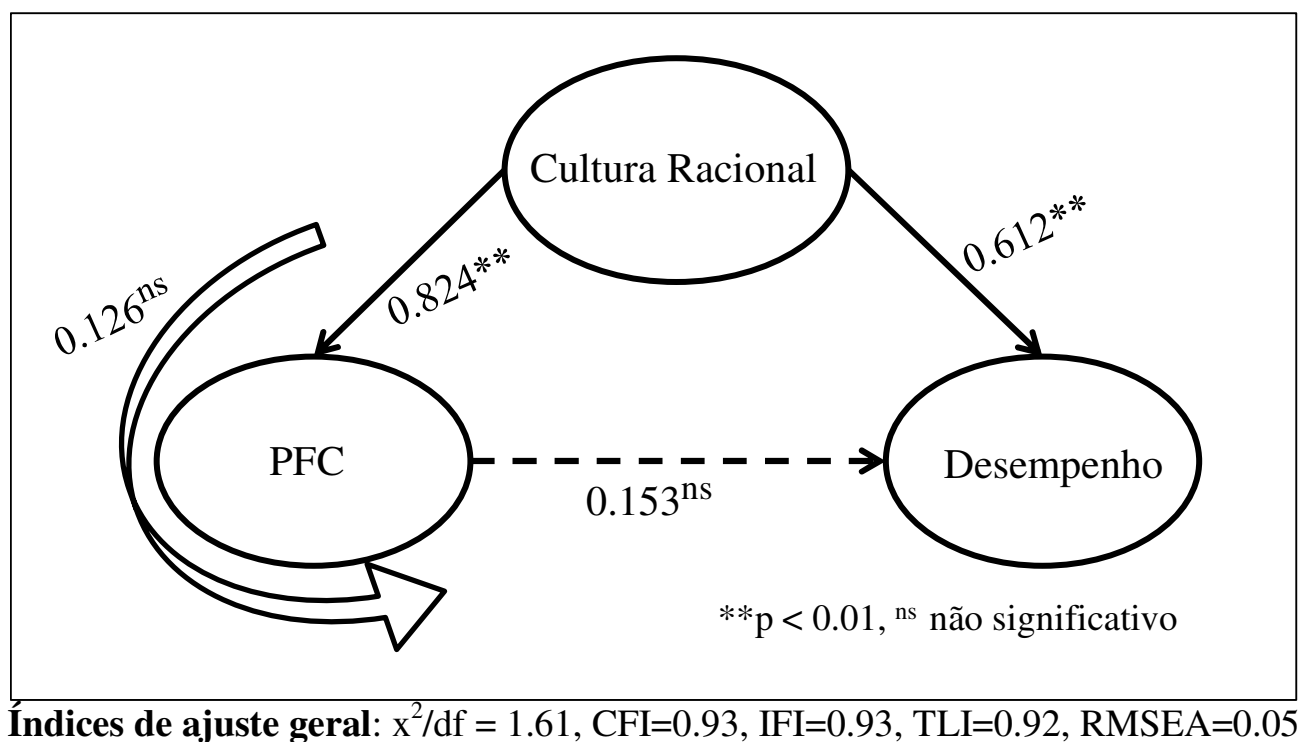

